\title{
REVENUE IMPACTS OF THE 2015 AVIAN INFLUENZA VIRUS OUTBREAK ON UNITED STATES TABLE EGG WHOLESALERS
}

\author{
A Thesis \\ by \\ MICHELLE RENEE PAUKETT \\ Submitted to the Office of Graduate and Professional Studies of \\ Texas A\&M University \\ in partial fulfillment of the requirements for the degree of \\ MASTER OF SCIENCE
}

Chair of Committee, Senarath Dharmasena

Co-Chair of Committee, David Bessler

Committee Member, Craig Coufal

Head of Department, $\quad$ C. Parr Rosson III

December 2016

Major Subject: Agricultural Economics

Copyright 2016 Michelle Paukett 


\begin{abstract}
From December 2014 to June 2015, the U.S. poultry industry experienced an outbreak of highly pathogenic avian influenza (HPAI), resulting in massive bird depopulations. Both turkey and egg producers were impacted and farms affected faced losses from costs of bird disposal and farm repopulation. This study isolates the table egg subsector of the poultry industry and looks at the revenue impact of the AI outbreak at the wholesale level. To determine this revenue impact, a vector error correction model (VECM) was defined and used to generate the counterfactual revenue during the time period the outbreak occurred. This counterfactual revenue was compared to the actual revenue observed during that time period and the difference is the revenue impact due to the outbreak, ceteris paribus. Additionally, machine learning algorithms, using residuals from the VECM, allowed us to determine causal relationships in contemporaneous time among the variables considered within the industry. The results from this study provide us with a better understanding of the table egg industry based on sound econometric modeling and provide a basis for conducting future revenue impact studies for similar events.
\end{abstract}

Our model was developed using eight variables defined by previous studies including the number of hens and eggs, egg price, feed input prices, retail pork and beef prices, and real disposable personal income. After rigorous testing using RATS software, the vector error correction model for forecasting was identified with one lag and two cointegrating vectors. When the counterfactual revenue was compared to the actual 
revenue from December 2014 to June 2015, a gain of about $\$ 676$ million to wholesalers was determined to be attributed to the outbreak. Additionally, residual analysis of contemporaneous relationships, as shown by directed acyclic graphs, indicated that egg price is independent of direct production quantities, hens and eggs, but is impacted by production costs such as feed input costs. These results can be accounted for by various factors including the inelasticity of egg price and the imperfectly competitive behavior of the wholesalers. Future studies can use price transmission principles to expand this study and identify AI outbreak impacts at the consumer and producer levels. 


\section{DEDICATION}

This thesis is dedicated to my family who have provided support throughout my pursuit of higher education and drive me to higher standards. Specifically, this document is dedicated to my following family members:

Parents: Donald and Diane Paukett

Grandparents: Lucille Giles and Eleanor Paukett

Sister: Rachel Paukett 


\section{ACKNOWLEDGEMENTS}

I would like to thank my committee chair, Dr. Dharmasena, and my committee members, Dr. Bessler and Dr. Coufal, for their guidance and support over the course of this research project.

Additionally, I would like to thank the Department of Agricultural Economics for their contributions towards making my time at Texas A\&M University exceptional. Specifically, I would like to thank Dr. Leatham for his assistance in acquiring financial support and Brandi Blankenship for her help with all the details of obtaining my degree.

I would like to also thank my supervisor at the Texas A\&M Engineering Extension Service, Lisa Mutchler, for her understanding and flexibility that made working and completing my degree at the same time manageable.

Finally, thanks to my parents, grandparents, and sister for their encouragement and love throughout this endeavor. 


\section{CONTRIBUTORS AND FUNDING SOURCES}

This work was supervised by a thesis committee consisting of Dr. Senarath

Dharmasena and Dr. David Bessler of the Department of Agricultural Economics and Professor Craig Coufal of the Department of Poultry Science.

The data analyzed for Section 3 was provided, in part, by David Harvey from the USDA-ERS. All work for the thesis was completed by the student, in collaboration with Dr. Senarath Dharmasena and Dr. David Bessler of the Department of Agricultural Economics, as well as under the advisement of Dr. Craig Coufal of the Department of Poultry Science. Graduate study was supported by a departmental scholarship from Texas A\&M University. 


\section{NOMENCLATURE}

\begin{tabular}{|c|c|}
\hline $\mathrm{ADF}$ & Augmented Dickey-Fuller \\
\hline AI / HPAI & (Highly Pathogenic) Avian influenza \\
\hline $\mathrm{BIC}$ & Bayesian Information Criterion \\
\hline CATS & Cointegration Analysis for Time Series \\
\hline CFI & Comparative Fit Index \\
\hline $\mathrm{CV}$ & Coefficient of Variation \\
\hline $\mathrm{DF}$ & Dickey-Fuller \\
\hline GES & Greedy Equivalence Search \\
\hline LR & Likelihood Ratio \\
\hline $\mathrm{PC}$ & Peter-Clark Algorithm \\
\hline RATS & Regression Analysis for Time Series \\
\hline RDI & Real Disposable Personal Income \\
\hline RMSEA & Root Mean Square Error of Approximation \\
\hline $\mathrm{SIC}$ & Schwarz Information Criterion \\
\hline TSA & Time Series Analysis \\
\hline VAR & Vector Autoregressive Model \\
\hline VECM & Vector Error Correction Model \\
\hline
\end{tabular}




\section{TABLE OF CONTENTS}

ABSTRACT

1.1 Problem Statement and Justification ........................................................... 1

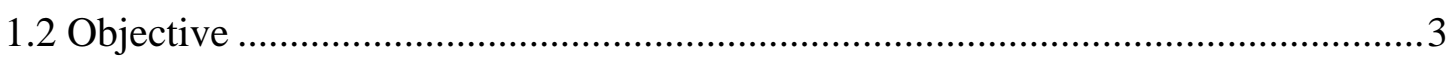

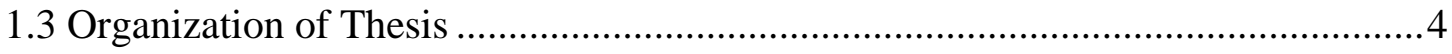

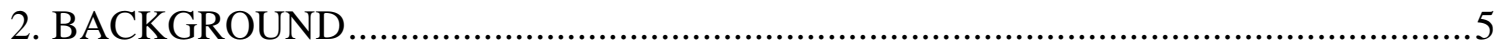

2.1 Brief Overview of the U.S. Layer Industry and Avian Influenza .........................5

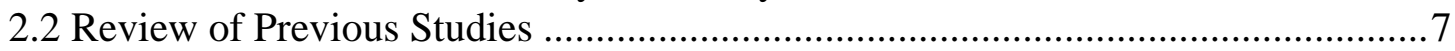

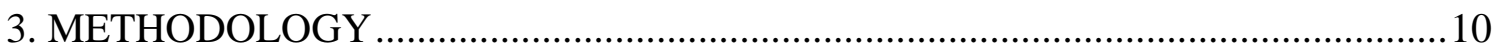

3.1 Conceptual Framework and Application.......................................................... 10

3.1.1 Introduction to Time Series ............................................................... 11

3.1.2 Vector Autoregressive Model and Vector Error Correction Model......... 12

3.1.3 Tests of Nonstationary ..................................................................... 14

3.1.4 Cointegration and Rank of $\Pi$............................................................. 16

3.1.5 Forecasting and Calculating Revenue Impact .................................... 17

3.1.6 Contemporaneous Time Analysis .................................................... 18

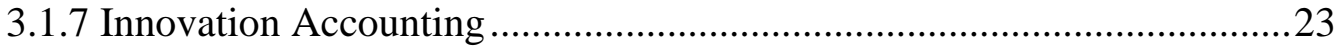

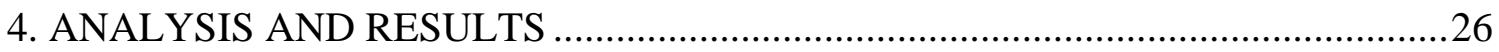

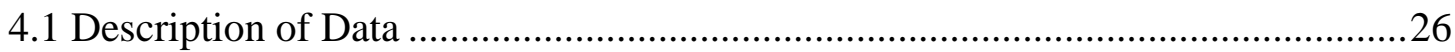


4.1.1 Summary Statistics .....................................................................2

4.1.2 Stationary Tests and the Number of Lags ........................................29

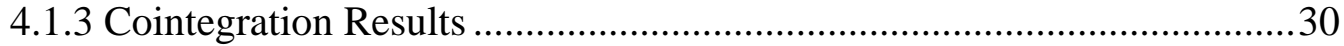

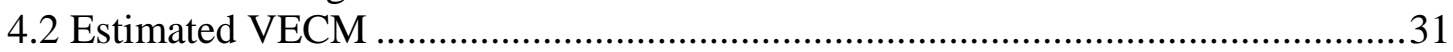

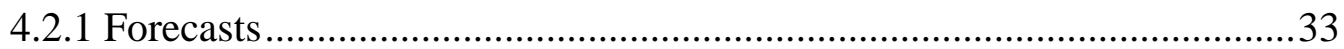

4.2.2 Directed Acyclic Graphs .................................................................... 34

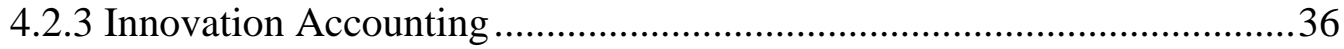

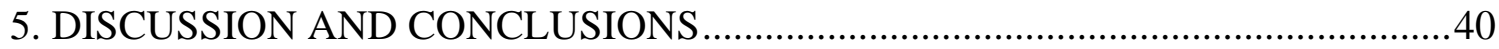

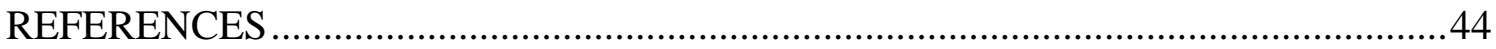

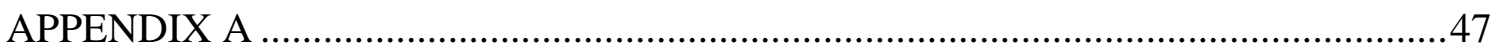

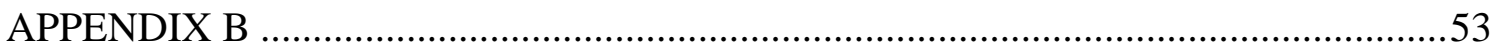

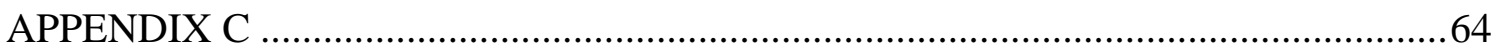

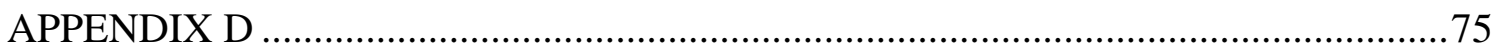




\section{LIST OF FIGURES}

FIGURE $\quad$ Page

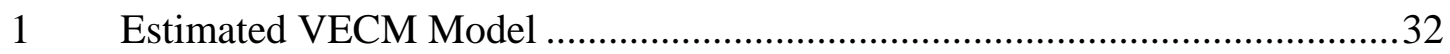

2 Directed Acyclic Graph Generated by Both the PC Algorithm and the Greedy Equivalence Search Algorithm .......................................................35

3 Marginal, Average and Total Revenue Graphs .........................................41

4A Historical Charts for United States Hens, Eggs, Egg Price and Soybean Meal Price from March 1986 to May 2016

5A Historical Charts for United States Cornmeal Price, Retail Beef \& Pork Prices, and Real Personal Disposable Income from March 1986 to May 2016 48

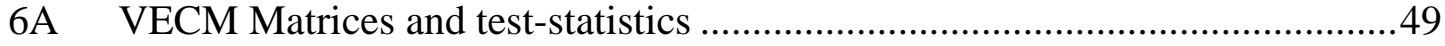

7A Realized and Counterfactual Forecast for United States Wholesale Table Egg Revenue 2010-2015 ....................................................................50

8A Impulse Response Functions to Innovations in Eggs and Hens ......................51

9A Impulse Response Functions to Innovations in Egg Price.............................52 


\section{LIST OF TABLES}

TABLE

Page

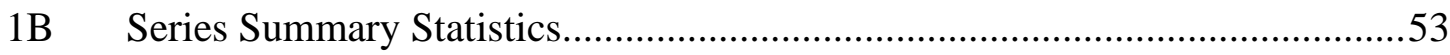

2B Dickey-Fuller and Augmented Dickey-Fuller Tests for Stationarity …….........54

3B Likelihood Ratio Test for Stationarity Based on a Rank of $\Pi$ of Two …….......55

4B Model Lag Determination Using Schwarz Information Criteria (SIC) .............56

5B Trace Tests for Model Rank and Cointegration ...............................................57

6B Exclusion Test Results for Two Cointegrating Vectors ......................................58

7B Weak Exogeneity Test Results for Two Cointegrating Vectors.........................59

8B Theil U-Statistic to Evaluate Forecast Performance..............................................60

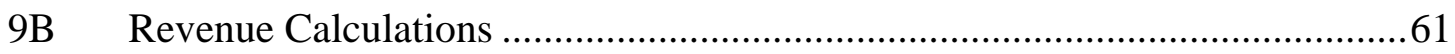

10B Greedy Equivalence Search (GES) and PC Algorithm (PC) Machine

Learning Edge Statistics ...............................................................................62

11B Percent Forecast Error Variance Decomposition for Hens, Eggs, and Egg

Price. 


\section{INTRODUCTION}

\subsection{Problem Statement and Justification}

Starting in December 2014 and continuing through June 2015, the United States poultry industry experienced an outbreak of highly pathogenic avian influenza virus (HPAI). As the name suggests, this economically important poultry disease spreads easily and causes flu-like symptoms like lethargy and swelling in birds, while also presenting the hazard of being a zoonotic disease with the potential to spread to humans. This particular outbreak affected 211 commercial flocks comprised of egg, broiler, and turkey producers in 15 states throughout the western and central United States, including the largest and third largest egg producing states, Iowa and Indiana respectively. By the end of the outbreak over 50 million birds had been killed to control the spread of this virus, resulting in huge losses for the affected producers (USDA 2015). While broilers take merely six weeks to go from hatching to market, egg layers must be raised for an average of five months before they can produce eggs and, subsequently, the hens remain in the houses for about two years. Thus the extended time element involved in the layer industry means that individual egg producers may take longer to recover from the outbreak than a broiler farmer would. With the massive bird depopulation, egg production decreased and higher prices for table eggs were realized on the markets. These higher prices impact consumer purchasing decisions and disrupt desired trends such as the increasing per capita consumption of eggs. While costs are typically discussed surrounding outbreaks, it is also interesting to consider the revenue impacts of these events to determine if the price increases imposed are able to offset the loss in 
revenue that would otherwise be realized by a decrease in the number of eggs. By delving into this research question we will find ourselves identifying the driving forces within the industry along the way. Overall, the goal of this thesis is to develop an acceptable econometrical model for use in calculating the revenue impact of the 2015 avian influenza outbreak on United States table egg wholesalers.

Obtaining an estimate of revenue impact will be of interest to those reporting on the AI outbreak and industry leaders. Our results will also be of interest to data researchers, such as those with the United States Department of Agriculture Economic Research Service (USDA-ERS), who collect and interpret data about the table egg industry. Individuals interested in expanding on the results of our study or applying our methods to other relevant problems will want to build off or reference the model and methodology we implemented. For instance, researchers interested in the impacts of the 2015 AI outbreak at the consumer, retail, and producer levels can use our model and results as a basis for implementing price transmission techniques. Industry leaders also will benefit from our research by having a method to generate reliable egg price and quantity forecasts which will provide even more stability to the industry as uncertainty is minimized. Finally, we hope that this study will encourage future studies that utilize the vector autoregressive or vector error correction model in not only finding the revenue impact due to naturally occurring events, but also in policy analysis for both proposed policies and retrospective analysis. 


\subsection{Objective}

The overarching goal of this thesis is to develop a sound econometric model that will generate a counterfactual revenue, or the revenue that would have been realized if the AI outbreak had not occurred, to which we can compare the actual reported revenue during the outbreak and obtain the revenue impact on US table egg wholesalers that is attributed to the AI outbreak, ceteris paribus. We outline four major objectives to ensure that we attain this goal and also obtain a clear understanding of relationships within the US table egg industry. The first objective is to identify general series characteristics for variables impacting the US table egg industry. This allows us to start identifying the specifications for a vector error correction model (VECM), or our second objective. The VECM is a widely accepted model for dealing with time series data and is useful for generating good forecasts, which is what we want to do to satisfy our third objective. Specifically, the third objective is essentially the primary goal of this thesis: to use our VECM to forecast the counterfactual revenue for US table egg wholesalers and compare this to their actual revenue received during the AI outbreak. This will provide us with the revenue impact on US table egg wholesalers due to the 2014-2015 AI outbreak, ceteris paribus. Our final objective is to derive additional information from our estimated model by analyzing the model's residuals, also known as innovations in time series literature, to determine contemporaneous causal relationships between variables in the US table egg industry. Altogether, satisfying these four objectives will provide us with an answer to our research question on what the impact of the AI outbreak on US table egg wholesaler revenue was. 


\subsection{Organization of Thesis}

This thesis is organized into four major sections. Section 1 introduces the problem and outlines specific objectives that will guide our approach to answering our research question on the revenue impact of AI at the US table egg wholesaler level. Additionally, it offers justification as to why we decided to pursue this line of research. Section 2 provides background on the US table egg industry and avian influenza, while also reviewing previous studies related to our research. Section 3 then explains the conceptual framework and methodology used for our research. Section 4 starts by describing the data used in this study and then presents the results. These results are

further analyzed and discussed in Section 5, where suggestions for future research and concluding remarks can also be found. 


\section{BACKGROUND}

\subsection{Brief Overview of the U.S. Layer Industry and Avian Influenza}

Egg production can be found throughout the US, with the top five largest egg producing states in America being Iowa, Ohio, Indiana, Pennsylvania, and Texas, from first to fifth respectively. The majority of eggs produced in the US are also consumed in the US, although in 2014 over 350 million eggs were exported from the US ("The Egg Business" 2016). Eggs are an important part of the American diet, as evidenced by the increasing per capita consumption over the past seven years to 258 eggs in 2014, with a further increase to 266 eggs per person in 2016 expected (Watson 2014; “The Egg Business" 2016). In general, eggs are considered a necessary good with no clearly identified close substitutes and thus have an inelastic price, meaning that a one percent change in egg price will result in a less than one percent change in the quantity of eggs purchased.

Egg wholesalers are defined as an intermediary between egg producers and retailers who ultimately sell the eggs to consumers. These wholesalers may strictly focus on eggs, such as S\&R Fresh Eggs in Wisconsin or CMC Farms in New Jersey, or be major wholesalers found throughout the US dealing with a wide variety of products like Kroger, Costco, and Walmart. Not all eggs pass through a wholesaler, as larger egg producing companies such as Cal-Maine Foods have enough market power to create direct agreements with retailers. Smaller farms, however, may use a wholesaler to send their eggs down the supply chain to consumers. 
US egg production primarily takes place in large commercial houses, with flocks of 75,000 or more birds representing about $99 \%$ of all layer hens in the US. Currently about $5.5 \%$ of US egg production is considered "cage-free" and only $4.5 \%$ of producers identify as organic, together a total of around 30 million birds. Layers, or hens used in the production of eggs, take an average of five months to begin producing eggs and are typically kept in production for about two years. The average rate of lay per day in the industry is currently 77 eggs per 100 layers, with about 286 eggs laid per hen per year (American Egg Board 2016, “The Egg Business" 2016). Practices like forced molting ${ }^{1}$ allow producers to extend the productive life of their birds if it is economically worthwhile to do so, although at lower productivity levels than these average laying rates. Egg producers unaffected by the AI outbreak may have implemented this practice in order to gain profit from the AI-inflated egg prices.

Highly pathogenic avian influenza (HPAI) virus is an economically important poultry disease that causes a variety of symptoms in poultry including lethargy, swelling, and sudden death in birds. Due to the highly infectious nature of the disease and its rare potential to spread to humans, once $\mathrm{AI}$ is detected on a farm all the birds must be killed and disposed of properly. This quickly leads to large losses of layers, as many commercial houses have an excess of 75,000 birds on site. Additional costs to producers include sanitizing houses, repopulating entire houses with birds, and the cost of having their facilities idle in the meantime.

The particular AI outbreak our research focuses on was first confirmed on US farms in December 2014 and quickly spread to a total of 211 commercial flocks and 21

${ }^{1}$ Forced Molting: A practice where farmers can induce their birds to stop laying and lose their feathers for a brief time so that afterwards their laying period can be extended. 
backyard flocks until June $16^{\text {th }} 2015$ when the last detection was reported. States with reported cases include the \#1 and \#3 egg producing states, Iowa and Indiana respectively, as well as California, Oregon, Washington, Idaho, Montana, North and South Dakota, Nebraska, Kansas, Minnesota, Wisconsin, Missouri, and Arkansas. This outbreak impacted layer, turkey, and some broiler production and altogether over 50 million birds were culled (USDA 2015). To compensate these affected producers, the United States Department of Agriculture (USDA) paid out \$190 million (McKenna 2015). Several cost estimates of losses from this outbreak can be found in extant literature such as Iowa alone having total economic damages of \$957 million (Fry 2015). According to McKenna (2015), the cost of all the culled birds in the US was \$1.57 billion and, when combined with costs to industries further down the supply chain like egg wholesalers and food service firms, this resulted in a total loss of $\$ 3.3$ billion due to this particular AI outbreak. Since these authors don't clearly explain what these cost estimates include and do not describe how they are modeled, these estimates primarily serve to paint a general picture of the negative impact that the 2014-2015 AI outbreak had in the US.

\subsection{Review of Previous Studies}

As a major poultry industry event, many researchers are interested in the impacts of the 2014-2015 avian influenza outbreak. Many of these studies, such as those by Gao, Richardson, and Maisashvili (2016), look at the impacts to the whole poultry industry including broilers, layers, and other poultry products. The current research on this AI outbreak also focuses more on analyzing price changes, trade impacts, welfare analysis 
and regional impacts (Dobrowolska \& Brown 2016; Seitzinger and Paarlberg 2016). This study will isolate table egg production, which was heavily impacted by the AI outbreak, and consider the revenue impact to US table egg wholesalers. By defining this smaller aspect of the industry, future studies will be able to expand on our model and results to answer larger questions about the impacts of AI on the poultry industry.

Estimates of the US wholesale table egg revenue impacts do not seem to be available in the extant literature, although McKenna (2015) implied that losses from these wholesalers contributed to the $\$ 3.3$ billion in costs to the US poultry industry as a whole. As mentioned previously, this article is unclear on how this estimate was derived and specifically what it includes, but we can still compare it with our results to see if table egg wholesalers did realize a revenue loss due to the outbreak.

A paper published by Chavez and Johnson (1981) outlined a series of structural models that defined various aspects of the US egg industry from hatching to production and prices. Included was a wholesale egg price structural model with variables relevant to the industry today, such as feed prices and the number of hens and eggs, which we incorporated into the vector error correction model (VECM) we developed. We chose to find revenue impact using a VECM because this model tends to generate superior forecasts compared to structural models because of its ability to capture the dynamic effects of all the variables better than large structural models (Sims 1980). The VECM also has a history of being utilized as a tool to determine economic impacts of animal diseases in other studies, such as Costa, Bessler, and Rosson (2015), although this study forecasted price to analyze trade disruptions from the swine flu of 2005. Additionally, 
we use monthly data to more accurately measure the impacts of the AI outbreak throughout the time period it occurred, a suggestion offered by Chavez and Johnson (1981).

Overall, our review of the literature indicated a lack of emphasis on research regarding revenue impact due to the AI outbreak and supported the methodology we proposed to use in our study. From understanding the literature, we were able to define our objectives as first identifying series characteristics and then the specifications, such as the number of cointegrating vectors, required for the VECM model. Using the VECM we will estimate the revenue impact of the AI outbreak on US table egg wholesalers by generating a counterfactual forecast of revenue to compare to the actual observed revenue during the outbreak. Finally, using the residuals from the VECM, we will determine causal relationships with machine learning algorithms to better understand how the different industry variables interact in contemporaneous time. 


\section{METHODOLOGY}

\subsection{Conceptual Framework and Application ${ }^{2}$}

Current evaluations of the 2014-2015 AI outbreak have focused on costs to the poultry industry, rather than revenue impacts, with reported estimates unclear as to what they encompass and how they were derived. Additionally, past approaches modeling the US wholesale table egg price did not implement time series techniques; for instance, Chavez and Johnson (1981) developed a structural model of this sector which, as stated by the authors themselves, is not ideal for forecasting. Thus a need for an updated, robust econometric model for wholesale table egg prices is another driving force behind this thesis document. We use observational data in this study, which recommends us to use a less structured model with relaxed dependency on the ceteris paribus assumption which is not as applicable to observed data, allowing us to generate better predictions of the real world. Therefore, this thesis focuses on using vector autoregressive (VAR) time series modelling techniques, specifically the VECM, to understand the effects of the 2014-2015 US avian influenza (AI) outbreak on US wholesaler revenue for table eggs. Additionally, this thesis will incorporate the concepts of innovation accounting and directed acyclic graphs (DAGs) to highlight variable interactions due to shocks like the AI outbreak and identify causal relationships in the US table egg industry in terms of the new information discovered for each variable.

This section on methodology opens with an introduction to the theoretical properties of time series modeling and a description of two widely accepted time series

\footnotetext{
${ }^{2}$ This discussion follows Dharmasena (2003), Bessler \& Yang (2003), and Dharmasena, Bessler, \& Capps (2016).
} 
must be conducted to define a time series model, such as stationarity tests and tests for cointegration. Applications of the VAR and VECM in terms of forecasting, determining causal relationships between variables, and innovation accounting will conclude this section.

\subsubsection{Introduction to Time Series}

By definition, time series analysis (TSA) studies involve data reported at specific intervals over a defined timeframe, with the assumption that the order of observation within this timeframe matters. Therefore, the variable subscript $t$ is used to indicate the chronological order of observations for TSA. Stationarity is another important stipulation of TSA, as it ensures a series has a finite and constant mean, variance, and covariance. This allows us to analyze the errors, or new information found from TSA modeling, without interference from variations in the historical mean. Before conducting time series modeling on a non-stationary series, the series must be converted to a stationary series by taking differences as described in Section 3.1.3.

The basic time series model is a univariate model that focuses on a single series of data and its movement through time. In this model, a random variable $\left(X_{t}\right)$ is considered dependent only on past lagged values of itself, along with some error $\left(e_{t}\right)$. In TSA, error is considered an innovation or new information that causes a variable in current time to deviate from its most recent value $\left(X_{t-1}\right)$ in a way not necessarily tied to the historical mean value. Therefore, forecasting with the historical mean itself will not be as effective for generating a good forecasts. This simple model can be visualized as the following equation: 


$$
X_{t}=\mu+\beta_{1} X_{t-1}+\beta_{2} X_{t-2}+\ldots+\beta_{k} X_{t-k}+e_{t}
$$

Where $\mu$ is a constant intercept term and the $\beta$ 's are unknown parameters. The uncorrelated error term, $e_{t}$, is assumed to have a mean of zero and a variance of $\sigma_{e}^{2}$. This equation represents an autoregressive model of order $k$, where $k$ is the number of lags in the model. Lags refer to how many observations in the past $\left(X_{t-k}\right)$ one must include in a model to define the variable's present value $\left(X_{t}\right)$. For instance, if $k=3$ then the value of the variable in present time is considered a function of a constant $(\mu)$, the innovation term $\left(e_{t}\right)$, and its values in the three periods preceding the current point in time $\left(X_{t-1}, X_{t-2}\right.$, $X_{t-3)}$. This univariate model provides the basis off of which we build our VAR, before transforming it in to a VECM to account for cointegrating vectors. These models will be discussed in the following section, Section 3.1.2.

\subsubsection{Vector Autoregressive Model and Vector Error Correction Model}

Expanding on the univariate model to account for the array of interacting variables found in the real world, multivariate vector autoregressive (VAR) models are useful in analyzing and summarizing the regularities in several series of observational data over time. The VAR is a non-structural model, allowing the researcher to choose variables relevant to his or her specific problem rather than being constrained by predetermined models based on an overarching prior theory. The unrestricted VAR, with no constant, is shown below:

$$
\mathrm{X}_{\mathrm{t}}=\sum_{\mathrm{k}=1}^{\mathrm{k}} \alpha(\mathrm{k}) \mathrm{X}_{\mathrm{t}-\mathrm{k}}+\delta_{\mathrm{t}}
$$


In this equation, $X_{t}$ is an (mxl) matrix of variables, $\alpha(k)$ is an $(m x m)$ matrix, and $\delta_{t}$ is an (mxl) matrix with $m$ being the number of variables in the model. The $\delta_{t}$ term represents innovations which are uncorrelated through time but often contemporaneously correlated, making them useful for determining contemporaneous causal relationships between variables. The unknown parameter to be estimated from the observed data in the model is $\alpha$. Lag length, denoted as $k$ in VAR analysis, is commonly derived using statistical loss functions where the lag with a minimum Schwartz Information Criteria (SIC) value is selected. This function seeks to identify a parsimonious model by considering the tradeoff between the number of variables in the model and the number of lags. SIC is calculated using the following equation:

$$
\mathrm{SIC}=\log \left|\widehat{\Sigma}_{\mathrm{k}}\right|+(\log \mathrm{T}) \mathrm{m}^{2} \mathrm{k} / \mathrm{T}
$$

Here, $\left|\widehat{\Sigma}_{k}\right|$ is the determinant of the residual variance-covariance matrix for the $\operatorname{VAR}(k)$ model, $m$ is the number of variables, and $T$ is the number of effective observations.

The VAR is converted to a vector error correction model if cointegration is found between series. Extra vectors accounting for the cointegrating relationships are added to the formula and the VAR portion is reduced to $k-1$ lags, while the error term remains untouched. As an equation, with an adjustment for seasonality, this would be:

$$
\Delta \mathrm{X}_{\mathrm{t}}=\Pi \mathrm{X}_{\mathrm{t}-1}+\Psi \mathrm{S}_{\mathrm{t}}+\sum_{\mathrm{i}=1}^{\mathrm{k}-1} \Gamma_{\mathrm{i}} \Delta \mathrm{X}_{\mathrm{t}-\mathrm{i}}+\mathrm{e}_{\mathrm{t}}
$$

Where $\Delta X_{t}=\left(X_{t}-X_{t-1}\right)$. In this equation, $X_{t}$ is an $(m x l)$ vector of variables, $\Gamma_{i}$ is an $(m \mathrm{x} m)$ matrix of short run dynamics coefficients, and $e_{t}$ is an $(m x l)$ vector of innovations representing contemporaneous time. $\Psi$ is an $(m x l 1)$ matrix of coefficients 
for the $S_{t}(11 x 1)$ vector of monthly dummy variables. $\Pi$ is an $(m x[m+1])$ matrix of coefficients corresponding to an $([m+1] x l)$ vector of variables and a constant. $\Pi=\alpha \beta^{\prime}$ and the rank of $\Pi$ is $r$, the number of cointegrating vectors. $\alpha$ is a coefficient matrix representing the short run adjustment to return to equilibrium after a shock to the system, whereas $\beta$ is the transposed cointegration matrix representing the long-run relationships between variables (Bessler \& Yang 2003). Note that a VECM converted from a VAR with one lag would be lacking the $\sum_{i=1}^{k-1} \Gamma_{i} \Delta X_{t-i}$ portion of the model (Magee 2008). Overall, the VECM allows for some interesting analysis because the long run, short run, and contemporaneous structures can be isolated and further analyzed.

\subsubsection{Tests of Nonstationary}

By definition, a non-stationary series is comprised of data points that move away from their historical mean for extended periods of time. This results in a series with infinite variance that, when modeled, can lead to faulty conclusions from reported significance. For this reason, data series $\left(X_{t}^{\prime} s\right)$ used in autoregressive models are expected to be stationary and differences should be taken until this condition is satisfied, with first differences represented as $\Delta X_{t}=\left(X_{t}-X_{t-1}\right)$. If a non-stationary series is differenced once and is then stationary, it is said to be integrated to order 1 , or $I(1)$. Therefore, a naturally stationary series is considered to be integrated to order 0 , or $I(0)$.

A common test to determine if a series is stationary is the Dickey-Fuller (DF) test. In this test, $\Delta X_{t}=\left(X_{t}-X_{t-1}\right)$, or first differences, are regressed on a constant $\left(\alpha_{0}\right)$ plus the non-differenced variable lagged one period $\left(\alpha_{I} X_{t-1}\right)$ : 


$$
\Delta \mathrm{X}_{\mathrm{t}}=\alpha_{0}+\alpha_{1} \mathrm{X}_{\mathrm{t}-1}
$$

The null hypothesis is that the series is non-stationary $\left(\alpha_{1}=0\right)$. If the ordinary least squares estimate of $\alpha_{l}$ in this equation has a t-statistic more negative than the $\mathrm{t}$ statistic at the $5 \%$ level of -2.89 , then this null hypothesis is rejected. For instance, if a calculated t-statistic value of -3.5 is found, based on the ratio between the estimated coefficient and the standard error of the estimated coefficient, then you can reject the null hypothesis and state that the series is stationary.

To account for possible autocorrelation in the estimated residuals, it is recommended that one also expands the DF test into an augmented Dickey-Fuller test (ADF) when testing if a series is stationary. The ADF test has the same null hypothesis and critical value at the 5\% level as the DF test, but adds an additional term to the basic DF test formula:

$$
\Delta \mathrm{X}_{\mathrm{t}}=\alpha_{0}+\alpha_{1} \mathrm{X}_{\mathrm{t}-1}+\sum_{\mathrm{i}=1}^{\mathrm{k}} \beta_{\mathrm{i}} \Delta \mathrm{X}_{\mathrm{t}-\mathrm{i}}
$$

Where $k$ is the lag length selected to "whiten" or remove the autocorrelation from the residuals. The ideal lag length can be found by minimizing Schwarz Information Criterion (SIC), as described in Section 3.1.2.

Likelihood ratio (LR) tests can also be used to test if a series is stationary using the following formula:

$$
\mathrm{L}(\mathrm{X})=\frac{\mathrm{p}\left(\mathrm{H}_{0} \mid \mathrm{X}\right)}{\mathrm{p}\left(\mathrm{H}_{1} \mid \mathrm{X}\right)}
$$

Where $p$ represents the probability of the hypothesis occurring. Unlike the DF test, the null hypothesis $\left(H_{0}\right)$ is that a series is stationary. Therefore, $H_{l}$ represents the alternative hypothesis that the series tested is non-stationary. The statistic is distributed 
chi-squared under the null hypothesis with $p$ - $r$ degrees of freedom, where $r$ is the rank of the cointegrating vector which will be discussed further in section 3.1.4. The chisquared test statistic is calculated as:

$$
\mathrm{C}(\mathrm{X})=\Sigma \frac{\left(\mathrm{H}_{1}-\mathrm{H}_{0}\right)^{2}}{\mathrm{H}_{0}}
$$

If the calculated chi-squared values are greater than the chi-square critical value at the $10 \%$ significance level, then the null hypothesis is rejected and the series would be considered non-stationary.

\subsubsection{Cointegration and Rank of $\Pi$}

If series are found to be $I(1)$, or non-stationary, there is a possibility that these I(1) series are co-integrated, meaning that they move together in a random walk. A random walk is where the best prediction of a variable's value tomorrow $\left(X_{t+1}\right)$ is its value today, along with some white noise $\left(e_{t+1}\right)$ :

$$
\mathrm{X}_{\mathrm{t}+1}=\mathrm{X}_{\mathrm{t}}+\mathrm{e}_{\mathrm{t}+1}
$$

When cointegrating series are differenced from each other, the results will be stationary, or $I(0)$. Cointegration in a set of series requires one to develop a vector error correction model to avoid "spurious" regression and correlation.

Recall that $\Pi$ with a rank of $r$ cointegrating vectors is the product of the transposed matrix of cointegrating relationships $\left(\beta^{\prime}\right)$ and the matrix of adjustment coefficients $(\alpha)$. If $r=0$ there is no $\Pi$ matrix and a VAR in first differences can be modeled. If $r=m$, where $m$ is the number of variables in the model, $\Pi$ has full rank and there is no cointegration so a VAR in levels can be done. If $\Pi$ has a reduced rank, where 
$r<m$, cointegration exists and both $\alpha$ and $\beta$ are (mxr) matrices with a rank of $r$.

Therefore, there are at most $m-1$ cointegrating vectors.

Testing for cointegration is done using the Johansen (1991) trace test, which is a likelihood ratio test with a null hypothesis of $r=0$ and an alternative hypothesis of $r_{0}<$ $\operatorname{rank}(\Pi)<m$. If this null hypothesis is rejected, then the test proceeds stepwise, such that the next null hypothesis is $r 0+1$ and the alternative hypothesis is $r_{0}+1<\operatorname{rank}(\Pi)<m$ (Dwyer 2015). The value of $r$ at the first failure to reject the null hypothesis, using provided critical values, is the rank of $\Pi$. The trace test statistic is calculated as:

$$
\lambda_{\text {trace }}(\mathrm{r})=-\mathrm{T} \sum_{\mathrm{i}=\mathrm{r}+1}^{\mathrm{m}} \ln \left(1-\hat{\lambda}_{\mathrm{i}}\right)
$$

Where $\hat{\lambda}$ represents the estimated values of the characteristic roots obtained from the estimated $\Pi$ and $T$ represents the number of observations. The Johansen trace test is an accepted method for identifying the rank of $\Pi$, especially when working with data sets comprised of more than two variables.

\subsubsection{Forecasting and Calculating Revenue Impact}

Forecasting is a major application of the VAR and VECM models and forecasts for any $t+h$ horizon can be computed using the chain rule of forecasting. Based on a VAR(1) model, which has one lag, the $h$-step ahead forecast is equal to:

$$
\widehat{\mathrm{X}}_{\mathrm{t}+\mathrm{h} \mid \mathrm{t}}=\Phi_{1}^{\mathrm{h}} \mathrm{X}_{\mathrm{t}}
$$

Where $\Phi$ simply represents the estimated parameters and $h$ is how far in the future you are forecasting. $\hat{X}_{t}$ represents an out-of-sample estimated value, or the 
forecast. Future errors are assumed to be zero, thus they are not shown here. The true observation for $t+h$ for a VAR(1) model would be:

$$
\mathrm{X}_{\mathrm{t}+\mathrm{h}}=\Phi_{1} \mathrm{X}_{\mathrm{t}+\mathrm{h}-1}+\left(\mathrm{e}_{\mathrm{t}+\mathrm{h}}\right)=\Phi_{1}^{\mathrm{h}} \mathrm{X}_{\mathrm{t}}+\left(\mathrm{e}_{\mathrm{t}+\mathrm{h}}\right)+\Phi_{1} \mathrm{e}_{\mathrm{t}+\mathrm{h}-1}
$$

Since we want to avoid contamination in our forecasts from AI influenced data, we chose to do a 12 -step ahead forecast for our counterfactual forecast. These forecasts were evaluated on their performance compared to a random walk using the Theil $\mathrm{U}$ statistic, calculated as:

$$
\mathrm{U}_{\mathrm{t}}=\mathrm{RMS}_{\mathrm{t}} / \mathrm{RMSNCF}_{\mathrm{t}}
$$

Where RMS is the root mean square error for our model forecasts and RMSNCF is the root mean square error for the no-change forecasts, or the random walk model. A Thiel U statistic less than one is an indication of good forecast performance, in which our model forecasts better than a random walk (Dharmasena 2003).

After developing and using the VECM to forecast counterfactual egg quantities and price over the time period that the AI outbreak occurred, a simple revenue calculation was done for both the counterfactual and actual data at each month during the outbreak by multiplying the price of eggs per dozen and the number of dozens of eggs. The difference between these two revenue amounts at each month of the outbreak represents revenue change due to the AI outbreak, ceteris paribus.

\subsubsection{Contemporaneous Time Analysis}

Since we are using observational data from a non-experimental setting, ceteris paribus does not hold true and we find ourselves in a system with many unknown, omitted variables and no specific economic theory to tell us the relationships among our 
variables. Thus enters the concept of DAGs, proposed by Pearl (1995), which possess the ability to find causal relationships among the variables in our model by simply using the correlation, or variance-covariance, matrix from the residuals of the VECM.

A directed graph is a comprised of an ordered triple, $\langle V, M, E\rangle$, where $V$ is a nonempty set of vertices, or variables, and $M$ is a non-empty set of symbols attached to the end of undirected edges, such as an arrow. $E$ is a set of ordered pairs and each member is an edge, with vertices connected by an edge being considered adjacent. A directed acyclic graph is a graph with an arrow on at least one edge of $E$ and which contains no directed cyclic paths, where one vertex causes a variable than in turn causes the original vertex. Directed acyclic graphs represent conditional independence given by the recursive product decomposition:

$$
\operatorname{Pr}\left(\mathrm{X}_{1}, \mathrm{X}_{2}, \mathrm{X}_{3}, \ldots, \mathrm{X}_{\mathrm{n}}\right)=\prod_{\mathrm{i}=1}^{\mathrm{n}} \operatorname{Pr}\left(\mathrm{X}_{\mathrm{i}} \mid \mathrm{P}_{\mathrm{ai}}\right)
$$

Where $\operatorname{Pr}$ is the joint probability of vertices $X_{1}, X_{2}, X_{3}, \ldots, X_{n}$ and $P_{a i}$ is the realization of some subset of the variables that precede, in a causal sense, $X_{i}$ in the order $\left(X_{1}, X_{2}, X_{3}, \ldots\right.$. $X_{n}$ ). If the DAGs are made so that the variables corresponding to $P_{a i}$ are the direct causes, or parents of $X_{i}$, then the conditional independencies given by $\Pi \operatorname{Pr}$ can be derived from the graph using the concept of directional separation (d-separation). Dseparation is defined as the blocking, or screening off, effect which allows us to determine the direction of causal flow in a set of variables.

There are several main causal relationships that can be described. For simplicity, consider three variables, $X, Y$ and $Z$. A causal fork is where $X$ is a common cause for both $Y$ and $Z$ such that $Y \leftarrow X \rightarrow Z$. If $X$ is not considered when studying $Y$ and $Z$ you will 
find a non-zero correlation between $Y$ and $Z$, meaning they are correlated and are directionally connected (d-connected). By introducing knowledge of $X$, the association between the joint effects will be d-separated and the correlation between $Y$ and $Z$ will be zero (Bessler \& Lee 2002).

Another possibility is an inverted causal fork where $Y$ and $Z$ are joint causes of $X$, or $Y \rightarrow X \leftarrow Z$. Here the unconditional correlation between $Y$ and $Z$ is zero, and conditioning on $X$ would cause their correlation to be non-zero. Therefore, common effects don't screen off association between their joint causes, but rather makes them dconnected. Expanding on this, if $X$ is also the parent of a variable, $W$, then by conditioning on $W$ rather than the collider $X$ we will be able to d-connect $Y$ and $Z$.

The final main scenario is a simple causal chain, which would be defined as $X$ causing $Y$ which causes $Z$, such as $X \rightarrow Y \rightarrow Z$. If we condition on $Y$, then we block the information flow between the endpoints and $X$ and $Z$ would have zero correlation. However, if only $X$ and $Z$ are considered, their unconditional association will be nonzero and these endpoints would be d-connected.

There are several computer algorithms one can use to build DAGs and we used the Peter-Clark (PC) Algorithm and Greedy Equivalence Search (GES) Algorithm in TETRAD V to identify causal relationships in our model. TETRAD software is freely provided by research workers at Carnegie Mellon University and only requires the correlation matrix, or the variance-covariance matrix, of the variables and the number of observations to build the DAGs. Knowledge of the problem area can be incorporated into the graphs by putting expected exogenous variables in the top tier of the knowledge 
structure and more endogenous variables in the lower tiers (Spirtes, Glymour, \& Schenies 1993).

For the PC algorithm, the software starts with a completely undirected graph, where all variables are connected to all others with an edge with no arrow, and systematically uses correlation and conditional correlations to remove the edges between variables with significantly zero edges. All edges that pass this first test are then assigned arrows by applying the concept of d-separation, as described above.

The GES algorithm starts with a DAG with no edges, meaning all variables are independent, and begins to add edges between variables from equivalent classes, which are comprised of multiple DAGs that have the same probability distribution and independence constraints. It searches stepwise, scoring each graph with the Bayesian Information Criterion (BIC) metric which considers the tradeoff between model fit and parsimony:

$$
\mathrm{B}(\mathrm{G}, \mathrm{D})=\ln \mathrm{p}\left(\mathrm{D} \mid \hat{\theta}, \mathrm{G}^{\mathrm{h}}\right)-\frac{\mathrm{d}}{2} \ln \mathrm{m}
$$

Where $d$ is the number of free parameters in graph $G, \hat{\theta}$ is the maximumlikelihood estimate of the unknown parameters, and $m$ is the number of observations in the data $D \cdot \ln p\left(D \mid \widehat{\theta}, G^{h}\right)$ represents model fit and the rest of the function represents model parsimony. The equivalence class that increases the score most is chosen for the next step in this first phase until no new replacement can increase the score. In the second phase of GES, single edges are deleted and the scores of DAGs in equivalence classes are repeatedly compared until a local maximum is reached, which is considered the optimal solution (Dharmasena, Bessler \& Capps 2016). 
The models generated by these algorithms in TETRAD V also are evaluated by several statistical measures including chi-squared testing, comparative fit index (CFI), and root mean square error of approximation (RMSEA). The chi square test assumes a minimized maximum likelihood function over the measured variables and has a null hypothesis that the population covariance matrix is equal to the estimated covariance matrix for all measured variables. A good fit is indicated by values close to zero. The degrees of freedom for this test are calculated as $m(m+1) /(2-d)$, where $d$ is the number of linear coefficients, variance terms, and error covariance terms that are not fixed in the model.

The CFI statistic assumes that all latent variables are uncorrelated and compares the sample covariance matrix with this null model, while also adjusting for sample size. Values range from 0 to 1 , with larger values indicating better fit. RMSEA is an indication of how well the model would fit the covariance matrix of the population and will favor a more parsimonious model. RMSEA also ranges from 0 to 1 , however here a value closer to zero is an indication of good fit. As a note, goodness-of-fit is important to consider, however it doesn't mean that a poor fitting model is necessarily bad or completely useless.

There are three main assumptions to consider when deciding on the edges of DAGs. The first is to assume there are no omitted variables that cause two or more of the variables in the algorithm, known as the causal sufficiency condition. The second is the causal Markov condition, where one only conditions on the parents of a variable to fully capture its joint probability distribution. In the case of the causal chain previously 
described, the underlying probability distribution under this condition would be $\operatorname{Pr}(X, Y, Z)=\operatorname{Pr}(X) \operatorname{Pr}(Y \mid X) \operatorname{Pr}(Z \mid Y)$. The last condition is the faithfulness condition which states that if there is zero or partial correlation between variables it is not due to cancellations of parameters in the model, but rather only occurs because their correlation is not significantly different from zero. Especially with observational data, these three conditions may not be met so care must be taken when interpreting the DAGs generated by TETRAD software, particularly if you want to apply the results to policy.

\subsubsection{Innovation Accounting}

The coefficients obtained from a VAR model are difficult to interpret and analyze on their own, so further analysis is often done based on the moving average representation of the VAR. The moving average matrix at lag zero contains information

on the relationships between series in current time, $t$. However, the VAR can only tell us if series are contemporaneously correlated based on the $i, j$ element of $\Sigma$, the variancecovariance matrix, and gives no insight on the direction of causal behaviors. To solve this problem, we utilize Bernanke factorization. For this, innovations are assumed orthogonal and can be written in matrix form as:

$$
\left[\begin{array}{l}
\mathrm{u}_{1, t} \\
\mathrm{u}_{2, \mathrm{t}} \\
\mathrm{u}_{3, \mathrm{t}}
\end{array}\right]=\left[\begin{array}{ccc}
1 & \mathrm{a}_{12} & \mathrm{a}_{13} \\
\mathrm{a}_{21} & 1 & \mathrm{a}_{23} \\
\mathrm{a}_{31} & \mathrm{a}_{32} & 1
\end{array}\right]\left[\begin{array}{l}
\mathrm{e}_{1, t} \\
\mathrm{e}_{2, \mathrm{t}} \\
\mathrm{e}_{3, \mathrm{t}}
\end{array}\right]
$$

Where $e_{i, t}$ are observed innovations from the VAR and $u_{i, t}$ are orthogonal innovations. Lagged relationships are assumed unrestricted.

One benefit of using Bernanke factorization over alternative methods, such as Choleski factorization, is that we don't need to know how to order the factorization. 
Bernanke lets us arbitrarily impose a particular causal ordering on variables, allowing for a better view of unknown causal flows (Bessler 2015). We can use directed acyclic graphs to assign zeros to certain $a_{i, j}{ }^{\prime}$ s which allows us to identify causal relationships between series. Bernanke factorization can also be used to transform a VAR into:

$$
\mathrm{AX}_{\mathrm{t}}=\Sigma_{\mathrm{k}} \mathrm{A} \Phi \mathrm{X}_{\mathrm{t}-\mathrm{k}}+\mathrm{Au}_{\mathrm{t}}
$$

Where $A$ is the matrix of $a$ 's from the previous equation. Using this equation, we can decompose each series into their historical shocks or look at their simulated responses to a particular shock over time. Analyzing these decompositions is a common form of VAR analysis known as "innovation accounting."

Impulse response functions show us how the $X$ vector responds over time to a one-time shock in a single series, found in the error term $\left(\delta_{t}\right)$. For this we set the error of the shocked variable equal to one and all the other variable's errors to zero, so that we can focus on how $X_{t+h}$ evolves throughout the periods following the shock. This equation is known as the "impulse response function:"

$$
\mathrm{X}_{\mathrm{t}+\mathrm{h}}=\theta(\mathrm{B}) \delta_{\mathrm{t}+\mathrm{h}}
$$

Where just the $i$ th element of $\delta_{t+h}=1$ and all other elements are zero when $h=0$ and all elements are zero when $h \neq 0$. Once again, $h$ represents the number of future periods being considered.

The $\theta(B)$ elements are derived from simulating the estimated VAR to a series of one time only shocks in each series' innovation term. Impulse responses are often shown as graphs and can indicate the elasticity of variables in the model; for instance, a variable the returns to its equilibrium level within a few periods after a shock would be 
considered inelastic. They also highlight relationships between variables, in terms of how much a series decreases or increases in response to a one-time shock to another variable.

Another form of innovation accounting are forecast error variance decompositions, which consider how much of the error variance of a series is caused by the error variance of specific variables in the VAR. Standing at time $t$, we fully expect all future innovations $\left(\delta_{t+h}\right)$ to equal zero. This means that when we take the difference of the expected $\left(\widehat{X}_{t+h}\right)$ from the actual $\left(X_{t+h}\right)$ to see the forecast error at horizon $h$ we are left with these future innovations as the forecast error $\left(F E_{t+h}\right)$ :

$$
\mathrm{FE}_{\mathrm{t}+\mathrm{h}}=\sum_{\mathrm{h}=1}^{\mathrm{h}} \theta_{\mathrm{h}-1} \delta_{\mathrm{t}+\mathrm{h}}
$$

Here $\theta_{h-1}$ is an $(m \times m)$ matrix that tells us how the forecast error in the future depends on innovation in the past and $\delta_{t+h}$ is a vector of the innovations at horizon $h$ periods ahead. For any particular element of vector $F E_{t+h}$, its variance is composed of the corresponding elements of each $\theta$ matrix and each variance term. An example of the variance $(\mathrm{V})$ of the forecast error (FE) at $h$ steps ahead is:

$$
\begin{gathered}
\mathrm{V}\left(\mathrm{FE}_{\mathrm{t}+\mathrm{h}}\right)=\mathrm{V}\left(\delta_{1 \mathrm{t}+\mathrm{h}}\right)+\theta_{11}^{2}(1) \mathrm{V}\left(\delta_{1 \mathrm{t}+\mathrm{h}-1}\right)+\theta_{12}^{2}(1) \mathrm{V}\left(\delta_{2 \mathrm{t}+\mathrm{h}-1}\right)+\ldots \\
\ldots+\theta_{11}^{2}(\mathrm{~h}+1) \mathrm{V}\left(\delta_{1 \mathrm{t}+1}\right)+\theta_{12}^{2}(\mathrm{~h}+1) \mathrm{V}\left(\delta_{2 \mathrm{t}+1}\right)
\end{gathered}
$$

This equation allows us to summarize the relative influence of each series on every other series in the VAR, including itself. By taking the variances associated with a particular series and dividing by the full variance of the forecast error we are able to obtain the percentage of variation in a series due to historical shocks in either its own series or shocks in another series (Franses, Djik, \& Opschoor 2014). 


\section{ANALYSIS AND RESULTS}

\subsection{Description of Data}

We considered both prior theory and previously developed models, like Chavez and Johnson's 1981 wholesale egg price model, and chose eight variables to use in our VECM. The number of table egg layers in the US are included because the premise of this study is that AI severely decreased the number of hens in the US and this lead to fewer eggs and higher egg prices. Since we plan to conduct innovation accounting and determine causal relationships within the industry, this is an important variable to include in our model even though it is not used for calculating revenue. The number of eggs produced in the US and the wholesale price of NYC Grade A Large Table Eggs are linchpins in our VECM, as they are used to calculate revenue. For the purposes of this study we assumed that all table eggs produced in the US pass through a wholesaler and the prices we used in our counterfactual forecast are actual monthly prices of Grade A Table eggs to volume buyers, store door delivery, in the NY metropolitan area. Soybean meal and cornmeal prices are included as value-adding input costs of producing eggs. To account for factors influencing egg demand, especially for causal analysis, we incorporated the retail prices of beef and pork as suggested by Chavas and Johnson (1981). These were adjusted using the non-seasonally adjusted Consumer Price Index for All Urban Consumers (CPI-U) since seasonality is accounted for in the model using dummy variables. Finally, the model's token macro variable is seasonally-adjusted real disposable personal income (RDI), as monthly data was not available for non-seasonally adjusted RDI. Altogether, our model is well-rounded by encompassing supply and 
demand-side variables, the crucial table egg industry variables, and a relevant macro variable.

Monthly data from March 1986 to May 2016 was collected for each variable from various government and online sources for a total of 363 observations. The VECM developed was identified using data from March 1986 to October 2014, providing a large sample size of 344 observations which strengthens the model and our confidence in the results. Truncating the full data set allows us to define a model that has not seen the effects of the 2014-2015 US AI outbreak, resulting in a counterfactual forecast that will better represent the revenue that would have been seen if the outbreak had not occurred.

The full data set is provided in Appendix C. This data was analyzed and the model estimated using Regression Analysis for Time Series software (RATS) and Cointegration Analysis for Time Series (CATS). Directed graphs were generated using TETRAD V software. Software input programs are located in Appendix D.

\subsubsection{Summary Statistics}

Summary statistics on the full data set and the truncated set for defining the VECM are shown in Table 1B. This information allows us to understand the historical characteristics of the data, which may need to be accounted for by the model. For instance, the mean provides an overall sense of the magnitude of different series values in relation to others. The amount of standard error, a form of standard deviation representing the accuracy of the sample compared to what is actually found in the industry, may be attributed to the evolution of the industry over the 30 year timeframe we summarized. For example, production methods in the 1980s may not have allowed 
for as many hens as there are on a commercial farm today, thus advancements and trends in the industry can correlate to a larger deviation in egg production. A useful descriptive statistic summarizing the mean and standard deviation of a series is the coefficient of variance $(\mathrm{CV})$, a unit-less measure that represents the percent of dispersion around a series' mean. The higher the CV, the greater the dispersion; for instance, in both the estimated and full model data sets egg price had the highest CV at a $51 \%$ and $57 \%$ respectively, indicating more volatility in this series. Hens had the smallest CV (9\%), followed by egg production (13\%).

There is some skewness and kurtosis in the series, as expected from observed data, with both the estimated model series and the full data set returning similar results. However, there is a large, significant jump in kurtosis for egg price in the full data set, suggesting that the AI outbreak resulted in outliers that created a fat-tailed distribution for egg price. While normality is often favored in analysis, it is not a requirement for the VECM. Considering we have three decades of agricultural data, it is likely that these statistics represent structural changes in the industry due to shifts in demand and production. While it is important to acknowledge fat tails and deviations from normality, no adjustments were made to the data to account for these characteristics since they should not have a major impact on the model we are creating.

An analysis of the maximum and minimum data points and their corresponding dates was conducted to see if the results were within the relevant timeframe. Before the AI outbreak in 2015, the highest egg price at the wholesale level in the 30 year timespan had been in March of 2008 during the beginnings of the Great Recession. However, 
when looking at the full data set statistics, the highest egg price was realized in August 2015, or two months after the last reported AI case for this outbreak. Prior to the outbreak, the number of layers and egg production had both reached their 30 year maximum in December 2014. Overall, these summary statistics highlight some of the impacts the outbreak appears to have had on the variables in the model.

Graphs of the historical data, shown in Figures 4A and 5A, provide a visual analysis of trends in the various series. For example, both the number of hens and egg production trend upward before significantly dropping in 2015 . These series also show signs of the seasonality expected in an agricultural production setting, which can be accounted for in the model using monthly dummy variables. Additionally, the plots of cornmeal and soybean meal price tend to move together, suggesting that we should test for possible cointegration. Finally, all series appear to have the potential for being nonstationary series which will be officially tested using DF and LR tests.

\subsubsection{Stationary Tests and the Number of Lags}

The Dickey-Fuller test and augmented Dickey-Fuller tests were initially used to determine if a series was stationary and the results are found in Table 2B. The DF test indicted that both the egg production and egg price series are stationary, although this result is not clear from the historical graphs. The ADF was run through 6 lags to see where SIC was minimized, with the results indicating that the number of hens, egg production, and egg price series require more lags to whiten their residuals, while the other supplementary variables require fewer. Based on the minimum SIC for each series, 
the ADF returned the same conclusion as the DF test, while also finding the number of hens series stationary.

Since the Dickey-Fuller tests did not agree and we want to consider cointegration in our model, we also conducted likelihood ratio tests on the series based on the rank of $\Pi$. When $r=2$, all series were non-stationary $I(1)$ series which is what we expect based on the length of time the data covers and the historical graphs plots (see Table 3B).

The number of lags for the VECM was selected based on comparing the SIC for scenarios including a levels VAR with a constant, trend or no trend, seasonality or no seasonality, and lags or no lags. Each scenario considered can be seen in Table 4B and we found that one lag will provide us with a parsimonious model ideal for forecasting, as SIC increases with additional lags.

\subsubsection{Cointegration Results}

I(1) cointegration analysis using CATS in RATS shows Johansen trace test results which suggest that, at the $90 \%$ confidence level, there are three cointegrating vectors $(r=3)$. However, the SIC value suggests the presence of one cointegrating vector (see Table 5B). Therefore, we assume there is a minimum of one and a maximum of 3 co-integrating vectors possible in this model. Since our objective is to forecast with our model, we generated forecast statistics for $r=1, r=2$, and $r=3$ to determine which forecasts best for both egg production and egg price, which are the variables for calculating revenue. When the model was run at each level, $r=2$ had the "best" forecasts, based on a Theil U statistic less than 1.0 at each step during the AI outbreak for both series. Selecting a rank of two ensures that we account for enough cointegration in the 
model to avoid spurious results, while also maintaining a parsimonious model ideal for forecasting.

Tests for variable exclusion and weak exogenetity were also conducted and the results for two cointegrating vectors can be seen in Table 6B and 7B, respectively. For the exclusion test, a decision to reject indicates that the series is part of the co-integrating space. In our case, all series except pork and beef price are in the co-integrating space at a $95 \%$ confidence level. The test of weak exogeneity given two cointegrating vectors shows that, except for RDI being weakly exogenous within the cointegration vector, all other series respond and make adjustments toward the estimated long run relationship (Bessler \& Yang 2003). These tests provide insight into the composition of the cointegrating vector we are including in our model.

\subsection{Estimated VECM}

Based on the cointegration tests, we needed to develop a vector error correction model to account for the two cointegrating vectors in our data set. Since the LR test at $r=2$ indicated that the series were all non-stationary, we took the first differences of each series to make them stationary. The following variables are used in the model: number of hens $\left(X_{1}\right)$, number of eggs $\left(X_{2}\right)$, egg price $\left(X_{3}\right)$, soybean meal price $\left(X_{4}\right)$, corn meal price $\left(X_{5}\right)$, retail beef price $\left(X_{6}\right)$, retail pork price $\left(X_{7}\right)$, and real disposable personal income $\left(X_{8}\right)$. Seasonal dummy variables for January to November $\left(D_{1}\right.$ to $\left.D_{11}\right)$ are also included in the model.

In the vector error correction model, lagged first differences are shown in the long-run series with the cointegrating vectors. Only one lag was included in the model, 
therefore the short run VAR portion, with $k-1$ lags, becomes zero. This results in a simpler model with the following VECM equation:

$$
\Delta \mathrm{X}_{\mathrm{t}}=\Pi \mathrm{X}_{\mathrm{t}-1}+\Psi \mathrm{S}_{\mathrm{t}}+\mathrm{e}_{\mathrm{t}}
$$

With $e_{t}$ representing innovations in contemporaneous time and the constant accounted for in the $\Pi$ matrix. The results of this estimated VECM model are shown below:

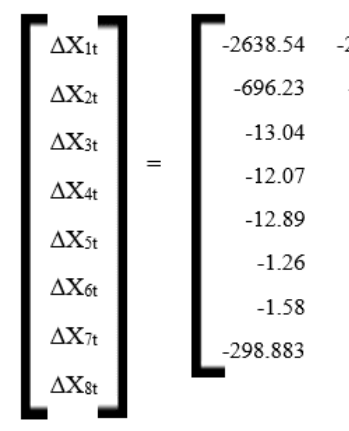

$(8 \times 1)$

$$
\left[\begin{array}{cccccccc}
-0.0459 & 2.2849 & 6.6781 & -0.7812 & -1.6748 & -2.6320 & 0.8017 & -0.0928 \\
0.0054 & -0.2481 & -0.0988 & 0.2005 & 0.0195 & 0.1897 & -0.1925 & 0.0077 \\
-0.0001 & -0.0010 & -0.2188 & -0.0396 & 0.0567 & 0.0343 & 0.0360 & 0.0008 \\
-0.0003 & 0.0188 & 0.2026 & 0.0209 & -0.0521 & -0.0443 & -0.0183 & -0.0013 \\
0.0003 & 0.0074 & 0.7554 & 0.1331 & -0.1957 & -0.1210 & -0.1211 & -0.0030 \\
0.0000 & 0.0023 & 0.0356 & 0.0046 & -0.0092 & -0.0071 & -0.0041 & -0.0002 \\
0.0000 & 0.0016 & 0.0253 & 0.0033 & -0.0065 & -0.0050 & -0.0029 & -0.0001 \\
-0.0068 & 0.3628 & 1.8844 & 0.0282 & -0.4796 & -0.5443 & -0.0115 & -0.0178 \\
& & & & & & &
\end{array}\right.
$$

$$
\begin{array}{r}
-465.19 \\
-417.95 \\
-13.31 \\
-3.22 \\
1.03 \\
-1.63 \\
1.54 \\
-23.40
\end{array}
$$

$$
\begin{array}{rrr}
-1800.58 & -512.35 & - \\
-675.98 & -332.22 & -4 \\
-3.86 & -2.15 & \\
-4.02 & -9.15 & -21 \\
14.44 & 7.08 \\
-2.23 & -2.60 \\
1.69 & 2.18 & \\
-240.66 & -145.68 & -207
\end{array}
$$

$$
\begin{array}{rrr}
-55.26 & 544.70 & 11 \\
-457.10 & -633.17 & -2 \\
-1.58 & -4.69 & \\
-21.86 & -17.12 & -19 \\
-1.57 & 3.26 & \\
-1.88 & -3.39 & \\
1.08 & -0.53 & \\
-207.95 & -272.77 & -1
\end{array}
$$

Figure 1. Estimated VECM Model

$$
\begin{array}{rr}
544.70 & 1149.34 \\
-633.17 & -272.74 \\
-4.69 & -5.38 \\
-17.12 & -19.73 \\
3.26 & 12.36 \\
-3.39 & -1.50 \\
-0.53 & -0.90 \\
-272.77 & -173.01
\end{array}
$$
(8x9 П matrix)

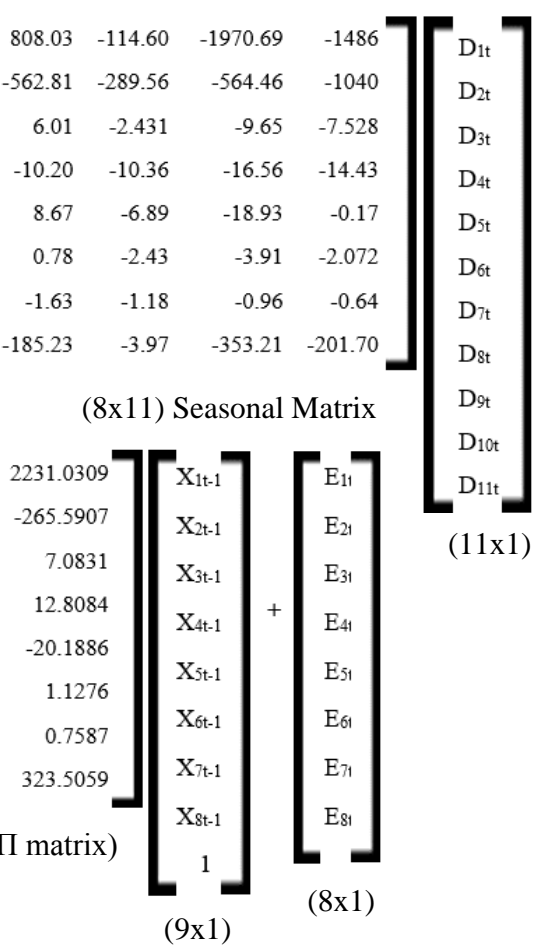

(9x1)

In Figure $1, X_{t}$ is an $(8 \times 1)$ vector of variables, $\Pi$ is a $(9 \times 8)$ vector of coefficients corresponding to a $(9 \mathrm{x} 1)$ vector of $X_{t-1}$ lagged variables, which includes a constant. $e_{t}$ is 
an $(8 \mathrm{x} 1)$ vector of innovations, which were found to be stationary and not autocorrelated. The t-statistic values and the components of $\Pi, \alpha$ and $\beta$ ' are shown in Figure 6A. Using $e_{t}$, innovation accounting is conducted to provide insight on what the model tells us about contemporaneous relationships.

\subsubsection{Forecasts}

We generated a 12-step ahead forecast for the number of eggs and egg price to avoid the influence of the AI outbreak on the counterfactual revenue. These are point forecasts, which are typically reported for major events, providing us with a definite amount of revenue change. These forecasts can be considered reliable because they are better than a random walk, as shown by Thiel U statistics less than one at each forecast step in Table 8B. Forecasts were calculated by first converting the number of eggs from millions of eggs to dozens of eggs using the equation $\left(X^{*} 10^{6}\right) / 12$. The number of dozens of eggs was then multiplied by egg price, converted from cents per dozen to dollars per dozen using $(X / 100)$, to obtain the revenue at each time period. This was done for both the actual data set values and the forecasts generated by the VECM from October 2014 to October 2015. This particular AI outbreak “officially" started in December 2014 and ended in June 2015 so the revenue for each month in this period was summed and the difference between the realized and counterfactual revenue was obtained (see Figure 7A and Table 9B). Our results showed that the realized revenue during the AI outbreak was higher, at $\$ 6.76$ billion, compared to the counterfactual revenue which was only about $\$ 6.08$ billion. Thus, ceteris paribus, the 2015 AI outbreak allowed wholesalers to gain 
about $\$ 676$ million in revenue between December 2014 and June 2015. These results will be further discussed in Section 5 .

\subsubsection{Directed Acyclic Graphs}

Both the GES and PC Algorithms were run in TETRAD V software using the estimated VECM residual covariance matrix and the number of observations as input. Knowledge for these graphs was given as income, soybean meal and cornmeal price in the top tier, pork and beef price in the second tier, eggs and hens in the third tier, and egg price in the fourth tier. The PC Algorithm was run with $\alpha=0.4$ and the GES was run with a 0.15 penalty discount so that we could create a complete directed acyclic graph. The two models agreed on the contemporaneous relationships of the variables by finding the same edges. The graph we developed, shown in Figure 2, has a BIC score of 31.59, a CFI score of 0.57 , and a RMSEA of 0.14 , indicating that this is a fairly good fitting model.

The graph has no bi-directed edges, indicating that no major variables are missing in the model. We find that the number of eggs and egg price are endogenous variables in this system, while the number of hens are weakly exogenous. The significant edges, at the .05 level, in both graphs are found going from pork price to beef price, soybean meal price to egg price, and the number of hens to eggs (see Table 10B). Pork and beef are expected to have a causal relationship, as they are considered substitutes for each other. We found that a higher pork price yields a higher beef price, meaning that when the price of pork increases consumers switch to beef, pushing the beef demand curve rightward so that the same quantity they purchased of beef before now costs more. 
Inputs like soybean meal add value to the number of eggs, which is manifested in their price. For example, a higher soybean meal price yields a higher egg price as the cost of the input is passed down the supply chain. Finally, eggs literally come from hens, so it would have been surprising if the DAG did not pick up on this positive relationship of an increase in the number of hens yielding a larger amount of eggs.

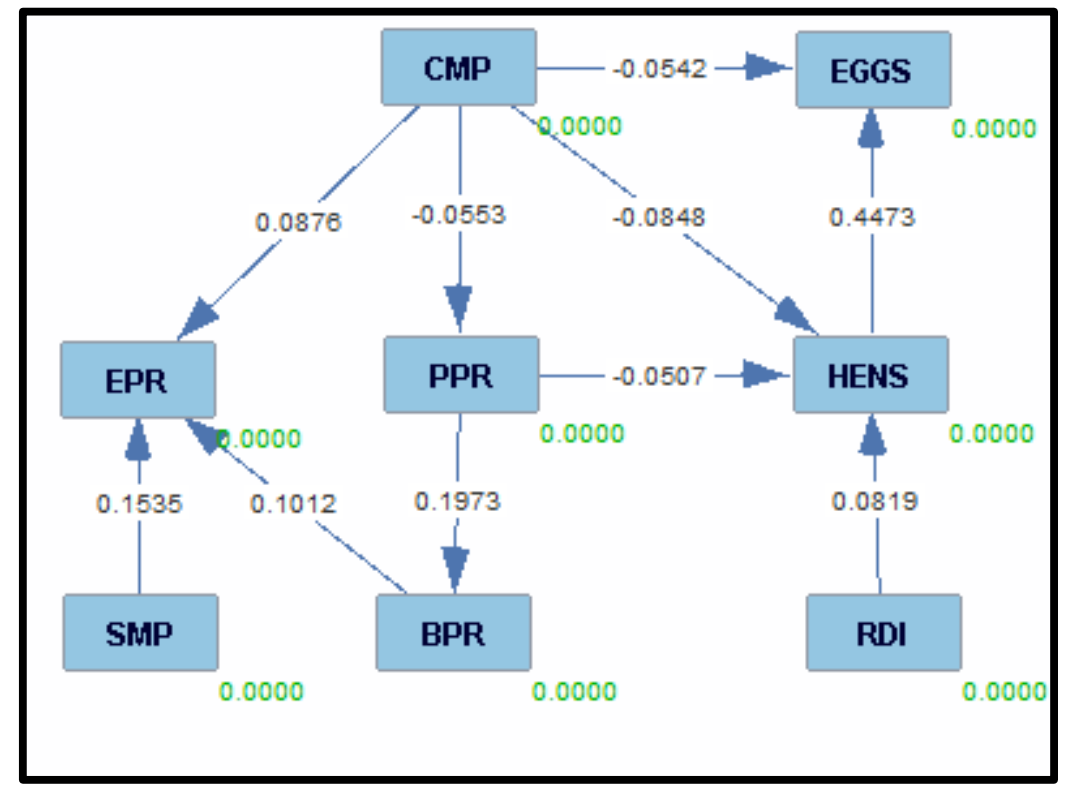

Figure 2. Directed Acyclic Graph Generated by Both the PC Algorithm and the Greedy Equivalence Search Algorithm

It is interesting to note is that neither the number of hens nor egg production is connected to egg price. Rather than these direct production factors impacting egg price, it appears from the DAG that cornmeal price is a common cause between the number of 
eggs and egg price, thus indirectly connecting them. Although cornmeal price has no significant relationships in the graph it does have the positive non-significant relationship with egg price and production we expect from an input, as well as having an indirect impact through pork and beef which require the same inputs as eggs production. Retail beef price is nearly significant with a significance of $p=0.0569$, highlighting that the prices of commodities using similar inputs can appear causally related based on this common point. Unless otherwise noted, all of these results are for significant contemporaneous time relationships between the variables in the VECM we estimated.

\subsubsection{Innovation Accounting}

Impulse response functions, shown in Figures 8A and 9A, look at all the variable's responses to a one-time shock in one series. For the estimated model series, hens never really recovered from the shock, meaning they remained at the shocked amount even at two years following the shock. This is a logical result based on current production methods where layer houses are typically filled all at once and the hens remain there throughout their approximately two year productive cycle. As the DAGs indicate, a positive shock in hens elicits an increase in the number of eggs and, since the average rate of lay will not change drastically in the short run, the number of eggs is constant over the two years following a shock. Egg price decreases minimally following a shock in hens and levels out within about three months. This corroborates the economic theory of demand that the larger the quantity of a commodity for sale, in this case stemming from a supply shock in hens, the lower the price. 
The supply of eggs decreases to a constant level higher than its original amount by about six months after a shock to itself, with the slope suggesting that the supply is inelastic. A shock in eggs also generates a positive response in hens that levels out around six months, or approximately the length of time it takes for a hen to start producing eggs, providing further evidence of the relationship between these two variables. The decrease in egg price due to a shock in the number of eggs is even smaller than it was for a shock in the number of hens, suggesting that egg price is relatively indifferent to shocks in these series. All other series estimated by the VECM have a positive response to shocks in the number of eggs and hens. These increases reflect that when there are more hens and eggs, more inputs are necessary for production which increases their prices. As these inputs are also used in beef and pork production, the retail prices for these commodities will absorb these costs and increase as well. As the prices of commodities increase, real personal disposable income should increase to cover the new norm. A shock in hens realizes smaller increases in these variables compared to a shock in eggs, as both the number of eggs and the other variables lie further on the demand side of the industry and thus interact and have a greater influence on each other than a supply variable like hens.

Approximately six months following a shock in egg price, egg prices level out at a higher level than where they started. The slope of egg price's response to a shock to itself suggests price inelasticity, which is expected of a necessary good and may explain some of its independence from its direct inputs: hens and eggs. The number of hens increase for a couple months before stabilizing following a shock in egg price, likely as 
an effort to generate a larger egg supply to benefit from the higher price. The number of eggs decrease slightly, possibly to due to the effects of changing production, then rise when hens stabilize. The egg price series also induces more positive responses from other series starting immediately after the shock, with cornmeal price having the largest response by stabilizing at 50\% from its baseline by around six months. The responses from these other variables support the concept that prices are more sensitive and responsive to other price changes, rather than changes in production.

Forecast error variance decompositions, shown in Table 11B, consider what contributes to the variability in a series after a shock. Immediately after a shock, the variability in the number of hens is almost entirely due to itself and as time passes other variables, such as the number of eggs and input prices begin to have an impact on the variability in hens. Supporting the DAG's finding of hens causing eggs, a $20 \%$ influence of hens on eggs in the first period after a shock in eggs is observed. This influence increases to $45 \%$ over the period of two years as the contribution of eggs to itself falls to $30 \%$. Feed input prices gradually impact the number of eggs more over time.

The variability in egg price is essentially independent of its direct inputs, eggs and hens, which have less than a $0.5 \%$ impact combined on egg price even after two years. In the first period after a shock, egg price itself contributes about $96 \%$ to its own variability with feed input prices explaining about $3 \%$ of the rest of the changes in egg price. By six months cornmeal price begins to have a large impact on egg price and this influence increases to $44 \%$ over two years as the contribution on egg price variability on itself decreases to $50 \%$. A relationship between cornmeal price and egg price can also be 
seen in the DAG generated from the residuals of our model, which were discussed in Section 4.2.2. 


\section{DISCUSSION AND CONCLUSIONS}

At the beginning of this paper we set an overarching goal to develop a sound econometric model that will allow us to obtain the revenue impact on US table egg wholesalers that is attributed to the 2014-2015 AI outbreak, ceteris paribus. The first objective in attaining this goal was to identify series characteristics for the model variables, which was done using summary statistics like $\mathrm{CV}$ and by plotting the historical values over the past 30 years to identify trends and possible cointegration. From this visual analysis we began to conduct tests to determine factors necessary for a VECM, such as identifying if series are stationary, how many lags to include in our model, and if cointegration is present. To satisfy our second objective of identifying a VECM, we were able to define an eight variable VECM for the US table egg industry with one lag and two cointegrating vectors. This was used to fulfill the third objective and primary goal of this research: to generate counterfactual point revenue forecasts over the time period the 2014-2015 AI outbreak occurred and compare these forecasts to actual revenue received to pinpoint revenue impact. This led us to a positive revenue impact of $\$ 676$ million during this AI outbreak. Finally, we satisfied our fourth objective of determining contemporaneous relationships within the industry though DAGs, impulse response functions, and charts of forecast error variance decompositions.

Overall, our key finding is that while the 2014-2015 AI outbreak had a negative impact on many farms throughout the US, table egg wholesales were actually able to capture nearly $\$ 676$ million in increased revenue from this event. This can be explained 
by looking at the revenue curves in Figure 3 for these wholesalers, who are operating in an imperfectly competitive market.

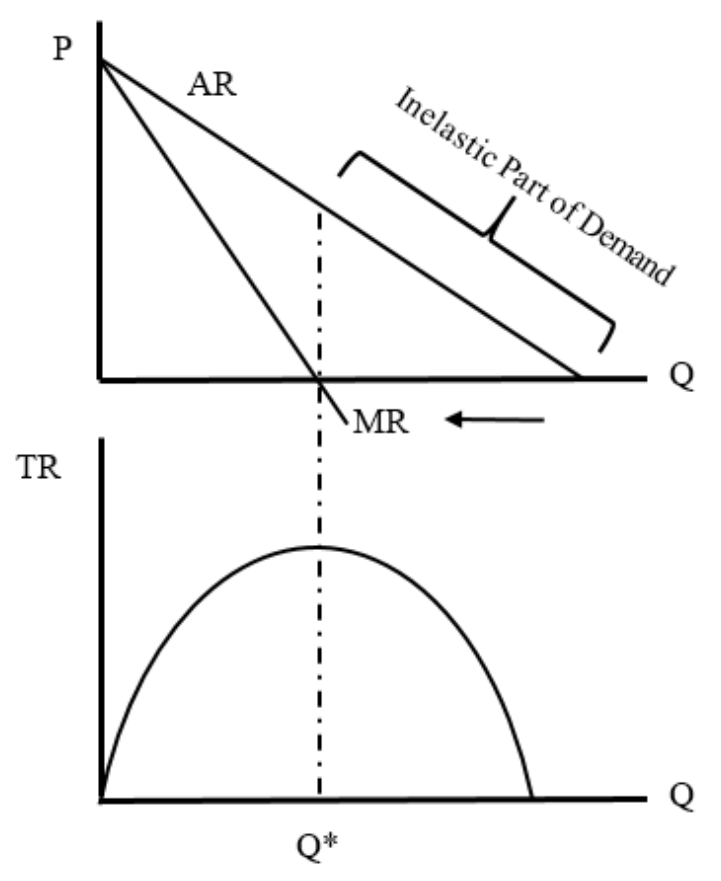

Figure 3. Marginal, Average and Total Revenue Graphs

In Figure 3, P and Q represent egg price and egg quantity, respectively. MR is marginal revenue, which when price equals zero is where total revenue (TR) is maximized. AR is average revenue, or the firm's demand curve, with the lower portion of the AR curve being inelastic where egg price would lie. Table egg wholesalers operate in this inelastic portion of their demand function, such that when the quantity of 
eggs decreases, their total revenue is actually increasing and a revenue gain of $\$ 676$ million can be realized. Using similar logic, producers would be found operating in the left-hand portion of the TR curve so that they would have experienced a revenue loss during the outbreak. In this way, we can conceptualize how wholesalers can see a positive effect on revenue from the AI outbreak, while the general table egg industry can still be said to have faced heavy losses. Additional considerations on the wholesaler's ability to gain from the outbreak, include the fact that the direct impact of the AI outbreak was at the farm level and wholesalers did not face the costs associated with handling AI infected birds. Additionally, some of the burden of cost from the production level is often passed down the supply chain to the retail and consumer levels such that the wholesalers may not absorb much, if any, of the cost.

To summarize our findings on contemporaneous relationships within the industry, one interesting result was that egg price does not appear causally related to the supply of eggs or the number of hens. This may be the result of feed input prices, such as cornmeal price, being a causal fork d-separating the number of eggs and hens from the egg price. Additionally, results from innovation accounting support the relationship of egg price to the prices of feed inputs by indicating that variability in egg price following a shock, aside from itself, is largely due to cornmeal price. This does not mean that egg prices and the number of hens and eggs do not respond to shocks in the other's series, as our impulse response functions do show they respond to each other.

Based on our results, should another large-scale outbreak occur, one could consider implementing policies that allow for the revenue gains to be captured by those 
most effected by losses. This could possibly be done by ensuring that wholesalers share a certain amount of the cost burden that is passed down the supply chain. Additionally, because of the relationships input prices have with a host of other variables, policies regarding these commodities need to consider cross-industry impacts. These studies can consider revenue impacts using methods similar to those outlined in this thesis.

Future studies could try to regionalize the impacts of the AI outbreak, rather than looking at it from a U.S. macroeconomic standpoint. Exports and imports were also not considered in this study, but may be interesting to consider in future evaluations of AI outbreaks. Expanding on this study, one could use price transmission techniques to look at the consumer and retailer levels, or even the farm level revenue impact from the outbreak both on a macro or regionalized scale. Overall, we hope that this study will encourage the implementation of the VECM to calculate revenue loss and industry impacts due to either naturally occurring events, like the avian flu, or policies impacting an industry in future studies. 


\section{REFERENCES}

American Egg Board. 2016. “About the U.S. Egg Industry.” Retrieved from http://www.aeb.org/farmers-and-marketers/industry-overview.

—. 2016. "The Egg Business.” Retrieved from http://www.aeb.org/images/PDFs/EggBusiness515.pdf.

Bessler, D. A. 2015. “Time Series Analysis: Vector Autoregressions.” Lecture notes provided by instructor.

Bessler, D.A., and S. Lee. 2002. "Money and Prices: U.S. Data 1869-1914 (A Study with Directed Graphs).” Empirical Economics 27:427-446.

Bessler, D. A., and J. Yang. 2003. "The Structure of Interdependence in International Financial Markets.” Journal of International Money and Finance 22:261-287.

Chavez, J. and S.R. Johnson. 1981. "An Econometric Model of the US Egg Industry." Applied Economics 13: 321-335.

Costa, R., D.A. Bessler, and C.P. Rosson. 2015. "The Impacts of Foot and Mouth Disease Outbreaks on the Brazilian Meat Market." Journal of Food Distribution Research 46(3): 1-19.

Dharmasena, S. 2003. “International Black Tea Market Integration and Price Discovery.” MS Thesis, Texas A\&M University. Retrieved from http://hdl.handle.net/1969.1/273.

Dharmasena, S., D. A. Bessler, and O. Capps Jr. 2016. "Food Environment in the United States as a Complex Economic System.” Food Policy 61:163-175. 
Dobrowolska, A., Brown, S. 2016. "The Economic Impact of the 2015 Avian Influenza on U.S. Egg Prices." Proceedings of the NCCC-134 Conference on Applied Commodity Price Analysis, Forecasting, and Market Risk Management. St. Louis, MO.

Dwyer, G.P. 2015. “The Johansen Tests for Cointegration. Lecture Notes.” Retrieved from www.jerrydwyer.com/pdf/Clemson/Cointegration.pdf.

Franses, P.H., D. van Dijk, and A. Opschoor. 2014. Time Series Models for Business and Economic Forecasting. 2nd ed. Cambridge: Cambridge University Press.

Fry, E. 2015. "What the Worst Bird Flu Outbreak in U.S. History Means for Farms." Fortune. Retrieved from http://fortune.com/2015/06/25/bird-flu-outbreak-farms/.

Gao, L., Richardson, J., and A. Maisashvili. 2016. “An Evaluation of the 2015 Outbreak of Avian Influenza in the U.S." Paper presented at AAEA annual meeting, Boston MA, July 31-August 2.

Johansen, S. 1991. "Estimation and Hypothesis Testing of Cointegration Vectors in Gaussian Vector Autoregressive Models." Econometrica, 59(6), 1551-1580.

McKenna, M. 2015. "Bird Flu Cost the U.S. \$3.3 Billion and Worse Could Be Coming." National Geographic. Retrieved from http://phenomena.nationalgeographic.com/ 2015/07/15/bird-flu-2/.

Pearl, J. 1995. “Causal Diagrams for Empirical Research.” Biometrika 82(4):669-710.

Seitzinger, A. H., and P. Paarlberg. 2016. Regionalization of the 2014 and 2015 Highly Pathogenic Avian Influenza Outbreaks. Choices 31(2):1-8.

Sims, C.A. 1980. "Macroeconomics and Reality." Econometrica 48(1):1-48. 
Spirtes, P., C. Glymour, and R. Schenies. 1993. Causation, Prediction and Search. New York: Springer-Verlag.

U.S. Department of Agriculture. 2015. "HPAI 2014/15 Confirmed Detections." U.S. Department of Agriculture. Retrieved from https://www.aphis.usda.gov/aphis/ ourfocus/animalhealth/animal-disease-information/avian-influenza-disease/ sa_detections_by_states/hpai-2014-2015-confirmed-detections.

Watson, E. 2014. "U.S. Egg Consumption Highest It Has Been in 7 Years: Protein is Where There is Big Opportunity Right Now." Food Navigator. Retrieved from http://www.foodnavigator-usa.com/Markets/US-egg-consumption-highest-it-sbeen-in-7-years.

\section{Supplemental Sources}

Estima. 2012. RATS Handbook for Katarina Juselius' The Cointegrated VAR Model.

Estima. Retrieved from https://www.estima.com/textbook_juselius.shtml.

—. 2010. RATS Version 8 User Guide \& Reference Manual. Evanston IL, Estima. 


\section{APPENDIX A}

\section{FIGURES}
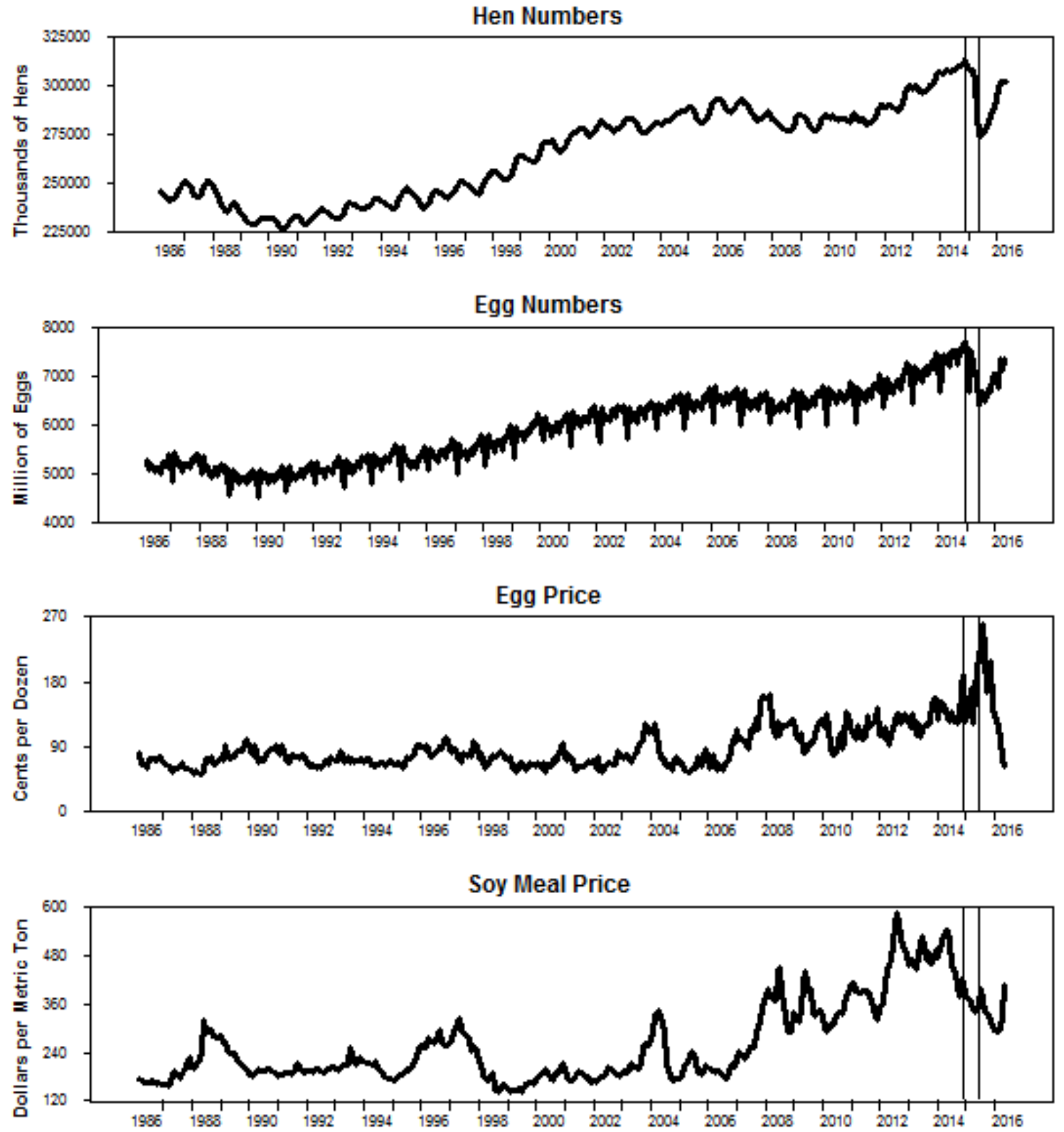

Figure 4A. Historical Charts for United States Hens, Eggs, Egg Price and Soybean Meal Price from March 1986 to May $2016^{3}$

${ }^{3}$ Hen and egg numbers are quantities in thousands and millions, respectively. Egg prices are the wholesale price of NYC Grade A Large Table Eggs, expressed in cents per dozen. Soybean meal prices, in dollars per metric ton, represent Chicago soybean meal futures, first contract forward, for minimum $48 \%$ protein meal. All prices are in US currency. These graphs represent 30 years of series data. 

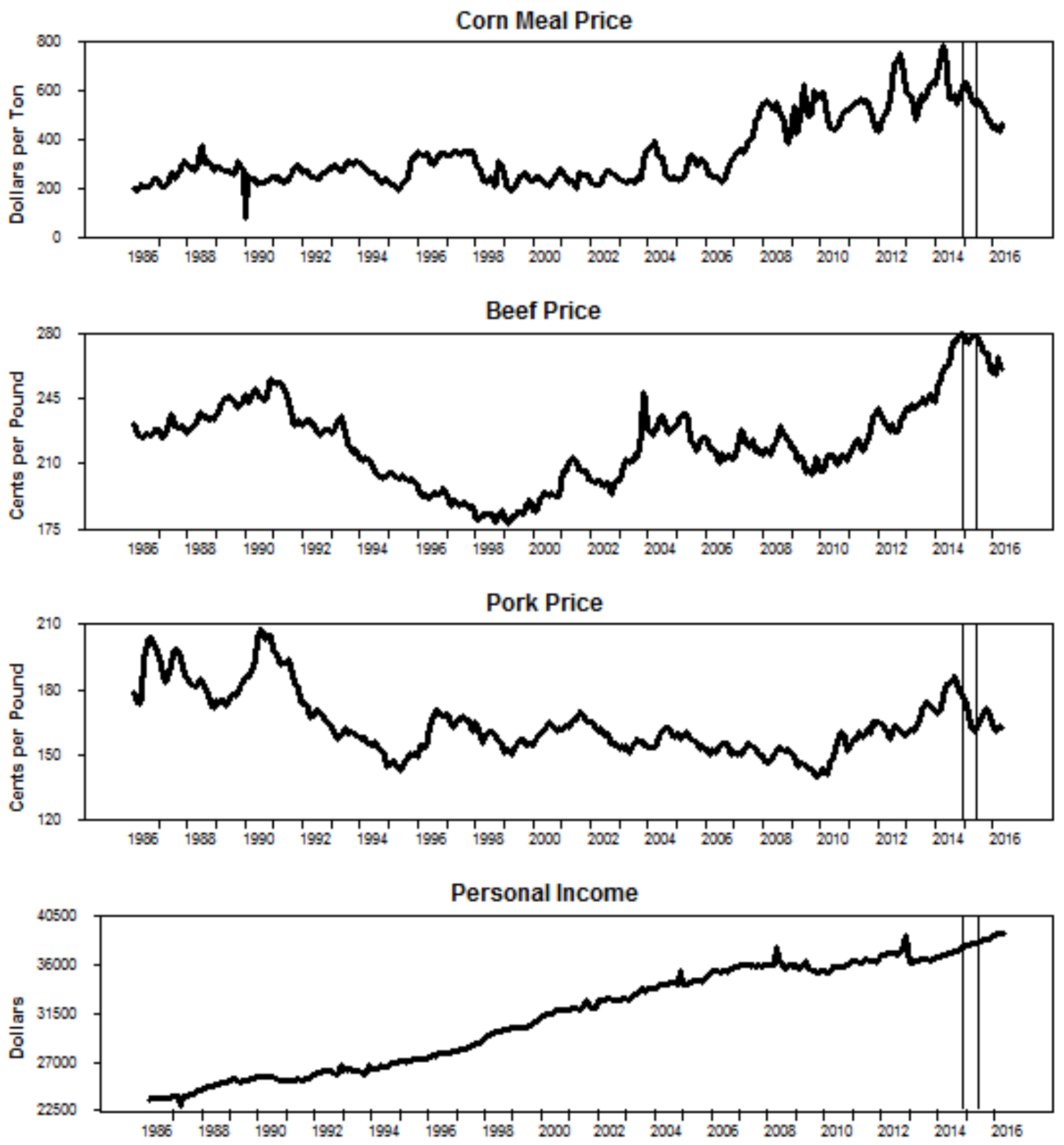

Figure 5A. Historical Charts for United States Cornmeal Price, Retail Beef \& Pork Prices, and Real Personal Disposable Income from March 1986 to May 2016 ${ }^{4}$

\footnotetext{
${ }^{4}$ Corn Meal Price represents the $60 \%$ protein corn gluten meal Midwestern US wholesale price, in dollars per ton. Both beef and pork price, in cents per pound for the retail weight equivalent, are retail prices adjusted using the non-seasonally adjusted consumer price index for all urban consumers (CPI-U), indexed at 1982-1984=100. Real disposable personal income per capita is the chained 2009 dollars seasonally adjusted annual rate. All series are in US currency. These graphs represent 30 years of series data.
} 


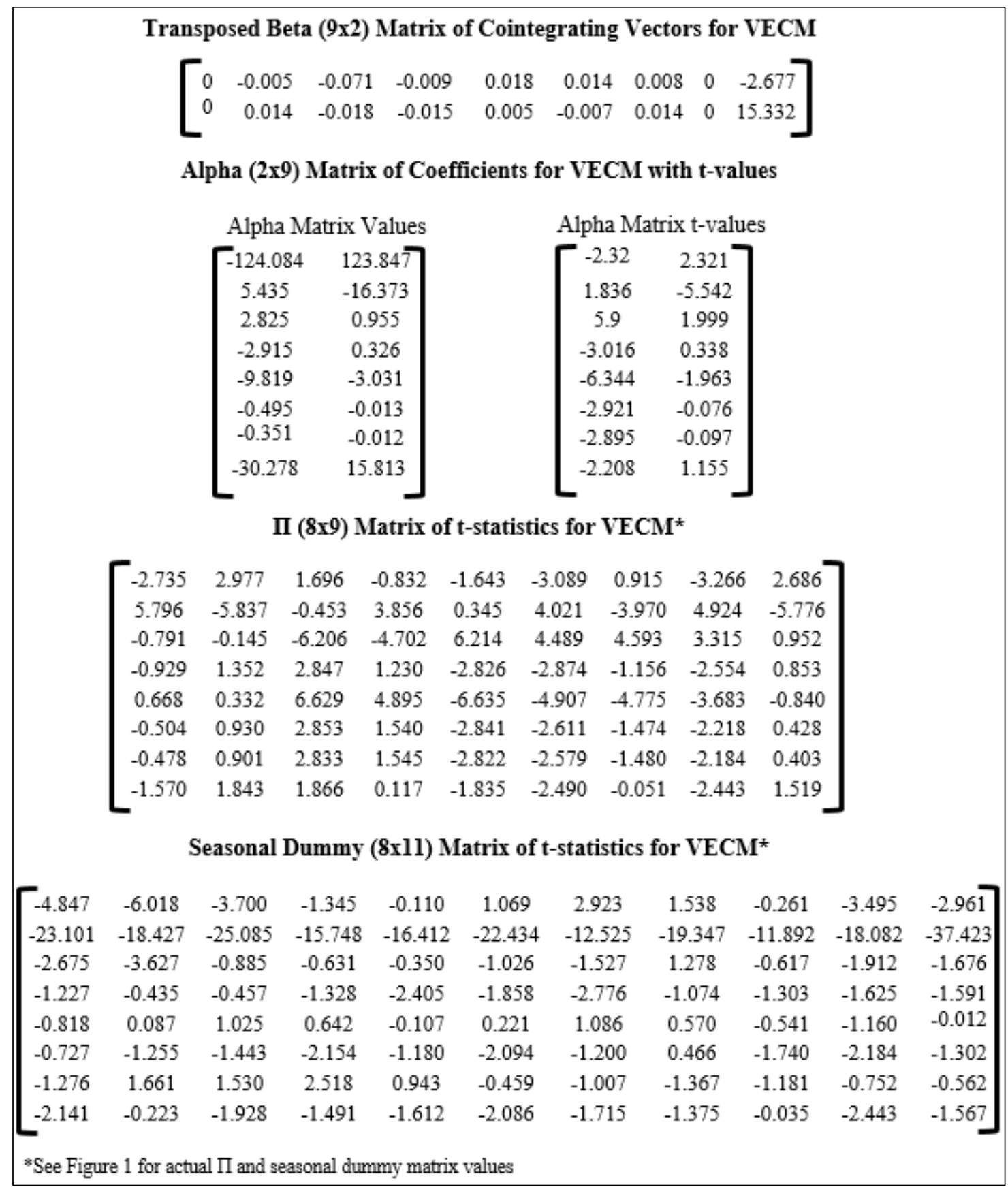

Figure 6A. VECM Matrices and test-statistics ${ }^{5}$

${ }^{5}$ Our 8 variable VECM has a I matrix of 2 cointegrating vectors lagged one period, generated by multiplying the transposed beta matrix with the alpha matrix, and a matrix for the 11 seasonal dummy variables in current time with December as the intercept. The constant is held within the cointegrating vector. $t$-statistics are reported at the $\alpha=0.05$ level based on the critical value of 1.960 with $\infty$ degrees of freedom for a two-tailed test. See Figure 1 for actual $\Pi$ and seasonal dummy matrix values. 


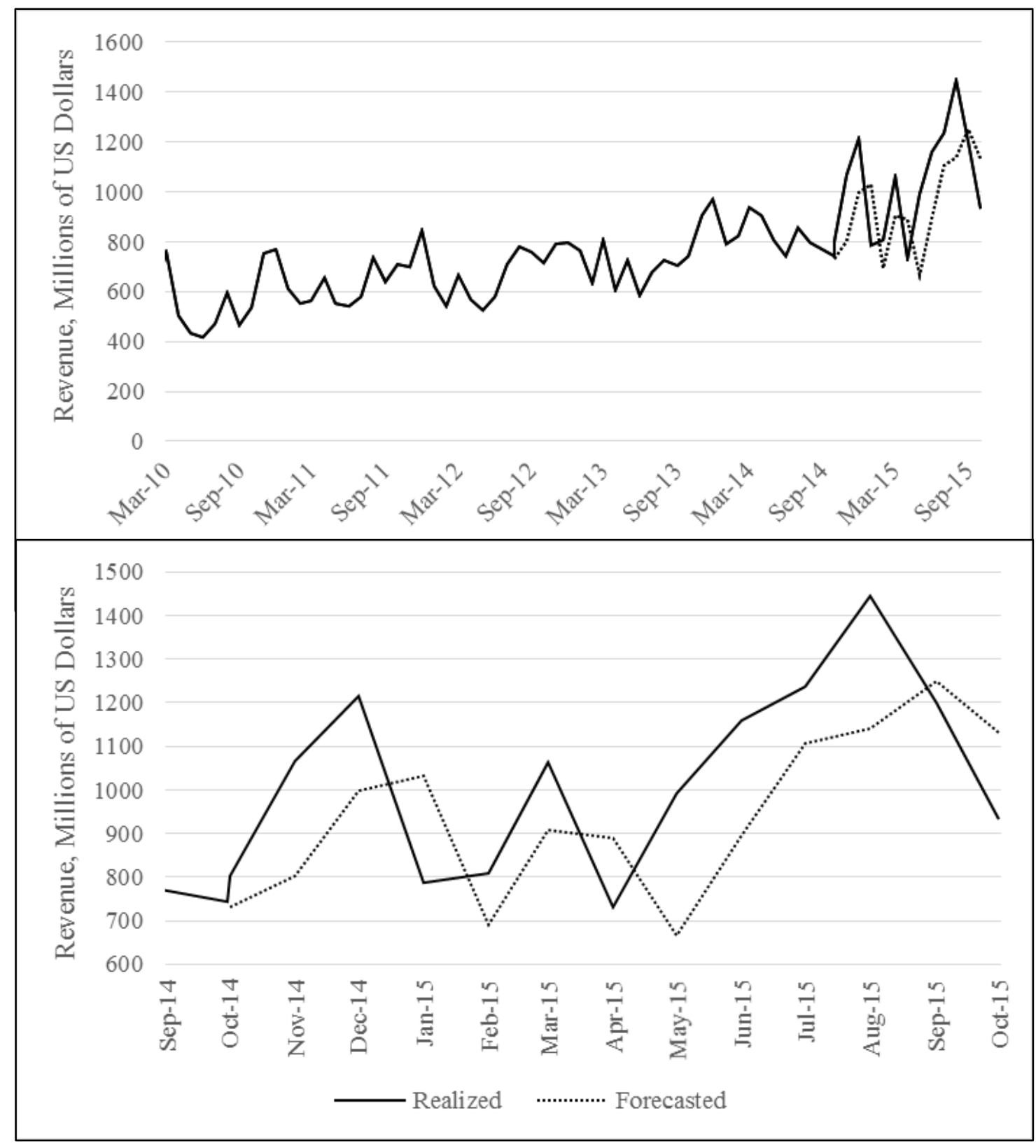

Figure 7A. Realized and Counterfactual Forecast for United States Wholesale Table Egg Revenue 2010-2015

${ }^{6}$ The counterfactual revenue forecast generated from the VECM, which we would have expected to see if the AI outbreak had not occurred, is shown as the dotted line. This was calculated by forecasting a 12-step ahead forecast of the egg price and number of eggs separately, then using these values to calculate revenue from December 2014 to June 2015 when outbreak officially started and ended. 


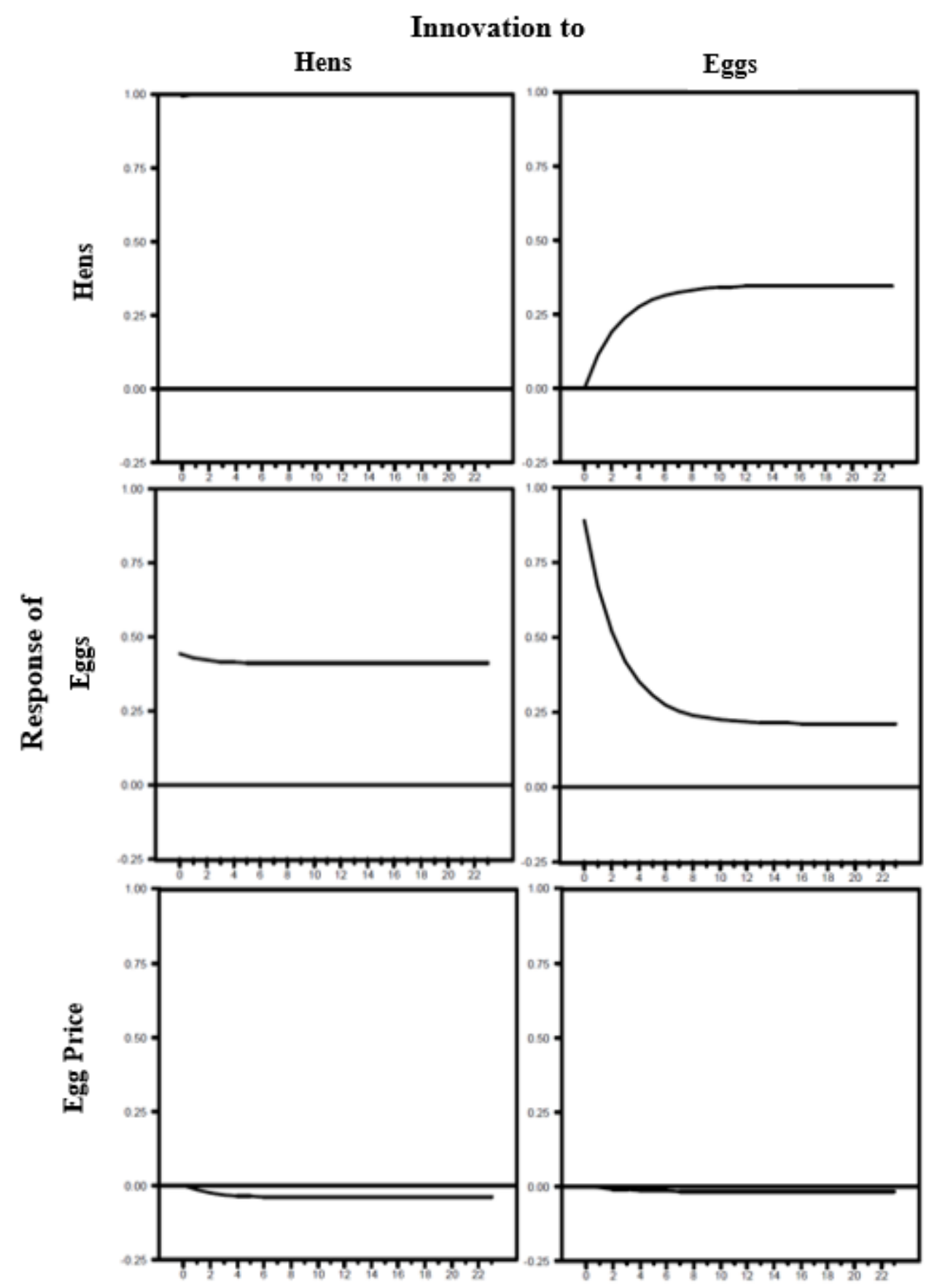

Figure 8A. Impulse Response Functions to Innovations in Eggs and Hens ${ }^{7}$

\footnotetext{
${ }^{7}$ The graphs represent the responses of series to a one time shock in the innovation series. The horizontal axis represents the number of months after a shock, during which a series is trying to recover or stabilize, set to 24 months or 2 years in this case. The vertical axis represents the magnitude and direction of a shock, from -0.25 to 1.0. Series are wholesale egg price and the number of hens and eggs in the US.
} 
Innovation to Egg Price
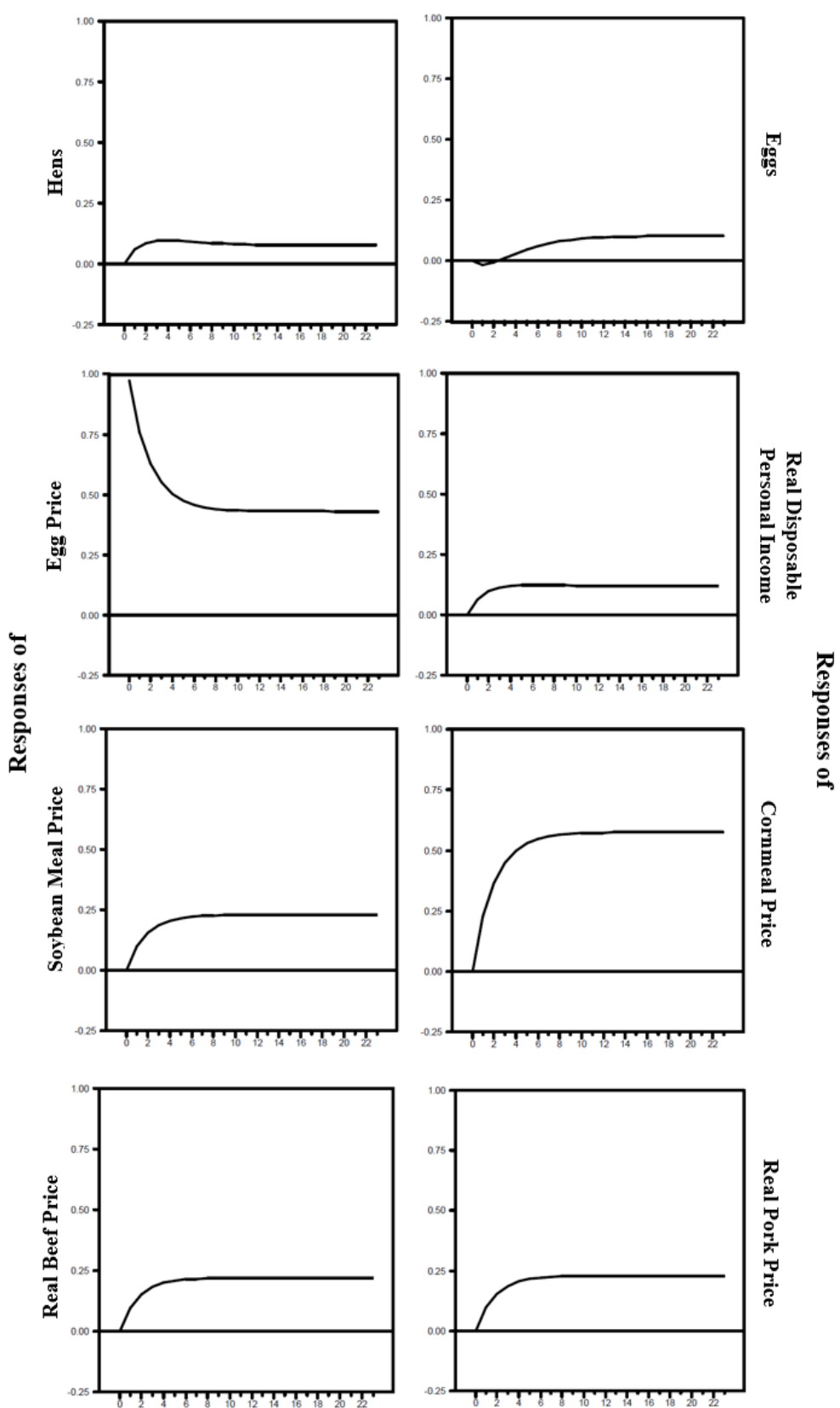

Figure 9A. Impulse Response Functions to Innovations in Egg Price ${ }^{8}$

${ }^{8}$ The graphs represent the responses of series to a one time shock in the innovation series. The horizontal axis represents the number of months after a shock, during which a series is trying to recover or stabilize, set to 24 months or 2 years in this case. The vertical axis represents the magnitude and direction of a shock, from -0.25 to 1.0. Series are US wholesale egg price, number of hens and eggs, cornmeal price, soybean meal price, retail beef price, retail pork price, and real disposable personal income. 


\section{APPENDIX B}

\section{TABLES}

Table 1B. Series Summary Statistics ${ }^{9}$

\begin{tabular}{|c|c|c|c|c|c|c|c|c|}
\hline \multirow{17}{*}{ 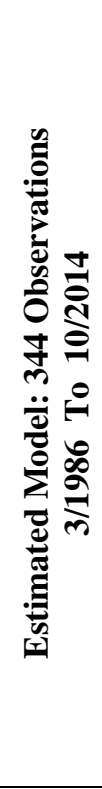 } & Series & Mean & $\begin{array}{l}\text { Std. } \\
\text { Error }\end{array}$ & $\mathrm{CV}^{10}$ & $\mathbf{S}$ & $\mathbf{K}$ & $\begin{array}{l}\text { Max } \\
\text { Min } \\
\end{array}$ & Date $^{11}$ \\
\hline & \multirow{2}{*}{$\begin{array}{l}\text { Hens Numbers } \\
\text { (Thousands) }\end{array}$} & \multirow{2}{*}{264854} & \multirow{2}{*}{23287} & \multirow{2}{*}{0.088} & \multirow{2}{*}{-0.039} & \multirow{2}{*}{-1.378} & 313019 & Oct \\
\hline & & & & & & & 226283 & 2014 \\
\hline & \multirow{2}{*}{$\begin{array}{l}\text { Egg Production } \\
\text { (Millions) }\end{array}$} & \multirow{2}{*}{5897} & \multirow{2}{*}{724} & \multirow{2}{*}{0.126} & \multirow{2}{*}{0.155} & \multirow{2}{*}{-1.090} & 7539 & Oct \\
\hline & & & & & & & 4495 & 2014 \\
\hline & Egg Price & \multirow{2}{*}{85} & \multirow{2}{*}{25} & \multirow{2}{*}{0.512} & \multirow{2}{*}{1.061} & \multirow{2}{*}{0.339} & 162 & Mar \\
\hline & (Cents/Dozen) & & & & & & 51 & 2008 \\
\hline & Soybean Meal & \multirow{2}{*}{257} & \multirow{2}{*}{99} & \multirow{2}{*}{0.457} & \multirow{2}{*}{1.273} & \multirow{2}{*}{0.742} & 586 & Aug \\
\hline & (Dollars/Metric Ton) & & & & & & 143 & 2012 \\
\hline & Corn Meal & \multirow{2}{*}{341} & \multirow{2}{*}{135} & \multirow{2}{*}{0.450} & \multirow{2}{*}{1.206} & \multirow{2}{*}{0.504} & 784 & Apr \\
\hline & (Dollars/Ton) & & & & & & 81 & 2014 \\
\hline & Retail Beef Price & 219 & 20 & 0176 & 0004 & -0.451 & 276 & Sep \\
\hline & (Cents/Pound) & 219 & 20 & 0.170 & 0.004 & -0.451 & 178 & 2014 \\
\hline & Retail Pork Price & 164 & 15 & 0205 & 1031 & ( 502 & 208 & Dec \\
\hline & (Cents/Pound) & 104 & 15 & 0.200 & 1.001 & 0.502 & 140 & 2009 \\
\hline & $\begin{array}{l}\text { Real Disposable Personal } \\
\text { Income, Per Capita }\end{array}$ & 30866 & 4568 & & & & 38639 & Dec \\
\hline & $\begin{array}{c}\text { (Chained } 2009 \$ \text {, seasonally } \\
\text { adjusted annual rate) }\end{array}$ & 50000 & 4500 & 149 & -0.093 & 50 & 23015 & 2012 \\
\hline & Hens Numbers & 266423 & 23820 & 0089 & - 0070 & -1324 & 313019 & Dec \\
\hline & (Thousands) & $200+25$ & 25020 & 0.009 & $-0.0 / 0$ & -1.524 & 226283 & 2014 \\
\hline & Egg Production & 5956 & 753 & 0130 & 0130 & -1.076 & 7731 & Dec \\
\hline$\tilde{\theta}^{2}$ & (Millions) & 3950 & 153 & 0.150 & 0.150 & $-1.0 / 0$ & 4495 & 2014 \\
\hline & Egg Price & 89 & & 0.568 & 794 & 3 & 261 & Aug \\
\hline 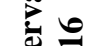 & (Cents/Dozen) & & 32 & 0.508 & 1.194 & 4.453 & 51 & 2015 \\
\hline 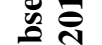 & Soybean Meal & 262 & 99 & 0.449 & 1.122 & 0.380 & 586 & Aug \\
\hline 0 in & (Dollars/Metric Ton) & & & & & & 143 & 2012 \\
\hline ?ֶ:0 & Corn Meal & 351 & 139 & 0449 & 1015 & -0048 & 784 & Apr \\
\hline$\because 6$ & (Dollars/Ton) & (1) & נד & 0.447 & 1.010 & -0.040 & 81 & 2014 \\
\hline ๘ & Retail Beef Price & 221 & 23 & 0.188 & 0.308 & -0.168 & 280 & Dec \\
\hline$\Xi \frac{\pi}{m}$ & (Cents/Pound) & & & & 0.500 & -0.108 & 178 & 2014 \\
\hline อี & Retail Pork Price & 164 & 14 & 0.198 & 1014 & 0.573 & 208 & Dec \\
\hline$\equiv$ & (Cents/Pound) & & & 0.198 & 1.014 & $0.5 / 3$ & 140 & 2009 \\
\hline & $\begin{array}{l}\text { Real Disposable Personal } \\
\text { Income, Per Capita }\end{array}$ & 31250 & 30 & & & & 38849 & May \\
\hline & $\begin{array}{c}\text { (Chained } 2009 \$ \text {, seasonally } \\
\text { adjusted annual rate) }\end{array}$ & העד & לנJוד & 0.10 & -0.120 & 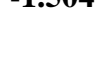 & 23015 & 2016 \\
\hline
\end{tabular}

\footnotetext{
${ }^{9}$ Bold values indicate significance at the .05 level for skewness $(S)$ and kurtosis $(K)$. Bold values in the Max/Min column are for max and min values in the series that occurred in the past decade, or since 2006. The full data set includes the raw data from when the AI outbreak occurred, whereas the model was estimated using data that stops before the outbreak to avoid AI contaminated values from influencing the counterfactual forecast. ${ }^{10}$ Coefficient of Variance, standard deviation divided by mean, is a measure of the volatility of a series.

${ }^{11}$ Date corresponds to the date of the bold value for max/min for that series.
} 
Table 2B. Dickey-Fuller and Augmented Dickey-Fuller Tests for Stationarity ${ }^{12}$

\begin{tabular}{|l|c|c||c|c|c|c|}
\hline & \multicolumn{2}{|c||}{ Dickey-Fuller Test } & \multicolumn{3}{|c|}{ Augmented Dickey-Fuller Test } \\
\hline & Series & \multicolumn{1}{|c|}{$\begin{array}{c}\text { Schwarz } \\
\text { Onformation } \\
\text { Criteria } \\
\text { Integration }\end{array}$} & $\begin{array}{c}\text { Lag } \\
\text { (k) }\end{array}$ & $\begin{array}{c}\text { (SIC) Value } \\
\text { t-stat. }\end{array}$ & $\begin{array}{c}\text { t-stat. } \\
\text { Order of } \\
\text { Integration }\end{array}$ \\
\hline Hens & 0.647 & $\mathrm{I}(1)$ & 6 & $13.742^{13}$ & $\mathbf{- 5 . 5 2 0}$ & $\mathrm{I}(0)$ \\
\hline Egg Production & $\mathbf{- 3 . 5 3 5}$ & $\mathrm{I}(0)$ & 6 & 10.550 & $\mathbf{- 3 . 9 3 6}$ & $\mathrm{I}(0)$ \\
\hline Egg Price & $\mathbf{- 4 . 1 1 1}$ & $\mathrm{I}(0)$ & 6 & $4.802^{14}$ & $\mathbf{- 4 . 6 3 4}$ & $\mathrm{I}(0)$ \\
\hline $\begin{array}{l}\text { Soybean Meal } \\
\text { Price }\end{array}$ & -1.666 & $\mathrm{I}(1)$ & 1 & 5.909 & $\mathbf{4 . 3 8 9}$ & $\mathrm{I}(1)$ \\
\hline Corn Meal Price & $\mathbf{- 1 . 9 9 9}$ & $\mathrm{I}(1)$ & 1 & 6.944 & 1.857 & $\mathrm{I}(1)$ \\
\hline Retail Beef Price & -0.263 & $\mathrm{I}(1)$ & 1 & 2.472 & $\mathbf{3 . 7 4 4}$ & $\mathrm{I}(1)$ \\
\hline Retail Pork Price & -1.400 & $\mathrm{I}(1)$ & 1 & 1.665 & $\mathbf{4 . 5 2 4}$ & $\mathrm{I}(1)$ \\
\hline $\begin{array}{l}\text { Real Disposable } \\
\text { Personal Income }\end{array}$ & -0.798 & $\mathrm{I}(1)$ & 3 & 11.133 & $\mathbf{- 2 . 8 3 0}$ & $\mathrm{I}(1)$ \\
\hline
\end{tabular}

${ }^{12}$ The null hypothesis for both tests is that a series is non-stationary. If the t-statistic value is less than the $5 \%$ level critical value of -2.89 , then the null hypothesis is rejected. Bold values indicate significance at the $\alpha=.05$ level. The Augmented Dickey-Fuller test is used to correct for autocorrelation in the estimated residuals by adding lags, selected by minimizing the SIC value, to "whiten" the errors. For the ADF test, the t-statistic and SIC values are associated with the particular lag listed, which had the smallest SIC value. For the order of integration, $I(0)$ represents a stationary series and $I(1)$ represents a non-stationary series.

${ }^{13}$ SIC values decreased to lag $4\left(2^{\text {nd }}\right.$ lowest SIC, I(O) here), increased for lag 5, then was lowest at lag 6. ${ }^{14}$ SIC values increased from the first lag $\left(2^{\text {nd }}\right.$ lowest SIC, I $(0)$ here $)$, then fluctuated up and down with lag 6 having the lowest SIC. 
Table 3B. Likelihood Ratio Test for Stationarity Based on a Rank of II of Two ${ }^{15}$

\begin{tabular}{|l|c|c|c|}
\hline Series & Chi-Value r=2 & p-value & Decision \\
\hline Hens & 46.05 & 0.000 & $\mathrm{R}$ \\
\hline Egg Production & 45.76 & 0.000 & $\mathrm{R}$ \\
\hline Egg Price & 45.52 & 0.000 & $\mathrm{R}$ \\
\hline Soybean Meal Price & 46.14 & 0.000 & $\mathrm{R}$ \\
\hline Corn Meal Price & 44.63 & 0.000 & $\mathrm{R}$ \\
\hline Retail Beef Price & 48.54 & 0.000 & $\mathrm{R}$ \\
\hline Retail Pork Price & 47.63 & 0.000 & $\mathrm{R}$ \\
\hline Real Disposable Personal Income & 45.69 & 0.000 & $\mathrm{R}$ \\
\hline
\end{tabular}

${ }^{15}$ The null hypothesis for this test is that a series is stationary. This test uses a chi-squared test statistic, with 14.07 being the critical value based on seven degrees of freedom. The p-values correspond with the chi-values given a $95 \%$ confidence interval. The Decision column represents the decision to reject $(R)$ or fail to reject $(F)$ the null hypothesis. 
Table 4B. Model Lag Determination Using Schwarz Information Criteria (SIC) ${ }^{16}$

\begin{tabular}{|c|c|c|c|c|c|c|}
\hline Lags & Nothing & $\begin{array}{c}\text { Seasonals } \\
\text { Only }\end{array}$ & $\begin{array}{c}\text { Seasonals } \\
\& \text { Lags }\end{array}$ & $\begin{array}{c}\text { Seasonals, } \\
\text { Trend, \& } \\
\text { Lags }\end{array}$ & Lags Only & $\begin{array}{c}\text { Trend \& } \\
\text { Lags }\end{array}$ \\
\hline 0 & 76.47 & 75.39 & - & - & - & - \\
\hline 1 & - & - & 55.42 & $\mathbf{5 5 . 2 5}$ & 57.99 & 57.93 \\
\hline 2 & - & - & 55.57 & 55.50 & 57.62 & 57.51 \\
\hline 3 & - & - & 56.19 & 56.14 & 58.10 & 57.91 \\
\hline 4 & - & - & 56.90 & 56.88 & 58.69 & 58.50 \\
\hline 5 & - & - & 57.66 & 57.67 & 59.19 & 59.15 \\
\hline 6 & - & - & 58.43 & 58.41 & 59.80 & 59.72 \\
\hline
\end{tabular}

${ }^{16}$ Schwarz Information Criteria evaluates the trade-off between the number of variables in a model and the number of lags, in an attempt to find the most parsimonious model. This table shows the SIC results for different scenarios of a levels VAR with a constant, with the bold value being where SIC is minimized. 
Table 5B. Trace Tests for Model Rank and Cointegration ${ }^{17}$

\begin{tabular}{|c|r|r|c|r|}
\hline $\mathbf{r}$ & \multicolumn{1}{c|}{$\mathbf{T}$} & $\mathbf{C}(\mathbf{1 0 \%})$ & Decision & \multicolumn{1}{c|}{ SIC } \\
\hline$=0$ & 294.70 & 159.74 & $\mathrm{R}$ & 55.44 \\
\hline$\leq 1$ & 180.85 & 126.71 & $\mathrm{R}$ & $\mathbf{5 5 . 0 2}$ \\
\hline$\leq 2$ & 113.96 & 97.17 & $\mathrm{R}$ & 55.06 \\
\hline$\leq 3$ & 62.51 & 71.66 & $\mathrm{~F} \#$ & 55.11 \\
\hline$\leq 4$ & 34.79 & 49.92 & $\mathrm{~F}$ & 55.20 \\
\hline$\leq 5$ & 19.15 & 31.88 & $\mathrm{~F}$ & 55.29 \\
\hline$\leq 6$ & 7.41 & 17.79 & $\mathrm{~F}$ & 55.36 \\
\hline$\leq 7$ & 2.62 & 7.50 & $\mathrm{~F}$ & 55.42 \\
\hline
\end{tabular}

${ }^{17}$ Trace tests for determining the rank of $\Pi$ were described by Johansen (1991) and have a null hypothesis of $r$ cointegrating relations, shown in the first column. This test is done in a step-wise fashion starting from the top of the table and ends at the first failure to reject $(F \#)$, which is where the trace test indicates the rank of $\Pi$ is at. The decision column indicates the decision to reject $(R)$ or fail $(F)$ the null hypothesis at the $90 \%$ confidence level. Results are associated with a constant in the co-integrating space. $T$ is the calculated test statistic and C(10\%) is the chi-squared critical value at the $90 \%$ confidence interval. The minimum Schwarz Information Criteria value from the residual analysis is in bold. 
Table 6B. Exclusion Test Results for Two Cointegrating Vectors ${ }^{18}$

\begin{tabular}{|l|c|c|c|}
\hline Series & Chi-Value r=2 & p-value & D \\
\hline Hens & 15.72 & 0.000 & $\mathrm{R}$ \\
\hline Egg Production & 20.43 & 0.000 & $\mathrm{R}$ \\
\hline Egg Price & 47.39 & 0.000 & $\mathrm{R}$ \\
\hline Soybean Meal Price & 8.80 & 0.012 & $\mathrm{R}$ \\
\hline Corn Meal Price & 30.45 & 0.000 & $\mathrm{R}$ \\
\hline Retail Beef Price & 5.74 & 0.057 & $\mathrm{~F}$ \\
\hline Retail Pork Price & 1.89 & 0.389 & $\mathrm{~F}$ \\
\hline Real Disposable Personal Income & 21.23 & 0.000 & $\mathrm{R}$ \\
\hline Constant & 13.00 & 0.002 & $\mathrm{R}$ \\
\hline
\end{tabular}

\footnotetext{
${ }^{18}$ The null hypothesis for the exclusion test is that the series is not in the co-integrating space. This test uses a chi-squared test statistic, with 5.99 being the critical value based on two degrees of freedom. The pvalues correspond with the given chi-values given a 95\% confidence interval. The D column represents the decision to reject $(R)$ or fail to reject $(F)$ the null hypothesis.
} 
Table 7B. Weak Exogeneity Test Results for Two Cointegrating Vectors ${ }^{19}$

\begin{tabular}{|l|c|c|c|}
\hline Series & Chi-Value r=2 & p-value & Decision \\
\hline Hens & 6.87 & 0.032 & $\mathrm{R}$ \\
\hline Egg Production & 11.91 & 0.003 & $\mathrm{R}$ \\
\hline Egg Price & 26.17 & 0.000 & $\mathrm{R}$ \\
\hline Soybean Meal Price & 8.57 & 0.014 & $\mathrm{R}$ \\
\hline Corn Meal Price & 24.87 & 0.000 & $\mathrm{R}$ \\
\hline Retail Beef Price & 7.89 & 0.019 & $\mathrm{R}$ \\
\hline Retail Pork Price & 8.25 & 0.016 & $\mathrm{R}$ \\
\hline Real Disposable Personal Income & 5.74 & 0.057 & $\mathrm{~F}$ \\
\hline
\end{tabular}

\footnotetext{
${ }^{19}$ The null hypothesis for this test is that the series is weakly exogenous with respect to perturbations in the co-integrating vector. This test uses a chi-squared test statistic, with 5.99 being the critical value based on two degrees of freedom. The p-values correspond with the given chi-values given a $95 \%$ confidence interval. The Decision column represents the decision to reject $(R)$ or fail to reject $(F)$ the null hypothesis.
} 
Table 8B. Theil U-Statistic to Evaluate Forecast Performance ${ }^{20}$

\begin{tabular}{|c|c|c|c|}
\hline Step & $\begin{array}{c}\text { Number of Eggs } \\
\text { (Millions) }\end{array}$ & $\begin{array}{c}\text { Egg Price } \\
\text { (Cents/Dozen) }\end{array}$ & $\begin{array}{c}\text { Number of } \\
\text { Observations }\end{array}$ \\
\hline 1 & 0.370 & 0.939 & 13 \\
\hline 2 & 0.504 & 0.958 & 13 \\
\hline 3 & 0.547 & 1.009 & 13 \\
\hline 4 & 0.589 & 0.935 & 13 \\
\hline 5 & 0.686 & 0.929 & 13 \\
\hline 6 & 0.674 & 0.934 & 13 \\
\hline 7 & 0.750 & 0.907 & 13 \\
\hline 8 & 0.758 & 0.905 & 13 \\
\hline 9 & 0.769 & 0.901 & 11 \\
\hline 10 & 0.752 & 0.918 & 10 \\
\hline 11 & 0.714 & 0.945 & 9 \\
\hline 12 & 0.805 & 0.943 & \\
\hline
\end{tabular}

${ }^{20}$ Theil's U-statistic is the ratio between the vector error correction model's forecast root mean square error and a random walk's forecast root mean square error. A value less than 1.0 indicates a model that forecasts better than a random walk. The step column is the number of steps ahead the model forecasts and the number of observations are those available for each step ahead forecast. 
Table 9B. Revenue Calculations ${ }^{21}$

\begin{tabular}{|c|c|c|}
\hline Date & Realized Revenue & Counterfactual Revenue \\
\hline $2014-12-01$ & $1,215,184,350$ & $998,313,465$ \\
\hline $2015-01-01$ & $787,607,333$ & $1,032,262,106$ \\
\hline $2015-02-01$ & $809,219,250$ & $691,581,641$ \\
\hline $2015-03-01$ & $1,061,901,533$ & $907,501,990$ \\
\hline $2015-04-01$ & $732,096,583$ & $890,371,289$ \\
\hline $2015-05-01$ & $993,284,500$ & $666,604,645$ \\
\hline $2015-06-01$ & $1,158,175,150$ & $894,403,187$ \\
\hline \hline Sum Total & $6,757,468,700$ & $6,081,038,323$ \\
\hline Difference & $676,430,377$ & \\
\hline
\end{tabular}

\footnotetext{
${ }^{21}$ A 12 -step ahead forecast was generated for the number of eggs and the egg price using a vector error correction model with one lag, two cointegrating vectors, and seasonal dummies. From the forecasted values, the counterfactual revenue was calculated and compared to the realized revenue, or the revenue that was reported by the industry. Both the realized and counterfactual revenue was calculated and summed over the official months the outbreak occurred, from December 2014 to June 2015. The difference of the counterfactual revenue taken from the realized revenue is in the Difference row and represents the revenue impact the avian influenza outbreak had on the industry at the wholesale level, ceteris paribus.
} 
Table 10B. Greedy Equivalence Search (GES) and PC Algorithm (PC) Machine Learning Edge Statistics ${ }^{22}$

\begin{tabular}{|c|c|c|c|}
\hline Edge & $\begin{array}{c}\text { Edge } \\
\text { Coefficient }\end{array}$ & t-statistic & $\mathbf{P}$ \\
\hline $\mathrm{PPR} \rightarrow \mathrm{BPR}$ & 0.1973 & 3.7160 & 0.0002 \\
\hline RDI $\rightarrow$ HENS & 0.0819 & 1.5194 & 0.1296 \\
\hline PPR $\longrightarrow$ HENS & -0.0507 & -0.9397 & 0.3480 \\
\hline HENS $\longrightarrow$ EGGS & 0.4473 & 9.2297 & 0.0000 \\
\hline $\mathrm{SMP} \longrightarrow \mathrm{EPR}$ & 0.1535 & 2.5952 & 0.0099 \\
\hline $\mathrm{CMP} \longrightarrow \mathrm{PPR}$ & -0.0553 & -1.0232 & 0.3069 \\
\hline $\mathrm{BPR} \longrightarrow \mathrm{EPR}$ & 0.1012 & 1.9105 & 0.0569 \\
\hline $\mathrm{CMP} \longrightarrow \mathrm{HENS}$ & -0.0848 & -1.572 & 0.1169 \\
\hline $\mathrm{CMP} \longrightarrow \mathrm{EPR}$ & 0.0876 & 1.4804 & 0.1397 \\
\hline $\mathrm{CMP} \longrightarrow \mathrm{EGGS}$ & -0.0542 & -1.1182 & 0.2643 \\
\hline
\end{tabular}

${ }^{22}$ The $t$-statistic and p-value are for a null hypothesis that the edge is zero. The PC Algorithm was run with $\alpha=0.55$ and the GES was run with a 0.1 penalty discount. The PC algorithm starts with a completely undirected graph and tests edges to remove those with significantly zero edges. The GES algorithm starts with no edges at all and scores graphs with the Bayesian Information Criterion (BIC) metric. Any edges found have an edge coefficient, with its significance shown with a t-statistic and associated p-value. Both searches generated the same results. 
Table 11B. Percent Forecast Error Variance Decomposition for Hens, Eggs, and Egg Price ${ }^{23}$

\begin{tabular}{|c|c|c|c|c|c|c|c|c|c|}
\hline \multirow{6}{*}{ 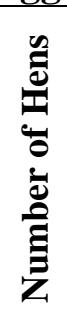 } & Month & HENS & EGGS & EPR & SMP & CMP & BPR & PPR & RDI \\
\hline & 1 & 98.40 & 0.00 & 0.00 & 0.00 & 0.67 & 0.00 & 0.26 & 0.67 \\
\hline & 6 & 92.74 & 4.11 & 0.57 & 0.07 & 2.07 & 0.00 & 0.21 & 0.23 \\
\hline & 12 & 89.91 & 6.78 & 0.59 & 0.20 & 2.19 & 0.01 & 0.19 & 0.14 \\
\hline & 18 & 88.83 & 7.87 & 0.56 & 0.27 & 2.18 & 0.01 & 0.18 & 0.10 \\
\hline & 24 & 88.29 & 8.43 & 0.54 & 0.31 & 2.17 & 0.01 & 0.18 & 0.09 \\
\hline \multirow{6}{*}{ 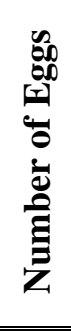 } & Month & HENS & EGGS & EPR & SMP & CMP & BPR & PPR & RDI \\
\hline & 1 & 19.68 & 79.30 & 0.00 & 0.00 & 0.83 & 0.00 & 0.05 & 0.13 \\
\hline & 6 & 33.57 & 59.29 & 0.11 & 3.86 & 1.22 & 0.07 & 0.21 & 1.67 \\
\hline & 12 & 40.32 & 43.29 & 0.84 & 9.79 & 2.41 & 0.17 & 0.34 & 2.84 \\
\hline & 18 & 43.15 & 34.99 & 1.44 & 13.20 & 3.20 & 0.22 & 0.41 & 3.39 \\
\hline & 24 & 44.71 & 30.23 & 1.81 & 15.18 & 3.68 & 0.25 & 0.45 & 3.70 \\
\hline \multirow{6}{*}{ 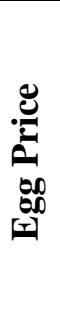 } & Month & HENS & EGGS & EPR & SMP & CMP & BPR & PPR & RDI \\
\hline & 1 & 0.00 & 0.00 & 95.82 & 2.38 & 0.76 & 1.00 & 0.04 & 0.00 \\
\hline & 6 & 0.13 & 0.02 & 74.83 & 1.45 & 21.95 & 1.19 & 0.18 & 0.26 \\
\hline & 12 & 0.22 & 0.04 & 59.99 & 2.36 & 35.51 & 1.19 & 0.25 & 0.45 \\
\hline & 18 & 0.26 & 0.04 & 53.62 & 2.80 & 41.29 & 1.18 & 0.27 & 0.54 \\
\hline & 24 & 0.28 & 0.05 & 50.21 & 3.04 & 44.38 & 1.18 & 0.29 & 0.58 \\
\hline
\end{tabular}

\footnotetext{
${ }^{23}$ Forecast error variance decompositions are found by taking the forecast error variances associated with one series and dividing by the full forecast error variance. From this we can see how much of the error variance in a shocked series is due to itself and other series over time, in months, after a one-time shock. The 8 series considered are number of hens (HENS), number of eggs (EGGS), egg price (EPR), soybean meal price $(S M P)$, cornmeal price $(C M P)$, retail beef price $(B P R)$, retail pork price $(P P R)$, and real disposable personal income (RDI).
} 


\section{APPENDIX C}

\section{INPUT DATA}

\section{C. Data for Regression Analysis for Time Series (RATS) Software ${ }^{24}$}

\begin{tabular}{|c|c|c|c|c|c|c|c|c|}
\hline Date & $\begin{array}{l}\text { Number } \\
\text { of Hens }\end{array}$ & $\begin{array}{l}\text { Number } \\
\text { of Eggs }\end{array}$ & $\begin{array}{l}\text { Egg } \\
\text { Price }\end{array}$ & $\begin{array}{c}\text { Soybean } \\
\text { Meal Price }\end{array}$ & $\begin{array}{l}\text { Cornmeal } \\
\text { Price }\end{array}$ & $\begin{array}{c}\text { Retail } \\
\text { Beef } \\
\text { Price }\end{array}$ & $\begin{array}{l}\text { Retail } \\
\text { Pork } \\
\text { Price }\end{array}$ & $\begin{array}{l}\text { Real Disposable } \\
\text { Personal Income }\end{array}$ \\
\hline Mar-86 & 246348 & 5287 & 80.8 & 175.93 & 198.75 & 231.26 & 179.18 & 23571 \\
\hline Apr-86 & 244527 & 5057 & 65.7 & 169.15 & 192.90 & 226.27 & 174.04 & 23649 \\
\hline May-86 & 242831 & 5182 & 65.2 & 165.23 & 210.60 & 224.70 & 173.10 & 23661 \\
\hline Jun-86 & 241247 & 5016 & 59.2 & 164.13 & 216.90 & 223.82 & 177.04 & 23631 \\
\hline Jul-86 & 241323 & 5116 & 73.0 & 167.45 & 211.50 & 223.72 & 194.23 & 23742 \\
\hline Aug-86 & 242073 & 5125 & 72.8 & 167.67 & 206.25 & 225.85 & 200.94 & 23760 \\
\hline Sep-86 & 243398 & 4997 & 72.6 & 168.41 & 208.00 & 225.52 & 204.25 & 23765 \\
\hline Oct-86 & 246548 & 5222 & 69.6 & 163.29 & 222.50 & 225.05 & 204.16 & 23731 \\
\hline Nov-86 & 248396 & 5162 & 77.2 & 165.29 & 230.60 & 227.08 & 201.25 & 23732 \\
\hline Dec-86 & 249569 & 5377 & 75.5 & 158.84 & 241.50 & 227.84 & 199.80 & 23760 \\
\hline Jan-87 & 250796 & 5331 & 67.1 & 159.03 & 232.20 & 228.26 & 195.30 & 23812 \\
\hline Feb-87 & 250549 & 4809 & 65.2 & 159.00 & 206.25 & 224.22 & 191.76 & 23925 \\
\hline Mar-87 & 249689 & 5409 & 62.0 & 155.27 & 208.50 & 223.78 & 186.95 & 23934 \\
\hline Apr-87 & 246853 & 5191 & 62.4 & 166.05 & 213.10 & 225.80 & 183.59 & 23015 \\
\hline May-87 & 244570 & 5226 & 55.6 & 184.11 & 226.40 & 231.43 & 187.96 & 23930 \\
\hline Jun-87 & 243234 & 5010 & 58.7 & 194.45 & 267.80 & 236.45 & 191.40 & 23878 \\
\hline Jul-87 & 243612 & 5173 & 59.1 & 186.47 & 268.75 & 234.39 & 196.76 & 23929 \\
\hline Aug-87 & 245226 & 5183 & 63.2 & 177.45 & 240.60 & 230.81 & 198.64 & 24012 \\
\hline Sep-87 & 247812 & 5088 & 68.3 & 189.72 & 259.50 & 229.81 & 198.40 & 23992 \\
\hline Oct-87 & 250079 & 5325 & 60.2 & 196.54 & 278.75 & 229.34 & 195.32 & 24122 \\
\hline Nov-87 & 251051 & 5217 & 60.5 & 218.22 & 305.60 & 230.20 & 190.10 & 24196 \\
\hline Dec-87 & 250074 & 5400 & 56.9 & 227.64 & 313.50 & 228.96 & 186.48 & 24398 \\
\hline Jan-88 & 248302 & 5348 & 55.9 & 206.32 & 309.40 & 226.35 & 185.83 & 24436 \\
\hline Feb-88 & 246878 & 5004 & 52.7 & 201.56 & 283.75 & 228.40 & 182.75 & 24557 \\
\hline Mar-88 & 244283 & 5346 & 56.4 & 208.33 & 287.00 & 229.61 & 182.27 & 24637 \\
\hline Apr-88 & 241899 & 5086 & 52.1 & 218.75 & 275.60 & 230.03 & 181.02 & 24707 \\
\hline May-88 & 239098 & 5142 & 50.9 & 245.04 & 278.75 & 231.97 & 181.03 & 24725 \\
\hline Jun-88 & 235807 & 4908 & 56.8 & 320.55 & 355.50 & 237.45 & 184.76 & 24799 \\
\hline Jul-88 & 235184 & 5054 & 73.7 & 292.11 & 380.00 & 236.46 & 183.92 & 24878 \\
\hline Aug-88 & 236703 & 5089 & 69.5 & 294.76 & 310.00 & 234.63 & 181.72 & 24930 \\
\hline Sep-88 & 238647 & 4945 & 75.6 & 295.28 & 309.40 & 235.73 & 180.63 & 24943 \\
\hline Oct- 88 & 240214 & 5169 & 66.0 & 281.67 & 313.75 & 233.12 & 176.76 & 25060 \\
\hline Nov-88 & 239442 & 5040 & 65.3 & 277.51 & 293.00 & 234.86 & 172.77 & 25052 \\
\hline Dec-88 & 236540 & 5154 & 70.4 & 276.26 & 277.50 & 233.85 & 171.72 & 25174 \\
\hline
\end{tabular}




\section{C. Continued}

\begin{tabular}{|c|c|c|c|c|c|c|c|c|}
\hline Date & $\begin{array}{l}\text { Number } \\
\text { of Hens }\end{array}$ & $\begin{array}{l}\text { Number } \\
\text { of Eggs }\end{array}$ & $\begin{array}{c}\text { Egg } \\
\text { Price }\end{array}$ & $\begin{array}{l}\text { Soybean } \\
\text { Meal Price }\end{array}$ & $\begin{array}{c}\text { Cornmeal } \\
\text { Price }\end{array}$ & $\begin{array}{c}\text { Retail } \\
\text { Beef } \\
\text { Price }\end{array}$ & $\begin{array}{l}\text { Retail } \\
\text { Pork } \\
\text { Price }\end{array}$ & $\begin{array}{l}\text { Real Disposable } \\
\text { Personal Income }\end{array}$ \\
\hline Jan-89 & 235016 & 5062 & 72.0 & 280.23 & 281.00 & 236.50 & 174.82 & 25273 \\
\hline Feb-89 & 234336 & 4538 & 71.1 & 263.39 & 288.10 & 236.23 & 173.56 & 25338 \\
\hline Mar-89 & 232357 & 5060 & 92.2 & 264.55 & 280.60 & 243.29 & 174.75 & 25450 \\
\hline Apr-89 & 230448 & 4864 & 76.6 & 247.61 & 275.60 & 244.29 & 174.87 & 25298 \\
\hline Мay-89 & 229449 & 4968 & 73.7 & 238.93 & 272.00 & 244.90 & 172.06 & 25161 \\
\hline Jun-89 & 229446 & 4793 & 75.2 & 233.79 & 270.63 & 245.57 & 173.05 & 25208 \\
\hline Jul-89 & 229337 & 4926 & 76.5 & 236.36 & 271.25 & 246.30 & 176.62 & 25285 \\
\hline Aug-89 & 229473 & 4900 & 84.2 & 216.78 & 257.00 & 244.48 & 178.04 & 25324 \\
\hline Sep-89 & 230677 & 4777 & 83.8 & 216.57 & 267.00 & 241.56 & 177.04 & 25365 \\
\hline Oct-89 & 231885 & 4969 & 84.8 & 206.34 & 313.00 & 240.25 & 178.22 & 25458 \\
\hline Nov-89 & 232455 & 4878 & 93.4 & 203.73 & 298.75 & 241.30 & 181.70 & 25465 \\
\hline Dec-89 & 232234 & 5066 & 99.5 & 200.26 & 280.00 & 243.80 & 183.07 & 25453 \\
\hline Jan-90 & 231888 & 4984 & 92.4 & 191.31 & 81.00 & 246.76 & 185.63 & 25593 \\
\hline Feb-90 & 231752 & 4495 & 79.6 & 182.27 & 260.90 & 242.83 & 186.29 & 25639 \\
\hline Mar-90 & 231827 & 5065 & 91.5 & 184.33 & 238.75 & 243.09 & 185.93 & 25611 \\
\hline Apr-90 & 230881 & 4895 & 82.4 & 191.06 & 238.10 & 246.58 & 188.60 & 25735 \\
\hline May-90 & 228826 & 4968 & 67.9 & 199.97 & 240.50 & 250.75 & 192.89 & 25651 \\
\hline Jun-90 & 226779 & 4773 & 73.6 & 192.49 & 215.60 & 248.55 & 203.30 & 25679 \\
\hline Jul-90 & 226283 & 4931 & 70.9 & 193.97 & 222.00 & 245.96 & 206.58 & 25741 \\
\hline Aug-90 & 227475 & 4961 & 80.3 & 192.70 & 223.75 & 245.28 & 207.99 & 25558 \\
\hline Sep-90 & 228640 & 4811 & 82.2 & 198.24 & 229.40 & 244.00 & 203.14 & 25524 \\
\hline Oct-90 & 230229 & 5038 & 86.5 & 200.76 & 232.00 & 245.19 & 204.81 & 25291 \\
\hline Nov-90 & 231702 & 4958 & 86.5 & 192.01 & 231.90 & 252.69 & 204.36 & 25269 \\
\hline Dec-90 & 232810 & 5141 & 92.5 & 189.54 & 240.60 & 255.89 & 204.63 & 25383 \\
\hline Jan-91 & 233428 & 5102 & 87.6 & 180.40 & 247.00 & 254.88 & 197.61 & 25274 \\
\hline Feb-91 & 233135 & 4610 & 78.3 & 183.51 & 239.40 & 252.16 & 196.55 & 25290 \\
\hline Mar-91 & 231574 & 5135 & 91.8 & 184.07 & 247.50 & 253.56 & 194.25 & 25309 \\
\hline Apr-91 & 229598 & 4876 & 74.9 & 190.37 & 236.70 & 253.71 & 191.27 & 25369 \\
\hline May-91 & 229379 & 4973 & 67.0 & 189.32 & 226.90 & 252.00 & 192.06 & 25341 \\
\hline Jun-91 & 230072 & 4849 & 69.0 & 190.08 & 230.00 & 247.80 & 192.41 & 25443 \\
\hline Jul-91 & 230745 & 5045 & 79.6 & 184.68 & 236.20 & 243.38 & 194.37 & 25361 \\
\hline Aug-91 & 231833 & 5076 & 76.3 & 199.19 & 254.60 & 239.83 & 190.44 & 25377 \\
\hline Sep-91 & 233435 & 4917 & 75.5 & 212.96 & 269.40 & 233.81 & 187.14 & 25420 \\
\hline Oct-91 & 235449 & 5121 & 74.5 & 203.19 & 292.50 & 230.62 & 182.82 & 25431 \\
\hline Nov-91 & 236313 & 5019 & 75.8 & 198.68 & 296.25 & 233.58 & 180.38 & 25454 \\
\hline Dec-91 & 236940 & 5232 & 80.0 & 191.53 & 287.50 & 231.87 & 176.39 & 25662 \\
\hline Jan-92 & 235933 & 5135 & 66.6 & 193.36 & 267.50 & 230.14 & 173.60 & 25913 \\
\hline Feb-92 & 235175 & 4788 & 61.7 & 192.56 & 275.60 & 232.32 & 173.84 & 26019 \\
\hline Mar-92 & 235064 & 5209 & 63.1 & 194.94 & 272.00 & 233.52 & 171.46 & 26029 \\
\hline Apr-92 & 233550 & 5017 & 65.0 & 192.28 & 247.50 & 233.63 & 166.91 & 26077 \\
\hline
\end{tabular}




\section{C. Continued}

\begin{tabular}{|c|c|c|c|c|c|c|c|c|}
\hline Date & $\begin{array}{l}\text { Number } \\
\text { of Hens }\end{array}$ & $\begin{array}{l}\text { Number } \\
\text { of Eggs }\end{array}$ & $\begin{array}{c}\text { Egg } \\
\text { Price }\end{array}$ & $\begin{array}{l}\text { Soybean } \\
\text { Meal Price }\end{array}$ & $\begin{array}{l}\text { Cornmeal } \\
\text { Price }\end{array}$ & $\begin{array}{c}\text { Retail } \\
\text { Beef } \\
\text { Price }\end{array}$ & $\begin{array}{l}\text { Retail } \\
\text { Pork } \\
\text { Price }\end{array}$ & $\begin{array}{l}\text { Real Disposable } \\
\text { Personal Income }\end{array}$ \\
\hline May-92 & 231931 & 5069 & 58.9 & 199.53 & 246.25 & 230.86 & 167.84 & 26178 \\
\hline Jun-92 & 231721 & 4889 & 62.0 & 201.30 & 248.50 & 231.35 & 168.04 & 26259 \\
\hline Jul-92 & 232041 & 5095 & 58.6 & 192.64 & 243.75 & 228.14 & 170.61 & 26207 \\
\hline Aug-92 & 232548 & 5125 & 64.6 & 190.18 & 242.75 & 224.80 & 170.16 & 26262 \\
\hline Sep-92 & 235496 & 5004 & 70.5 & 194.99 & 266.00 & 227.28 & 168.94 & 26099 \\
\hline Oct-92 & 238442 & 5246 & 65.3 & 199.87 & 269.40 & 227.39 & 167.12 & 25901 \\
\hline Nov-92 & 239781 & 5132 & 75.3 & 199.12 & 266.90 & 228.04 & 165.04 & 25886 \\
\hline Dec-92 & 239916 & 5340 & 73.6 & 204.84 & 287.00 & 227.84 & 164.70 & 26776 \\
\hline Jan-93 & 238913 & 5237 & 71.7 & 203.32 & 283.10 & 226.37 & 162.77 & 26250 \\
\hline Feb-93 & 238669 & 4701 & 69.9 & 195.97 & 294.40 & 228.52 & 160.27 & 26317 \\
\hline Mar-93 & 238155 & 5260 & 85.2 & 199.39 & 295.50 & 229.60 & 159.40 & 26205 \\
\hline Apr-93 & 237533 & 5065 & 77.8 & 204.27 & 284.40 & 232.04 & 157.10 & 26299 \\
\hline May-93 & 237030 & 5172 & 67.6 & 211.56 & 276.90 & 235.45 & 159.52 & 26227 \\
\hline Jun-93 & 236919 & 5003 & 74.7 & 210.53 & 276.50 & 229.33 & 160.04 & 26146 \\
\hline Jul-93 & 237742 & 5171 & 68.9 & 250.73 & 300.60 & 227.53 & 162.43 & 26178 \\
\hline Aug-93 & 238635 & 5209 & 72.8 & 239.49 & 314.50 & 221.05 & 159.75 & 26185 \\
\hline Sep-93 & 239883 & 5096 & 67.2 & 219.99 & 305.60 & 217.33 & 160.73 & 26088 \\
\hline Oct-93 & 241321 & 5331 & 70.9 & 211.49 & 296.20 & 216.10 & 159.45 & 25919 \\
\hline Nov-93 & 241964 & 5244 & 71.5 & 227.76 & 305.75 & 217.49 & 159.81 & 25967 \\
\hline Dec-93 & 241985 & 5407 & 72.2 & 223.82 & 316.25 & 215.40 & 159.02 & 26827 \\
\hline Jan-94 & 240692 & 5292 & 68.0 & 217.13 & 309.40 & 213.08 & 158.15 & 26307 \\
\hline Feb-94 & 240293 & 4774 & 72.1 & 215.25 & 296.25 & 211.35 & 156.89 & 26344 \\
\hline Mar-94 & 240633 & 5404 & 74.4 & 213.48 & 288.50 & 213.56 & 157.84 & 26403 \\
\hline Apr-94 & 239634 & 5176 & 65.0 & 207.52 & 278.10 & 212.35 & 155.49 & 26384 \\
\hline May-94 & 238184 & 5248 & 61.9 & 210.81 & 263.50 & 212.46 & 155.11 & 26676 \\
\hline Jun-94 & 237376 & 5084 & 62.9 & 216.99 & 263.75 & 208.31 & 154.81 & 26597 \\
\hline Jul-94 & 237097 & 5268 & 66.2 & 199.92 & 263.75 & 205.65 & 155.75 & 26591 \\
\hline Aug-94 & 239256 & 5336 & 68.0 & 192.50 & 252.30 & 203.81 & 154.21 & 26600 \\
\hline Sep-94 & 242496 & 5218 & 66.7 & 186.32 & 235.60 & 204.08 & 152.15 & 26682 \\
\hline Oct-94 & 244495 & 5445 & 63.8 & 179.34 & 226.90 & 202.26 & 151.92 & 26901 \\
\hline Nov-94 & 246380 & 5371 & 68.5 & 175.45 & 232.50 & 203.34 & 149.72 & 26867 \\
\hline Dec-94 & 247818 & 5584 & 69.3 & 173.45 & 239.40 & 202.61 & 144.54 & 26967 \\
\hline Jan-95 & 246655 & 5443 & 65.2 & 172.51 & 230.50 & 204.63 & 146.63 & 27056 \\
\hline Feb-95 & 245556 & 4884 & 64.3 & 170.29 & 221.25 & 205.12 & 144.96 & 27094 \\
\hline Mar-95 & 244886 & 5530 & 66.2 & 177.20 & 215.60 & 204.38 & 146.97 & 27137 \\
\hline Apr-95 & 243500 & 5283 & 66.7 & 184.07 & 206.25 & 203.37 & 144.56 & 26904 \\
\hline May-95 & 241421 & 5326 & 59.5 & 185.63 & 196.50 & 202.00 & 144.65 & 27142 \\
\hline Jun-95 & 239040 & 5115 & 64.8 & 189.85 & 208.10 & 202.14 & 142.63 & 27196 \\
\hline Jul-95 & 237331 & 5240 & 75.6 & 199.36 & 218.75 & 204.56 & 144.13 & 27221 \\
\hline Aug-95 & 237361 & 5246 & 72.8 & 194.64 & 232.00 & 201.85 & 148.15 & 27213 \\
\hline
\end{tabular}




\section{C. Continued}

\begin{tabular}{|c|c|c|c|c|c|c|c|c|}
\hline Date & $\begin{array}{l}\text { Number } \\
\text { of Hens }\end{array}$ & $\begin{array}{l}\text { Number } \\
\text { of Eggs }\end{array}$ & $\begin{array}{c}\text { Egg } \\
\text { Price }\end{array}$ & $\begin{array}{c}\text { Soybean } \\
\text { Meal Price }\end{array}$ & $\begin{array}{c}\text { Cornmeal } \\
\text { Price }\end{array}$ & $\begin{array}{c}\text { Retail } \\
\text { Beef } \\
\text { Price }\end{array}$ & $\begin{array}{c}\text { Retail } \\
\text { Pork } \\
\text { Price }\end{array}$ & $\begin{array}{l}\text { Real Disposable } \\
\text { Personal Income }\end{array}$ \\
\hline Sep-95 & 238910 & 5106 & 77.1 & 209.81 & 250.00 & 200.64 & 148.25 & 27270 \\
\hline Oct-95 & 240992 & 5338 & 79.4 & 219.23 & 290.50 & 201.20 & 151.01 & 27273 \\
\hline Nov-95 & 244478 & 5331 & 91.1 & 230.54 & 326.90 & 201.69 & 149.61 & 27321 \\
\hline Dec-95 & 246272 & 5565 & 91.8 & 249.43 & 331.90 & 200.21 & 150.76 & 27331 \\
\hline Jan-96 & 245921 & 5431 & 91.3 & 258.36 & 351.00 & 197.41 & 149.20 & 27353 \\
\hline Feb-96 & 245247 & 5049 & 85.7 & 253.71 & 342.50 & 194.83 & 153.93 & 27542 \\
\hline Mar-96 & 245382 & 5523 & 91.8 & 251.40 & 341.25 & 192.06 & 154.50 & 27608 \\
\hline Apr-96 & 244673 & 5309 & 85.6 & 274.40 & 336.50 & 193.96 & 153.26 & 27424 \\
\hline May-96 & 242827 & 5367 & 76.5 & 271.62 & 343.10 & 191.82 & 156.72 & 27747 \\
\hline Jun-96 & 242335 & 5229 & 79.4 & 264.25 & 315.00 & 191.34 & 163.02 & 27884 \\
\hline Jul-96 & 244133 & 5478 & 81.0 & 272.55 & 308.50 & 192.24 & 165.37 & 27780 \\
\hline Aug-96 & 245653 & 5487 & 86.9 & 281.53 & 295.00 & 194.13 & 169.08 & 27816 \\
\hline Sep-96 & 246860 & 5319 & 90.0 & 294.05 & 329.40 & 193.45 & 170.77 & 27851 \\
\hline Oct-96 & 248909 & 5561 & 86.7 & 260.90 & 344.00 & 193.48 & 169.19 & 27817 \\
\hline Nov-96 & 250580 & 5487 & 102.5 & 255.55 & 340.00 & 196.09 & 168.06 & 27862 \\
\hline Dec-96 & 251044 & 5706 & 100.9 & 258.24 & 342.50 & 197.05 & 167.77 & 27935 \\
\hline Jan-97 & 249923 & 5577 & 86.3 & 260.66 & 336.25 & 192.68 & 168.40 & 28003 \\
\hline Feb-97 & 249435 & 4997 & 82.0 & 273.45 & 335.60 & 189.91 & 166.81 & 28062 \\
\hline Mar-97 & 249343 & 5595 & 86.3 & 301.17 & 340.00 & 187.57 & 164.52 & 28165 \\
\hline Apr-97 & 248055 & 5350 & 75.6 & 309.33 & 342.50 & 189.28 & 162.58 & 28157 \\
\hline May-97 & 246382 & 5475 & 72.3 & 324.99 & 355.75 & 190.03 & 164.26 & 28245 \\
\hline Jun-97 & 245069 & 5285 & 68.4 & 300.66 & 349.40 & 187.57 & 167.06 & 28305 \\
\hline Jul-97 & 244569 & 5434 & 81.9 & 284.33 & 337.00 & 188.14 & 165.90 & 28387 \\
\hline Aug-97 & 245694 & 5489 & 74.7 & 279.81 & 345.60 & 188.59 & 167.58 & 28500 \\
\hline Sep-97 & 249095 & 5374 & 82.4 & 277.95 & 355.00 & 189.42 & 166.21 & 28546 \\
\hline Oct-97 & 251689 & 5630 & 77.0 & 245.04 & 343.75 & 186.62 & 166.24 & 28650 \\
\hline Nov-97 & 254381 & 5576 & 97.4 & 259.68 & 351.25 & 185.70 & 163.47 & 28800 \\
\hline Dec-97 & 255919 & 5802 & 90.3 & 241.42 & 350.50 & 187.64 & 160.29 & 28936 \\
\hline Jan-98 & 255085 & 5724 & 72.5 & 217.84 & 321.90 & 183.17 & 165.28 & 29174 \\
\hline Feb-98 & 255991 & 5154 & 81.5 & 207.11 & 295.00 & 180.25 & 164.41 & 29341 \\
\hline Mar-98 & 256720 & 5801 & 71.6 & 188.89 & 270.50 & 180.38 & 158.78 & 29487 \\
\hline Apr-98 & 254152 & 5559 & 60.5 & 176.48 & 238.10 & 183.15 & 155.10 & 29555 \\
\hline May-98 & 251887 & 5588 & 67.3 & 171.40 & 236.25 & 182.26 & 158.08 & 29647 \\
\hline Jun-98 & 252014 & 5437 & 73.3 & 178.42 & 225.60 & 182.75 & 159.41 & 29785 \\
\hline Jul-98 & 251881 & 5677 & 77.7 & 188.04 & 252.50 & 182.62 & 160.72 & 29808 \\
\hline Aug-98 & 252291 & 5658 & 77.0 & 152.85 & 245.00 & 182.73 & 160.24 & 29873 \\
\hline Sep-98 & 254787 & 5484 & 78.9 & 143.22 & 210.00 & 178.98 & 159.73 & 29933 \\
\hline Oct-98 & 258578 & 5759 & 83.6 & 151.25 & 227.50 & 178.92 & 157.58 & 29953 \\
\hline Nov-98 & 262410 & 5715 & 82.7 & 160.32 & 313.10 & 182.29 & 156.90 & 30047 \\
\hline Dec-98 & 264187 & 5989 & 75.8 & 160.90 & 291.50 & 184.76 & 155.11 & 30071 \\
\hline
\end{tabular}




\section{C. Continued}

\begin{tabular}{|c|c|c|c|c|c|c|c|c|}
\hline Date & $\begin{array}{l}\text { Number } \\
\text { of Hens }\end{array}$ & $\begin{array}{l}\text { Number } \\
\text { of Eggs }\end{array}$ & $\begin{array}{c}\text { Egg } \\
\text { Price }\end{array}$ & $\begin{array}{l}\text { Soybean } \\
\text { Meal Price }\end{array}$ & $\begin{array}{c}\text { Cornmeal } \\
\text { Price }\end{array}$ & $\begin{array}{c}\text { Retail } \\
\text { Beef } \\
\text { Price }\end{array}$ & $\begin{array}{l}\text { Retail } \\
\text { Pork } \\
\text { Price }\end{array}$ & $\begin{array}{l}\text { Real Disposable } \\
\text { Personal Income }\end{array}$ \\
\hline Jan-99 & 264211 & 5917 & 69.6 & 150.15 & 257.50 & 180.76 & 151.17 & 30162 \\
\hline Feb-99 & 264382 & 5312 & 75.5 & 143.06 & 222.50 & 179.47 & 152.94 & 30238 \\
\hline Mar-99 & 263708 & 5963 & 60.2 & 144.45 & 198.00 & 177.84 & 152.28 & 30248 \\
\hline Apr-99 & 262589 & 5731 & 59.3 & 146.51 & 192.50 & 181.64 & 150.22 & 30162 \\
\hline May-99 & 261960 & 5848 & 54.9 & 145.24 & 201.25 & 180.84 & 152.75 & 30195 \\
\hline Jun-99 & 261611 & 5673 & 68.7 & 150.37 & 209.50 & 183.28 & 153.92 & 30267 \\
\hline Jul-99 & 261289 & 5819 & 67.4 & 143.26 & 241.25 & 184.27 & 155.61 & 30268 \\
\hline Aug-99 & 262371 & 5897 & 62.4 & 154.13 & 252.50 & 183.73 & 156.90 & 30364 \\
\hline Sep-99 & 264984 & 5816 & 56.9 & 161.68 & 258.13 & 183.37 & 157.25 & 30310 \\
\hline Oct-99 & 268182 & 6059 & 67.2 & 166.01 & 265.00 & 186.61 & 154.58 & 30468 \\
\hline Nov-99 & 270902 & 5987 & 65.4 & 164.45 & 250.00 & 189.16 & 154.27 & 30655 \\
\hline Dec-99 & 271295 & 6218 & 65.6 & 161.50 & 234.00 & 190.26 & 155.17 & 30879 \\
\hline Jan-00 & 271006 & 6092 & 62.2 & 172.43 & 236.25 & 185.25 & 154.42 & 31111 \\
\hline Feb-00 & 271776 & 5655 & 67.1 & 180.47 & 248.50 & 183.98 & 157.25 & 31208 \\
\hline Mar-00 & 272078 & 6133 & 60.7 & 185.63 & 243.13 & 186.17 & 158.01 & 31260 \\
\hline Apr-00 & 269758 & 5933 & 68.5 & 187.86 & 246.25 & 190.63 & 159.49 & 31363 \\
\hline May-00 & 267250 & 5993 & 53.5 & 200.98 & 240.00 & 192.87 & 160.05 & 31454 \\
\hline Jun-00 & 266759 & 5745 & 64.2 & 191.49 & 223.75 & 194.35 & 162.39 & 31498 \\
\hline Jul-00 & 267605 & 5977 & 61.9 & 175.93 & 218.75 & 193.14 & 163.42 & 31635 \\
\hline Aug-00 & 268837 & 6042 & 72.5 & 171.07 & 211.00 & 192.74 & 165.20 & 31776 \\
\hline Sep-00 & 270736 & 5843 & 67.1 & 188.03 & 225.00 & 194.18 & 164.39 & 31747 \\
\hline Oct-00 & 273196 & 6087 & 73.0 & 186.00 & 247.00 & 192.96 & 162.22 & 31770 \\
\hline Nov-00 & 275636 & 6014 & 81.4 & 194.33 & 263.75 & 192.12 & 160.55 & 31722 \\
\hline Dec-00 & 276204 & 6234 & 94.9 & 211.81 & 273.13 & 192.23 & 162.77 & 31735 \\
\hline Jan-01 & 276471 & 6157 & 76.2 & 197.59 & 284.50 & 198.86 & 161.26 & 31886 \\
\hline Feb-01 & 277703 & 5543 & 71.5 & 178.71 & 267.50 & 206.43 & 161.54 & 31928 \\
\hline Mar-01 & 278639 & 6252 & 79.6 & 169.52 & 253.75 & 206.11 & 163.64 & 32004 \\
\hline Apr-01 & 278780 & 6043 & 74.4 & 169.02 & 228.75 & 211.20 & 162.05 & 31907 \\
\hline May-01 & 276503 & 6143 & 58.1 & 178.07 & 231.00 & 211.19 & 163.97 & 31814 \\
\hline Jun-01 & 274532 & 5936 & 57.3 & 185.04 & 237.50 & 213.28 & 166.19 & 31789 \\
\hline Jul-01 & 274414 & 6126 & 59.8 & 194.23 & 205.50 & 211.64 & 165.73 & 32239 \\
\hline Aug-01 & 275772 & 6170 & 62.8 & 189.10 & 263.75 & 207.67 & 169.11 & 32771 \\
\hline Sep-01 & 278442 & 6028 & 61.5 & 183.94 & 268.13 & 206.37 & 169.98 & 32502 \\
\hline Oct-01 & 280490 & 6306 & 66.1 & 177.63 & 260.00 & 206.08 & 168.55 & 31968 \\
\hline Nov-01 & 281479 & 6204 & 71.3 & 177.99 & 258.13 & 205.87 & 165.40 & 32019 \\
\hline Dec-01 & 282339 & 6391 & 67.1 & 166.50 & 257.50 & 201.54 & 165.62 & 32074 \\
\hline Jan-02 & 281179 & 6210 & 69.7 & 169.58 & 236.00 & 201.33 & 164.79 & 32733 \\
\hline Feb-02 & 279727 & 5619 & 60.7 & 165.45 & 221.88 & 200.89 & 165.18 & 32744 \\
\hline Mar-02 & 279236 & 6354 & 76.9 & 174.29 & 219.38 & 199.86 & 163.82 & 32707 \\
\hline Apr-02 & 277842 & 6057 & 55.8 & 175.93 & 217.00 & 200.66 & 160.46 & 32776 \\
\hline
\end{tabular}




\section{C. Continued}

\begin{tabular}{|c|c|c|c|c|c|c|c|c|}
\hline Date & $\begin{array}{l}\text { Number } \\
\text { of Hens }\end{array}$ & $\begin{array}{l}\text { Number } \\
\text { of Eggs }\end{array}$ & $\begin{array}{c}\text { Egg } \\
\text { Price }\end{array}$ & $\begin{array}{l}\text { Soybean } \\
\text { Meal Price }\end{array}$ & $\begin{array}{l}\text { Cornmeal } \\
\text { Price }\end{array}$ & $\begin{array}{c}\text { Retail } \\
\text { Beef } \\
\text { Price }\end{array}$ & $\begin{array}{l}\text { Retail } \\
\text { Pork } \\
\text { Price }\end{array}$ & $\begin{array}{l}\text { Real Disposable } \\
\text { Personal Income }\end{array}$ \\
\hline May-02 & 276403 & 6197 & 53.3 & 179.90 & 217.38 & 200.69 & 162.38 & 32821 \\
\hline Jun-02 & 276848 & 6075 & 66.1 & 185.83 & 230.00 & 198.53 & 160.42 & 32866 \\
\hline Jul-02 & 278323 & 6296 & 64.6 & 204.24 & 254.00 & 197.27 & 158.47 & 32736 \\
\hline Aug-02 & 279556 & 6314 & 67.3 & 201.12 & 275.00 & 200.18 & 159.55 & 32681 \\
\hline Sep-02 & 281501 & 6145 & 64.0 & 200.25 & 272.50 & 196.17 & 155.83 & 32670 \\
\hline Oct-02 & 282959 & 6394 & 65.2 & 185.35 & 268.50 & 193.71 & 155.14 & 32716 \\
\hline Nov-02 & 283412 & 6259 & 84.0 & 183.88 & 256.25 & 198.48 & 153.97 & 32765 \\
\hline Dec-02 & 283325 & 6406 & 77.1 & 181.98 & 255.90 & 200.69 & 154.84 & 32837 \\
\hline Jan-03 & 282983 & 6322 & 77.4 & 184.87 & 239.75 & 201.27 & 152.94 & 32828 \\
\hline Feb-03 & 281983 & 5691 & 74.1 & 192.42 & 234.00 & 204.92 & 154.66 & 32739 \\
\hline Mar-03 & 280697 & 6333 & 80.0 & 191.36 & 230.40 & 208.39 & 152.94 & 32832 \\
\hline Apr-03 & 278805 & 6121 & 77.1 & 200.26 & 226.20 & 212.96 & 154.03 & 33019 \\
\hline May-03 & 276767 & 6220 & 67.7 & 214.18 & 235.00 & 210.72 & 150.71 & 33249 \\
\hline Jun-03 & 276027 & 6046 & 76.9 & 210.61 & 230.40 & 212.04 & 153.38 & 33335 \\
\hline Jul-03 & 276475 & 6337 & 81.0 & 200.44 & 223.50 & 211.45 & 154.13 & 33682 \\
\hline Aug-03 & 277520 & 6318 & 93.8 & 199.30 & 226.90 & 216.13 & 156.62 & 33861 \\
\hline Sep-03 & 277883 & 6118 & 94.9 & 218.14 & 246.90 & 213.50 & 156.94 & 33442 \\
\hline Oct-03 & 279104 & 6403 & 100.0 & 245.71 & 239.48 & 226.04 & 155.44 & 33557 \\
\hline Nov-03 & 281735 & 6319 & 122.9 & 262.96 & 321.88 & 247.97 & 156.33 & 33778 \\
\hline Dec-03 & 281659 & 6487 & 109.3 & 255.64 & 337.50 & 243.85 & 154.03 & 33814 \\
\hline Jan-04 & 279983 & 6320 & 114.3 & 278.48 & 360.63 & 228.74 & 153.79 & 33830 \\
\hline Feb-04 & 280283 & 5894 & 107.5 & 286.39 & 371.25 & 226.90 & 153.04 & 33880 \\
\hline Mar-04 & 282021 & 6451 & 122.9 & 331.41 & 383.00 & 225.36 & 153.01 & 33979 \\
\hline Apr-04 & 282720 & 6280 & 89.6 & 343.71 & 390.38 & 229.32 & 153.38 & 34065 \\
\hline May-04 & 282532 & 6393 & 73.5 & 331.65 & 344.10 & 228.19 & 155.45 & 34214 \\
\hline Jun-04 & 283497 & 6223 & 75.9 & 311.68 & 332.50 & 234.43 & 158.97 & 34188 \\
\hline Jul-04 & 284372 & 6484 & 69.8 & 291.01 & 332.50 & 235.43 & 160.42 & 34213 \\
\hline Aug-04 & 285182 & 6472 & 63.4 & 212.15 & 267.50 & 231.72 & 162.56 & 34284 \\
\hline Sep-04 & 286172 & 6304 & 65.3 & 182.69 & 256.88 & 228.95 & 162.51 & 34255 \\
\hline Oct-04 & 287013 & 6588 & 57.9 & 171.44 & 241.25 & 226.26 & 162.48 & 34257 \\
\hline Nov-04 & 286869 & 6447 & 71.1 & 170.13 & 238.00 & 228.70 & 158.46 & 34149 \\
\hline Dec-04 & 287630 & 6647 & 75.1 & 175.72 & 253.63 & 230.93 & 157.71 & 35370 \\
\hline Jan-05 & 289304 & 6538 & 64.9 & 175.18 & 245.63 & 230.64 & 160.01 & 34164 \\
\hline Feb-05 & 289802 & 5925 & 67.8 & 178.55 & 232.50 & 232.15 & 159.73 & 34156 \\
\hline Mar-05 & 288013 & 6626 & 60.9 & 207.64 & 240.50 & 235.69 & 157.25 & 34240 \\
\hline Apr-05 & 284738 & 6333 & 56.2 & 210.27 & 246.25 & 236.66 & 158.46 & 34282 \\
\hline May-05 & 283103 & 6462 & 54.6 & 218.01 & 274.60 & 236.98 & 160.88 & 34398 \\
\hline Jun-05 & 281823 & 6273 & 56.8 & 241.22 & 322.13 & 232.59 & 159.00 & 34469 \\
\hline Jul-05 & 281001 & 6468 & 63.7 & 238.80 & 334.25 & 221.72 & 157.71 & 34527 \\
\hline Aug-05 & 282032 & 6450 & 60.1 & 217.60 & 327.70 & 220.89 & 156.12 & 34548 \\
\hline
\end{tabular}




\section{C. Continued}

\begin{tabular}{|c|c|c|c|c|c|c|c|c|}
\hline Date & $\begin{array}{l}\text { Number } \\
\text { of Hens }\end{array}$ & $\begin{array}{l}\text { Number } \\
\text { of Eggs }\end{array}$ & $\begin{array}{c}\text { Egg } \\
\text { Price }\end{array}$ & $\begin{array}{c}\text { Soybean } \\
\text { Meal Price }\end{array}$ & $\begin{array}{c}\text { Cornmeal } \\
\text { Price }\end{array}$ & $\begin{array}{c}\text { Retail } \\
\text { Beef } \\
\text { Price }\end{array}$ & $\begin{array}{c}\text { Retail } \\
\text { Pork } \\
\text { Price }\end{array}$ & $\begin{array}{l}\text { Real Disposable } \\
\text { Personal Income }\end{array}$ \\
\hline Sep-05 & 284135 & 6302 & 76.1 & 193.57 & 294.75 & 216.81 & 156.13 & 34341 \\
\hline Oct-05 & 286265 & 6587 & 62.8 & 186.58 & 300.00 & 219.30 & 154.02 & 34477 \\
\hline Nov-05 & 289160 & 6478 & 76.8 & 192.15 & 319.00 & 221.66 & 152.79 & 34686 \\
\hline Dec-05 & 292077 & 6736 & 85.5 & 209.58 & 319.75 & 224.45 & 154.01 & 34844 \\
\hline Jan-06 & 293010 & 6674 & 75.6 & 201.96 & 303.75 & 223.95 & 152.06 & 35286 \\
\hline Feb-06 & 293200 & 6030 & 59.0 & 198.43 & 259.38 & 221.67 & 152.72 & 35412 \\
\hline Mar-06 & 293688 & 6784 & 79.6 & 192.43 & 263.75 & 217.76 & 150.00 & 35451 \\
\hline Apr-06 & 292290 & 6519 & 65.9 & 190.55 & 250.63 & 218.74 & 152.13 & 35379 \\
\hline May-06 & 289261 & 6575 & 56.4 & 193.25 & 251.70 & 215.33 & 150.74 & 35321 \\
\hline Jun-06 & 287482 & 6393 & 65.8 & 196.26 & 250.00 & 213.47 & 152.38 & 35370 \\
\hline Jul-06 & 286523 & 6609 & 56.6 & 187.27 & 240.00 & 210.87 & 154.55 & 35330 \\
\hline Aug-06 & 286950 & 6616 & 68.0 & 175.91 & 229.25 & 215.38 & 154.39 & 35292 \\
\hline Sep-06 & 289003 & 6438 & 67.3 & 177.59 & 237.50 & 212.00 & 155.62 & 35476 \\
\hline Oct-06 & 290701 & 6662 & 71.4 & 194.12 & 272.20 & 213.34 & 154.93 & 35650 \\
\hline Nov-06 & 292414 & 6561 & 100.0 & 214.23 & 306.25 & 214.80 & 151.50 & 35747 \\
\hline Dec-06 & 292908 & 6740 & 95.7 & 205.69 & 314.31 & 212.74 & 150.20 & 35813 \\
\hline Jan-07 & 291592 & 6594 & 113.9 & 221.79 & 333.00 & 212.72 & 151.32 & 35819 \\
\hline Feb-07 & 290851 & 5973 & 100.2 & 244.10 & 346.88 & 217.49 & 150.23 & 35887 \\
\hline Mar-07 & 289892 & 6706 & 102.0 & 239.53 & 361.50 & 223.27 & 150.73 & 35970 \\
\hline Apr-07 & 287262 & 6400 & 93.9 & 221.75 & 363.33 & 227.91 & 149.65 & 35936 \\
\hline May-07 & 284035 & 6510 & 95.6 & 227.67 & 344.00 & 227.26 & 151.96 & 35891 \\
\hline Jun-07 & 282107 & 6300 & 86.4 & 249.16 & 352.75 & 222.18 & 153.34 & 35820 \\
\hline Jul-07 & 282434 & 6495 & 115.2 & 252.57 & 398.50 & 218.73 & 155.04 & 35870 \\
\hline Aug-07 & 283385 & 6497 & 112.3 & 251.83 & 404.38 & 219.47 & 154.69 & 35859 \\
\hline Sep-07 & 283744 & 6329 & 129.9 & 288.78 & 414.38 & 222.59 & 153.03 & 35918 \\
\hline Oct-07 & 285303 & 6628 & 113.8 & 300.43 & 472.50 & 216.33 & 153.45 & 35822 \\
\hline Nov-07 & 286884 & 6481 & 148.7 & 315.25 & 495.63 & 217.75 & 149.92 & 35759 \\
\hline Dec-07 & 285930 & 6664 & 160.6 & 351.22 & 540.79 & 216.13 & 150.26 & 35883 \\
\hline Jan-08 & 283595 & 6492 & 157.4 & 376.33 & 545.00 & 215.01 & 149.74 & 35961 \\
\hline Feb-08 & 281931 & 6028 & 157.3 & 396.71 & 543.13 & 218.26 & 147.30 & 35999 \\
\hline Mar-08 & 280925 & 6512 & 161.8 & 379.70 & 561.88 & 217.54 & 146.57 & 36049 \\
\hline Apr-08 & 279705 & 6251 & 123.4 & 375.32 & 547.00 & 214.38 & 146.89 & 35887 \\
\hline May-08 & 279114 & 6407 & 103.8 & 369.37 & 529.00 & 218.18 & 149.35 & 37585 \\
\hline Jun-08 & 278647 & 6258 & 124.9 & 436.91 & 524.38 & 220.85 & 150.77 & 36564 \\
\hline Jul-08 & 277289 & 6470 & 105.4 & 452.19 & 554.50 & 222.11 & 151.57 & 35958 \\
\hline Aug-08 & 277057 & 6434 & 119.0 & 388.40 & 505.00 & 230.43 & 153.62 & 35640 \\
\hline Sep-08 & 277321 & 6274 & 119.1 & 363.78 & 495.50 & 226.79 & 152.22 & 35650 \\
\hline Oct-08 & 278499 & 6547 & 119.2 & 290.84 & 464.13 & 226.47 & 151.45 & 35799 \\
\hline Nov-08 & 282330 & 6458 & 123.8 & 292.76 & 406.25 & 224.34 & 151.95 & 36022 \\
\hline Dec-08 & 285167 & 6723 & 124.8 & 292.94 & 389.00 & 223.13 & 152.70 & 35867 \\
\hline
\end{tabular}




\section{C. Continued}

\begin{tabular}{|c|c|c|c|c|c|c|c|c|}
\hline Date & $\begin{array}{l}\text { Number } \\
\text { of Hens }\end{array}$ & $\begin{array}{l}\text { Number } \\
\text { of Eggs }\end{array}$ & $\begin{array}{c}\text { Egg } \\
\text { Price }\end{array}$ & $\begin{array}{l}\text { Soybean } \\
\text { Meal Price }\end{array}$ & $\begin{array}{c}\text { Cornmeal } \\
\text { Price }\end{array}$ & $\begin{array}{c}\text { Retail } \\
\text { Beef } \\
\text { Price }\end{array}$ & $\begin{array}{l}\text { Retail } \\
\text { Pork } \\
\text { Price }\end{array}$ & $\begin{array}{l}\text { Real Disposable } \\
\text { Personal Income }\end{array}$ \\
\hline Jan-09 & 285120 & 6618 & 126.9 & 338.50 & 469.38 & 217.86 & 151.10 & 35993 \\
\hline Feb-09 & 284368 & 5932 & 100.7 & 320.89 & 539.38 & 219.32 & 149.03 & 35646 \\
\hline Mar-09 & 284268 & 6663 & 101.5 & 315.37 & 424.38 & 215.02 & 147.27 & 35624 \\
\hline Apr-09 & 283652 & 6436 & 107.7 & 349.57 & 443.13 & 211.85 & 144.61 & 35795 \\
\hline May-09 & 280815 & 6534 & 80.7 & 408.05 & 564.38 & 213.51 & 145.88 & 36326 \\
\hline Jun-09 & 277630 & 6315 & 80.6 & 441.78 & 630.00 & 210.57 & 145.58 & 35683 \\
\hline Jul-09 & 276960 & 6521 & 91.3 & 385.85 & 532.50 & 204.85 & 145.32 & 35531 \\
\hline Aug-09 & 277737 & 6541 & 96.9 & 397.30 & 495.00 & 206.96 & 143.88 & 35415 \\
\hline Sep-09 & 279430 & 6373 & 96.2 & 342.18 & 508.50 & 204.03 & 143.22 & 35433 \\
\hline Oct-09 & 281628 & 6662 & 105.4 & 328.54 & 606.25 & 205.42 & 142.72 & 35260 \\
\hline Nov-09 & 283863 & 6576 & 123.5 & 337.63 & 595.00 & 213.61 & 139.84 & 35317 \\
\hline Dec-09 & 285232 & 6804 & 124.2 & 345.58 & 573.50 & 212.14 & 139.74 & 35416 \\
\hline Jan-10 & 283998 & 6657 & 126.8 & 325.85 & 582.50 & 206.14 & 142.17 & 35331 \\
\hline Feb-10 & 283428 & 5971 & 116.4 & 303.66 & 594.94 & 205.68 & 143.35 & 35246 \\
\hline Mar-10 & 284913 & 6769 & 134.9 & 292.60 & 541.70 & 209.58 & 141.92 & 35303 \\
\hline Apr-10 & 283896 & 6536 & 92.5 & 308.05 & 492.13 & 214.63 & 141.22 & 35544 \\
\hline May-10 & 282226 & 6644 & 78.3 & 305.74 & 455.63 & 214.31 & 146.34 & 35761 \\
\hline Jun-10 & 282999 & 6450 & 77.6 & 314.32 & 445.00 & 214.62 & 148.96 & 35753 \\
\hline Jul-10 & 282896 & 6637 & 85.4 & 335.09 & 441.25 & 211.95 & 152.92 & 35758 \\
\hline Aug-10 & 283576 & 6685 & 107.4 & 339.14 & 451.50 & 209.34 & 155.43 & 35842 \\
\hline Sep-10 & 282914 & 6482 & 86.6 & 334.06 & 464.38 & 211.89 & 158.26 & 35772 \\
\hline Oct-10 & 280880 & 6639 & 97.2 & 353.75 & 501.88 & 214.30 & 160.94 & 35834 \\
\hline Nov-10 & 283352 & 6556 & 138.4 & 376.04 & 518.00 & 213.55 & 157.95 & 35915 \\
\hline Dec-10 & 286323 & 6866 & 134.2 & 387.51 & 520.00 & 210.94 & 151.80 & 36145 \\
\hline Jan-11 & 285012 & 6756 & 108.4 & 412.07 & 524.06 & 214.20 & 153.56 & 36312 \\
\hline Feb-11 & 282713 & 6046 & 109.4 & 410.16 & 533.75 & 216.49 & 155.09 & 36394 \\
\hline Mar-11 & 283457 & 6765 & 99.6 & 393.93 & 543.30 & 221.26 & 157.24 & 36321 \\
\hline Apr-11 & 283099 & 6559 & 120.0 & 388.22 & 556.25 & 223.18 & 157.18 & 36205 \\
\hline May-11 & 280041 & 6673 & 99.2 & 388.26 & 556.00 & 223.29 & 160.83 & 36165 \\
\hline Jun-11 & 280087 & 6464 & 100.5 & 391.54 & 567.50 & 218.46 & 159.09 & 36297 \\
\hline Jul-11 & 281585 & 6700 & 104.3 & 389.29 & 556.25 & 216.70 & 157.57 & 36418 \\
\hline Aug-11 & 282760 & 6715 & 131.9 & 393.80 & 559.00 & 222.19 & 160.29 & 36367 \\
\hline Sep-11 & 284823 & 6564 & 116.9 & 381.85 & 550.63 & 224.32 & 162.79 & 36236 \\
\hline Oct-11 & 286485 & 6836 & 124.4 & 347.45 & 524.38 & 227.54 & 160.14 & 36244 \\
\hline Nov-11 & 289155 & 6709 & 125.3 & 329.09 & 487.00 & 234.82 & 165.27 & 36185 \\
\hline Dec-11 & 290239 & 7035 & 144.0 & 320.68 & 441.25 & 237.29 & 164.62 & 36441 \\
\hline Jan-12 & 289631 & 6912 & 108.2 & 347.60 & 433.50 & 239.41 & 165.53 & 36673 \\
\hline Feb-12 & 289746 & 6361 & 102.5 & 364.49 & 448.75 & 236.02 & 164.69 & 36857 \\
\hline Mar-12 & 290722 & 6934 & 115.6 & 405.23 & 487.50 & 235.72 & 164.07 & 36933 \\
\hline Apr-12 & 290214 & 6690 & 102.1 & 440.62 & 498.75 & 231.77 & 162.23 & 37011 \\
\hline
\end{tabular}




\section{C. Continued}

\begin{tabular}{|c|c|c|c|c|c|c|c|c|}
\hline Date & $\begin{array}{c}\text { Number } \\
\text { of Hens }\end{array}$ & $\begin{array}{c}\text { Number } \\
\text { of Eggs }\end{array}$ & $\begin{array}{c}\text { Egg } \\
\text { Price }\end{array}$ & $\begin{array}{c}\text { Soybean } \\
\text { Meal Price }\end{array}$ & $\begin{array}{c}\text { Cornmeal } \\
\text { Price } \\
\end{array}$ & $\begin{array}{c}\text { Retail } \\
\text { Beef } \\
\text { Price }\end{array}$ & $\begin{array}{c}\text { Retail } \\
\text { Pork } \\
\text { Price } \\
\end{array}$ & $\begin{array}{l}\text { Real Disposable } \\
\text { Personal Income }\end{array}$ \\
\hline May-12 & 289203 & 6852 & 92.0 & 459.42 & 533.00 & 230.14 & 159.36 & 37028 \\
\hline Jun-12 & 288308 & 6622 & 105.0 & 464.02 & 579.00 & 226.89 & 157.49 & 37087 \\
\hline Jul-12 & 287696 & 6832 & 125.1 & 552.54 & 629.00 & 231.15 & 159.48 & 36962 \\
\hline Aug-12 & 289250 & 6922 & 135.5 & 585.75 & 718.75 & 227.69 & 163.39 & 36869 \\
\hline Sep-12 & 291763 & 6727 & 135.2 & 559.56 & 721.88 & 227.48 & 162.40 & 37016 \\
\hline Oct-12 & 295347 & 7046 & 121.7 & 519.91 & 753.50 & 231.46 & 161.18 & 37209 \\
\hline Nov-12 & 299793 & 7022 & 135.1 & 490.60 & 716.25 & 236.17 & 160.79 & 37679 \\
\hline Dec-12 & 300166 & 7263 & 131.7 & 489.69 & 673.34 & 235.13 & 158.68 & 38639 \\
\hline Jan-13 & 298678 & 7160 & 128.3 & 456.81 & 599.50 & 240.24 & 159.27 & 36139 \\
\hline Feb-13 & 299686 & 6437 & 117.8 & 469.16 & 584.38 & 238.95 & 161.06 & 36185 \\
\hline Mar-13 & 300399 & 7198 & 134.4 & 467.95 & 581.88 & 241.85 & 161.61 & 36230 \\
\hline Apr-13 & 298071 & 6954 & 104.8 & 446.36 & 540.50 & 239.62 & 160.86 & 36242 \\
\hline May-13 & 296590 & 7124 & 122.6 & 476.74 & 480.63 & 239.53 & 162.83 & 36399 \\
\hline Jun-13 & 296942 & 6878 & 102.4 & 503.56 & 550.00 & 241.98 & 165.92 & 36448 \\
\hline Jul-13 & 297353 & 7085 & 115.0 & 528.34 & 591.00 & 244.53 & 169.52 & 36416 \\
\hline Aug-13 & 299442 & 7186 & 121.6 & 470.99 & 565.63 & 245.09 & 172.11 & 36489 \\
\hline Sep-13 & 300095 & 7028 & 120.4 & 490.19 & 573.75 & 242.37 & 173.60 & 36554 \\
\hline Oct-13 & 301104 & 7300 & 121.8 & 460.83 & 601.25 & 244.83 & 174.17 & 36401 \\
\hline Nov-13 & 304497 & 7172 & 151.2 & 461.65 & 631.25 & 247.19 & 172.58 & 36490 \\
\hline Dec-13 & 307126 & 7471 & 156.1 & 495.00 & 638.13 & 244.57 & 171.61 & 36492 \\
\hline Jan-14 & 307221 & 7417 & 128.1 & 473.75 & 625.00 & 242.74 & 170.63 & 36608 \\
\hline Feb-14 & 306665 & 6667 & 148.5 & 499.36 & 668.13 & 251.93 & 168.40 & 36774 \\
\hline Mar-14 & 307713 & 7449 & 151.3 & 506.69 & 744.38 & 255.97 & 171.41 & 36879 \\
\hline Apr-14 & 308303 & 7256 & 150.0 & 533.63 & 784.00 & 261.05 & 175.63 & 36899 \\
\hline May-14 & 307596 & 7433 & 130.0 & 542.78 & 761.25 & 261.69 & 181.41 & 36934 \\
\hline Jun-14 & 307037 & 7185 & 123.9 & 519.27 & 694.50 & 262.13 & 182.33 & 37042 \\
\hline Jul-14 & 308198 & 7501 & 137.1 & 451.02 & 574.00 & 263.43 & 182.67 & 37048 \\
\hline Aug-14 & 309581 & 7497 & 127.7 & 447.82 & 572.88 & 275.43 & 185.38 & 37160 \\
\hline Sep-14 & 310357 & 7230 & 123.3 & 409.10 & 587.50 & 275.74 & 185.80 & 37167 \\
\hline Oct-14 & 310740 & 7539 & 128.0 & 378.82 & 549.38 & 275.62 & 183.22 & 37279 \\
\hline Nov-14 & 312700 & 7465 & 171.5 & 423.25 & 581.88 & 278.61 & 179.63 & 37477 \\
\hline Dec-14 & 313019 & 7731 & 188.6 & 418.09 & 613.50 & 279.60 & 176.86 & 37654 \\
\hline Jan-15 & 309465 & 7504 & 126.0 & 379.04 & 632.50 & 279.40 & 176.01 & 37774 \\
\hline Feb-15 & 308069 & 6685 & 145.3 & 374.25 & 631.25 & 275.40 & 173.11 & 37820 \\
\hline Mar-15 & 308050 & 7517 & 169.5 & 364.86 & 613.00 & 275.02 & 168.89 & 37708 \\
\hline Apr-15 & 303568 & 7198 & 122.1 & 349.71 & 575.63 & 278.23 & 163.82 & 37881 \\
\hline May-15 & 286793 & 6942 & 171.7 & 340.47 & 549.38 & 279.00 & 160.82 & 37946 \\
\hline Jun-15 & 274176 & 6402 & 217.1 & 353.90 & 571.60 & 279.17 & 161.38 & 38014 \\
\hline Jul-15 & 275146 & 6630 & 223.7 & 394.64 & 560.00 & 277.82 & 164.53 & 38086 \\
\hline Aug-15 & 276561 & 6656 & 260.7 & 370.41 & 550.63 & 274.68 & 166.43 & 38178 \\
\hline
\end{tabular}




\section{C. Continued}

\begin{tabular}{|c|c|c|c|c|c|c|c|c|}
\hline Date & $\begin{array}{c}\text { Number } \\
\text { of Hens }\end{array}$ & $\begin{array}{c}\text { Number } \\
\text { of Eggs }\end{array}$ & $\begin{array}{c}\text { Egg } \\
\text { Price }\end{array}$ & $\begin{array}{c}\text { Soybean } \\
\text { Meal Price }\end{array}$ & $\begin{array}{c}\text { Cornmeal } \\
\text { Price }\end{array}$ & $\begin{array}{c}\text { Retail } \\
\text { Beef } \\
\text { Price }\end{array}$ & $\begin{array}{c}\text { Retail } \\
\text { Pork } \\
\text { Price }\end{array}$ & $\begin{array}{c}\text { Real Disposable } \\
\text { Personal Income }\end{array}$ \\
\hline Sep-15 & 278923 & 6467 & 222.7 & 342.96 & 525.00 & 269.23 & 169.37 & 38232 \\
\hline Oct-15 & 281677 & 6744 & 166.0 & 338.21 & 509.38 & 269.36 & 171.74 & 38324 \\
\hline Nov-15 & 285491 & 6673 & 209.1 & 320.34 & 477.50 & 269.86 & 170.15 & 38370 \\
\hline Dec-15 & 289726 & 6986 & 147.2 & 303.86 & 482.25 & 260.09 & 167.50 & 38495 \\
\hline Jan-16 & 293069 & 7024 & 133.5 & 297.18 & 452.50 & 259.47 & 164.71 & 38645 \\
\hline Feb-16 & 298555 & 6759 & 130.6 & 291.37 & 457.50 & 257.83 & 161.01 & 38702 \\
\hline Mar-16 & 302464 & 7363 & 100.6 & 296.18 & 445.50 & 267.34 & 161.53 & 38791 \\
\hline Apr-16 & 302374 & 7095 & 75.3 & 327.70 & 434.00 & 262.55 & 163.38 & 38843 \\
\hline May-16 & 301963 & 7361 & 63.4 & 407.50 & 464.10 & 261.05 & 162.31 & 38849 \\
\hline
\end{tabular}

${ }^{24}$ The vector error correction model was estimated using the data from above the double-black line, ending in October 2014; the altosdata.txt file for the RATS programs provided. The highlighted portion indicates the period of time that the flu occurred. In the RATS programs, this full data set is beef\&pork.txt. 


\section{C. TETRAD V Input Data}

\begin{tabular}{|r|r|r|r|r|r|r|r|}
\hline /covariance & & & & & & & \\
\hline \multicolumn{1}{|c|}{343} & Observations & & & & & & \\
\hline HENS & EGGS & EPR & SMP & CMP & BPR & PPR & RDI \\
\hline 1.000 & & & & & & & \\
\hline 0.452 & 1.000 & & & & & & \\
\hline 0.026 & 0.011 & 1.000 & & & & & \\
\hline-0.058 & -0.023 & 0.196 & 1.000 & & & & \\
\hline-0.082 & -0.091 & 0.151 & 0.446 & 1.000 & & & \\
\hline 0.001 & -0.003 & 0.102 & 0.034 & -0.046 & 1.000 & & \\
\hline-0.046 & -0.052 & 0.026 & -0.018 & -0.055 & 0.197 & 1.000 & \\
\hline 0.082 & 0.068 & -0.037 & -0.004 & 0.003 & -0.033 & -0.005 & 1.000 \\
\hline
\end{tabular}




\title{
APPENDIX D
}

\section{REGRESSION ANALYSIS FOR TIME SERIES (RATS) INPUT PROGRAMS}

\section{D. Summary Statistics for the Estimated Model: March 1986 to October $2014^{25}$}

\author{
calendar 1986112 \\ allocate 500 2016:6 \\ eqv 1 to 8 \\ hens eggs eggprice soymealp cornmealp beefprice prkprice inc \\ $* * * * * * * * *$ \\ open data altosdata.txt \\ data(format=free,org=obs) 1986:3 2014:10 1 to 8 \\ ****************************************************
}

Table

EXTREMUM(print) hens 1986:3 2014:10

EXTREMUM(print) eggs 1986:3 2014:10

EXTREMUM(print) eggprice 1986:3 2014:10

EXTREMUM(print) soymealp 1986:3 2014:10

EXTREMUM(print) cornmealp 1986:3 2014:10

EXTREMUM(print) beefprice 1986:3 2014:10

EXTREMUM(print) prkprice 1986:3 2014:10

EXTREMUM(print) inc 1986:3 2014:10

STATISTICS(print) hens 1986:3 2014:10

STATISTICS(print) eggs 1986:3 2014:10

STATISTICS(print) eggprice 1986:3 2014:10

STATISTICS(print) soymealp 1986:3 2014:10

STATISTICS(print) cornmealp 1986:3 2014:10

STATISTICS(print) beefprice 1986:3 2014:10

STATISTICS(print) prkprice 1986:3 2014:10

STATISTICS(print) inc 1986:3 2014:10

End

${ }^{25}$ For the full data set, all 2014:10 dates are replaced with 2016:5 and the data file is changed to beef\&pork.txt. 


\section{D. Plots of Data for the Estimated Model Data Set ${ }^{26}$}

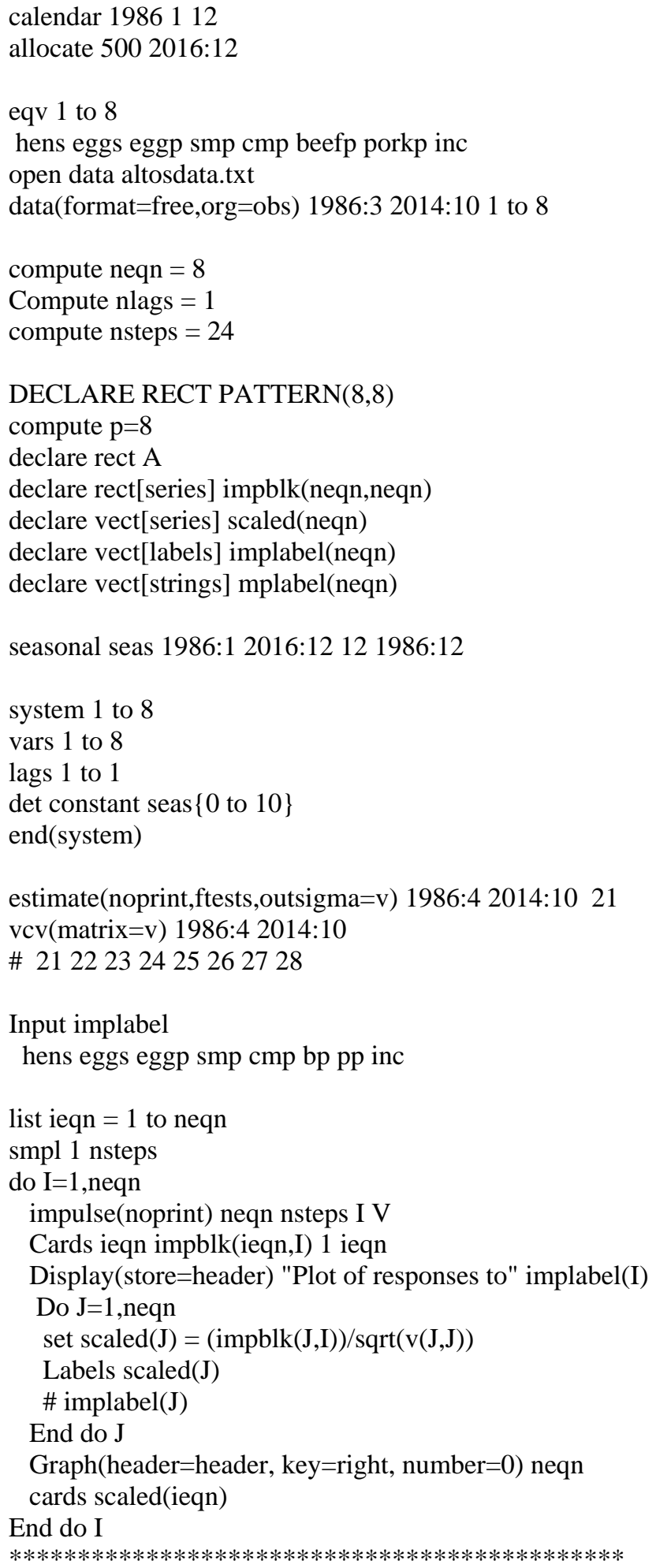




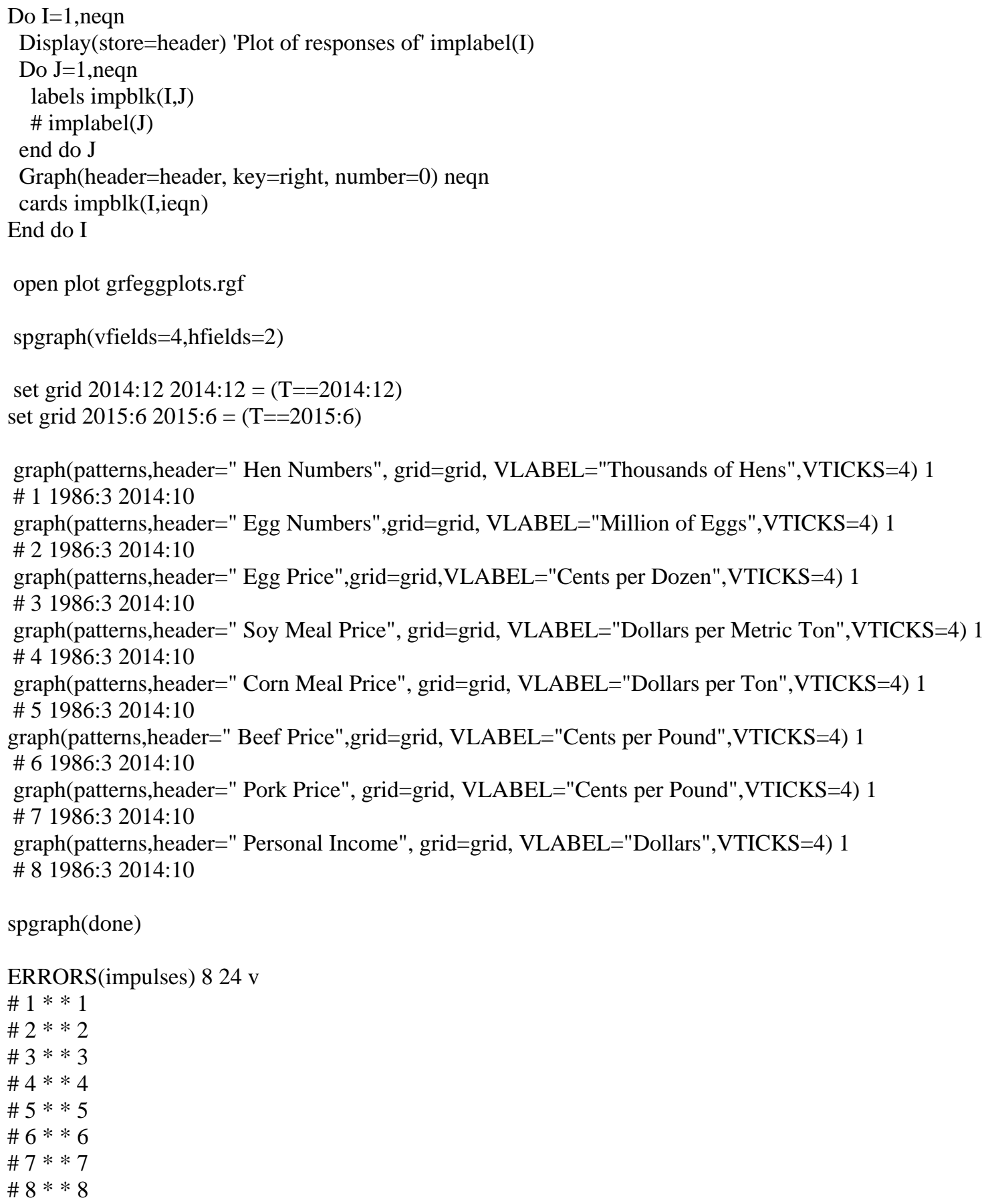

End

\footnotetext{
${ }^{26}$ For the full data set, all 2014:10 dates are replaced with 2016:5 and the data file is changed to beef\&pork.txt.
} 


\section{D. Generating Impulse Graphs}

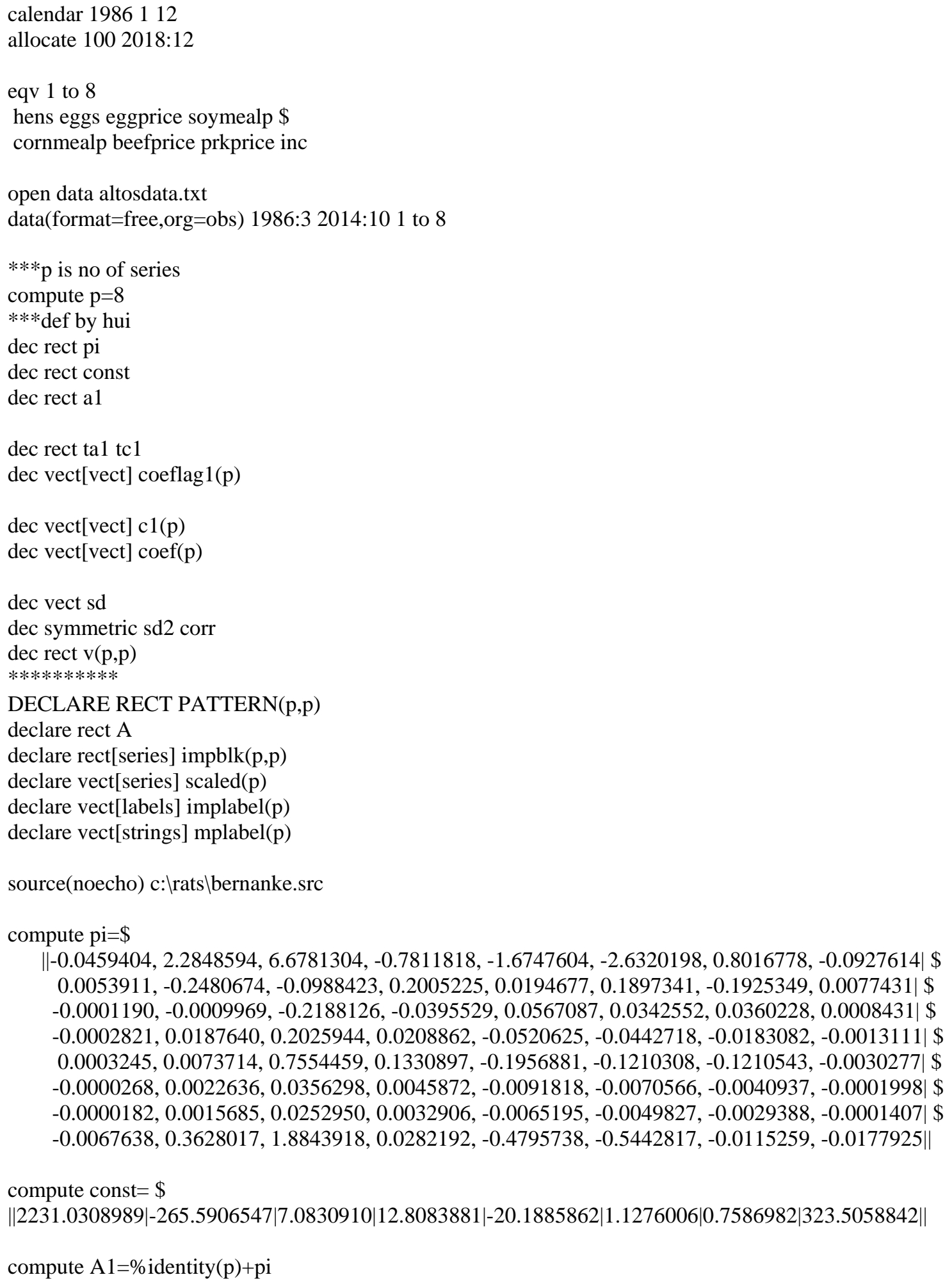




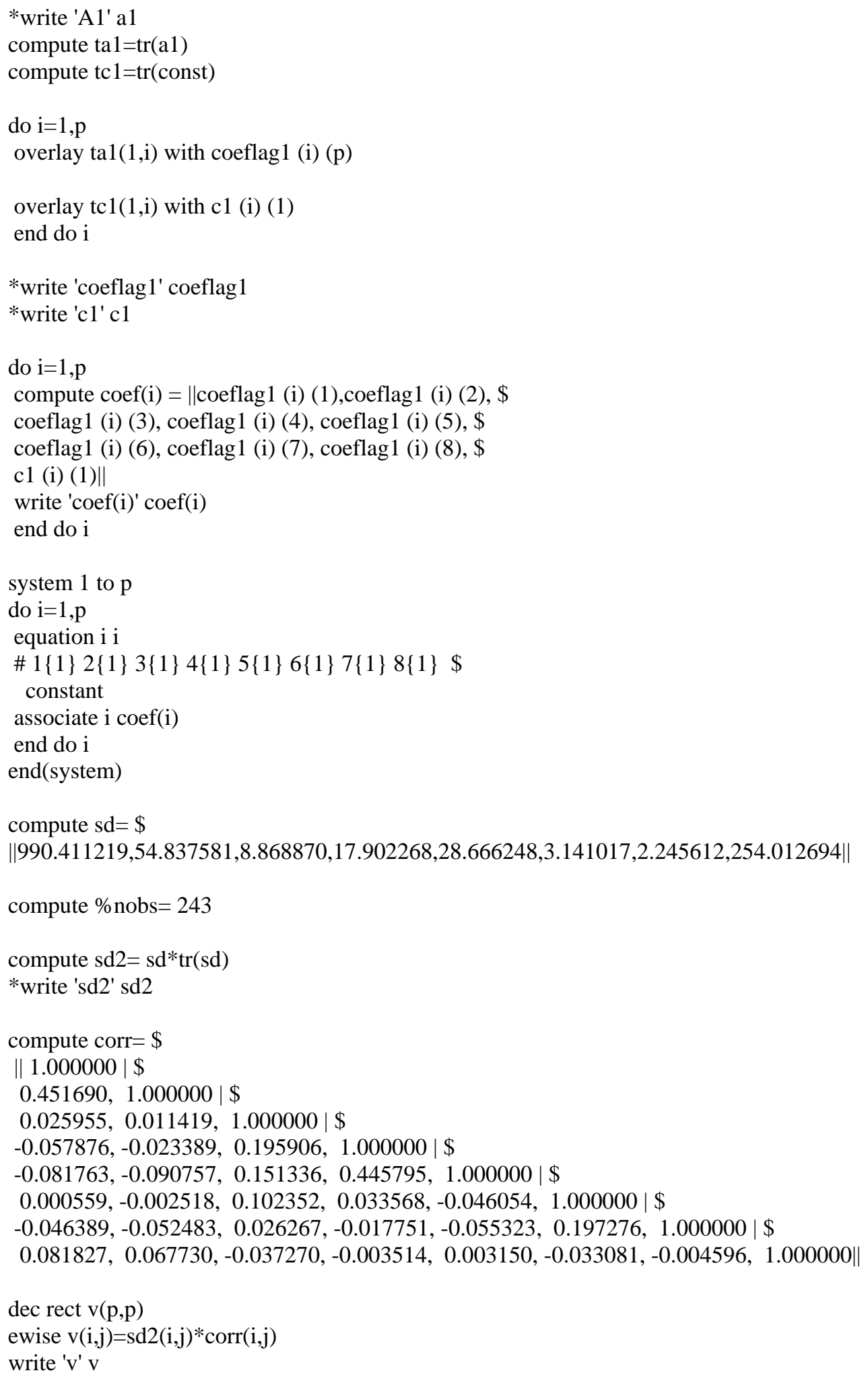




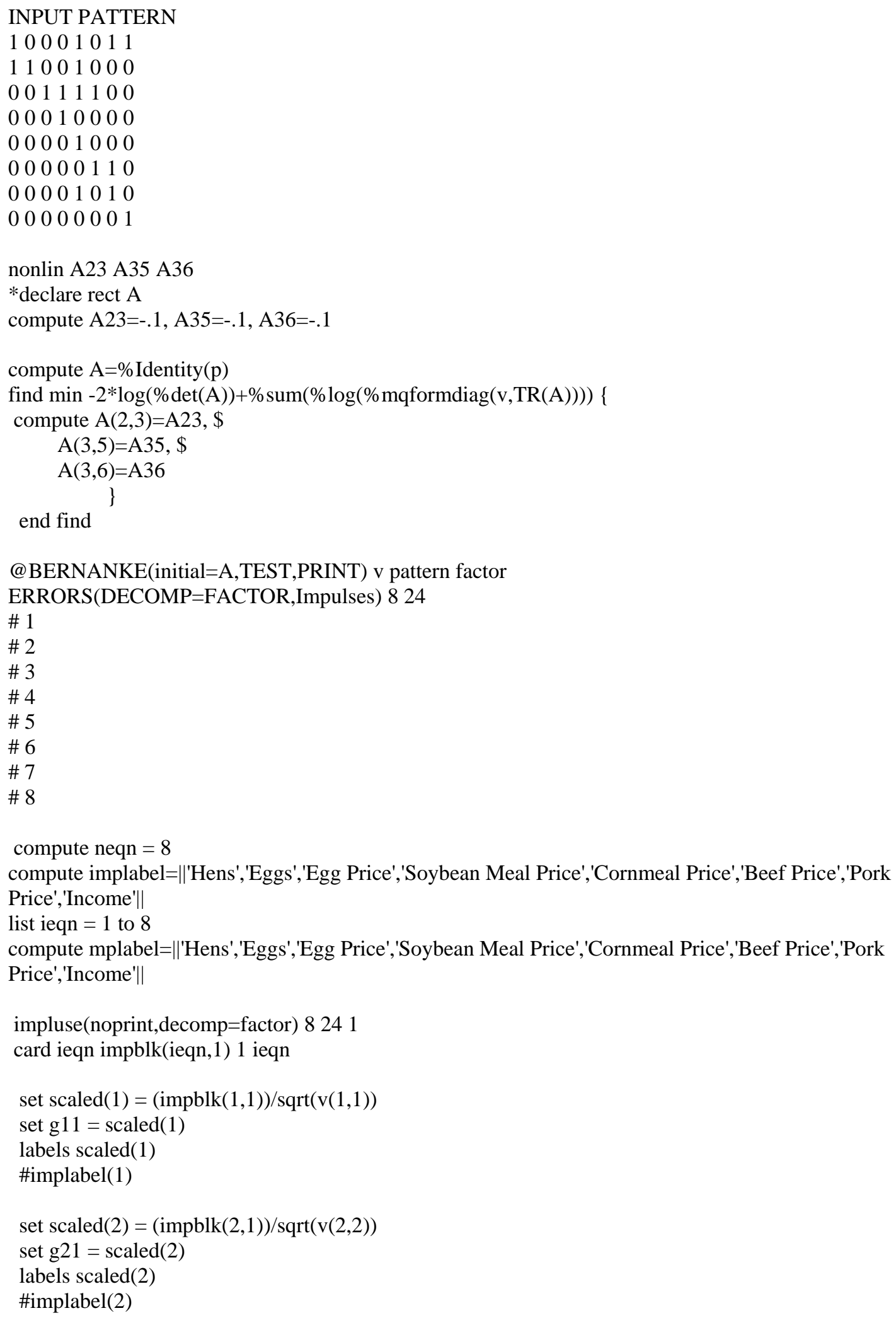




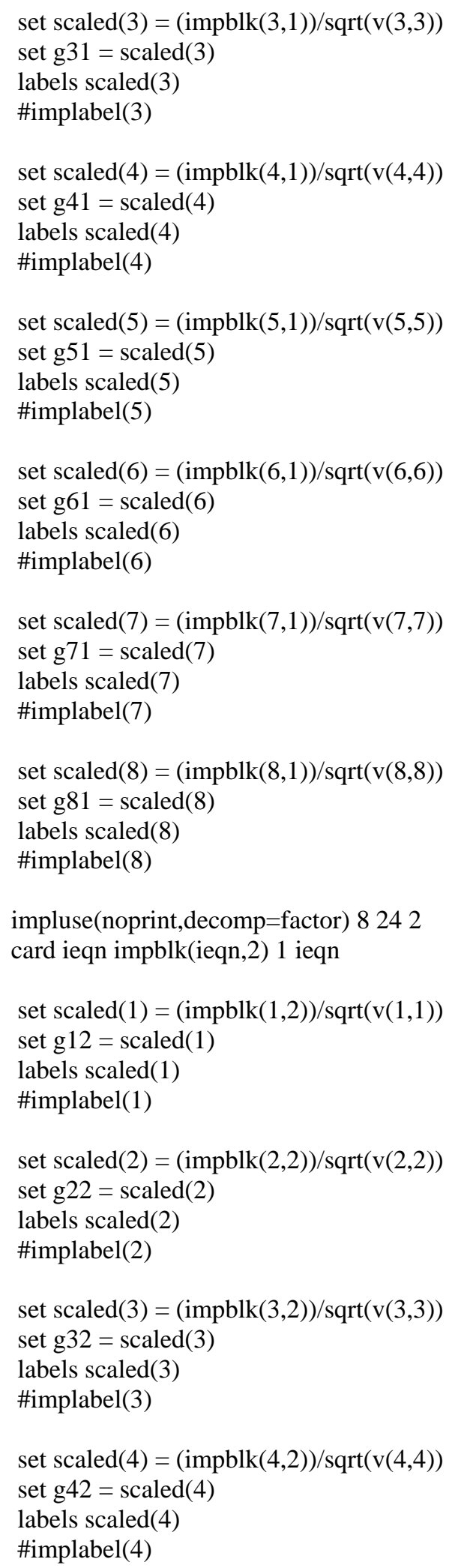




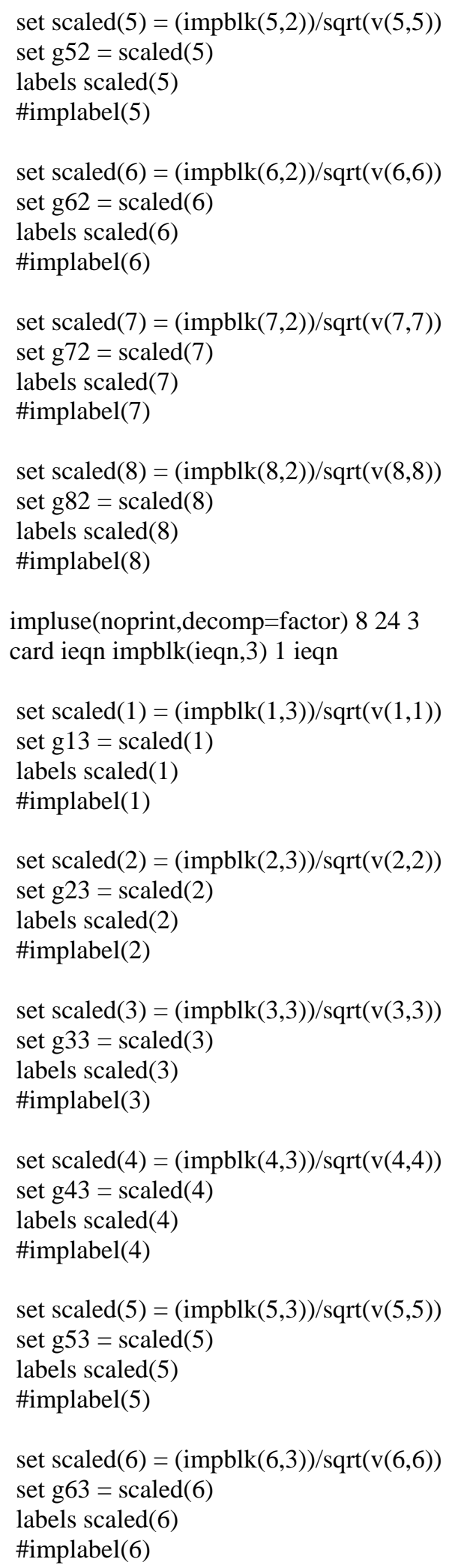




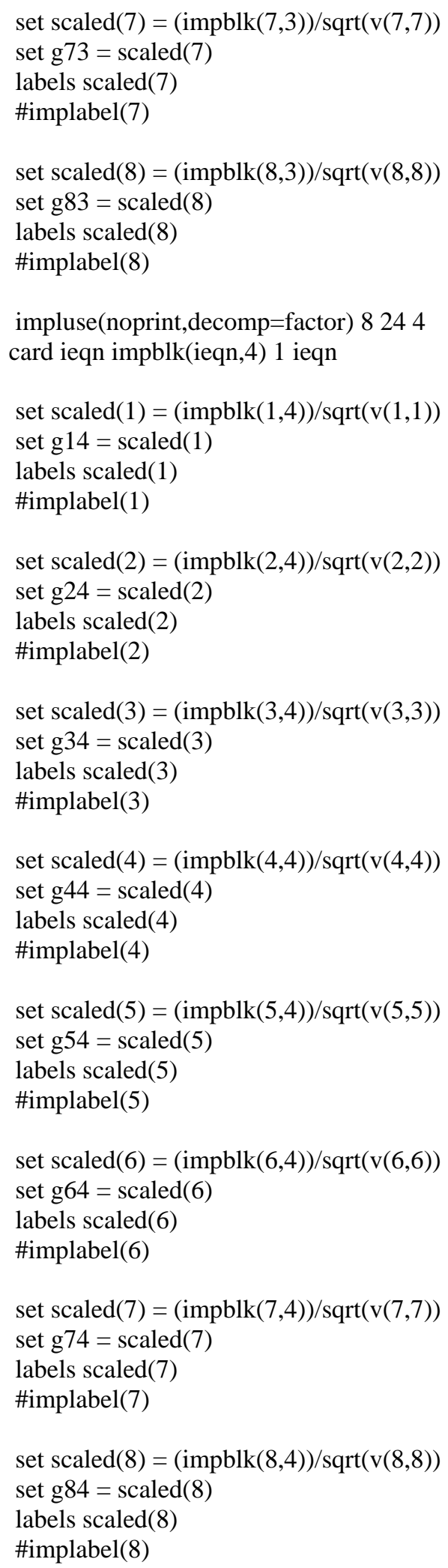




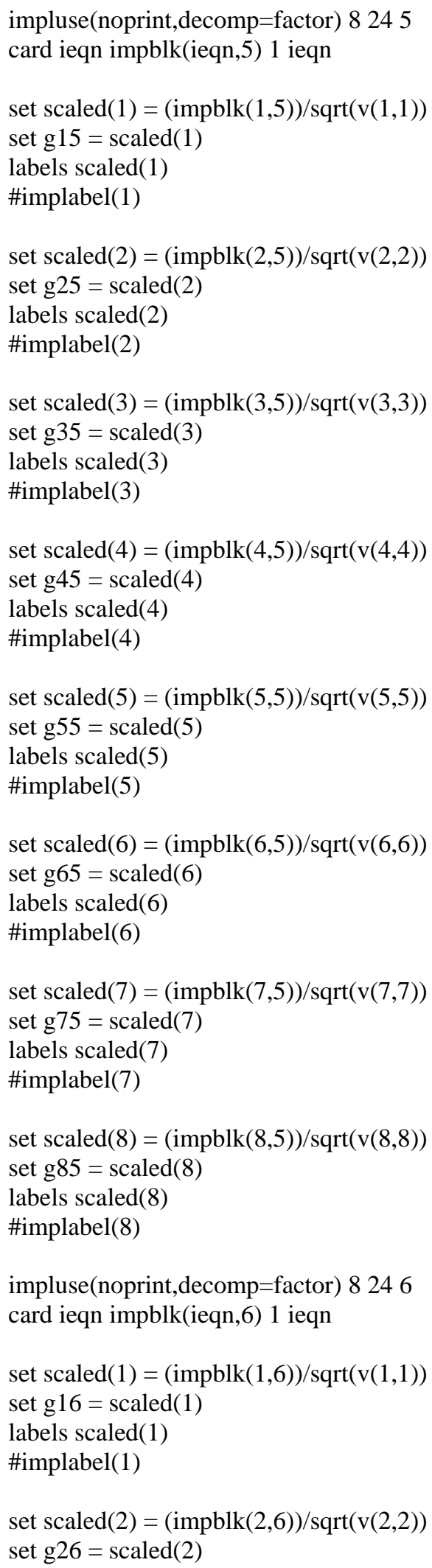




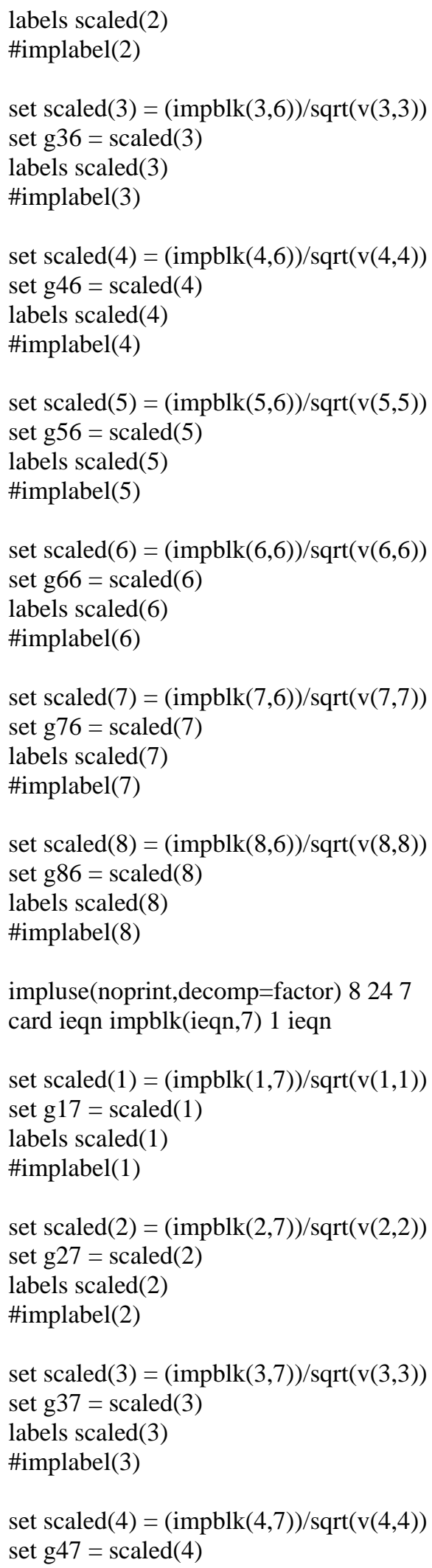




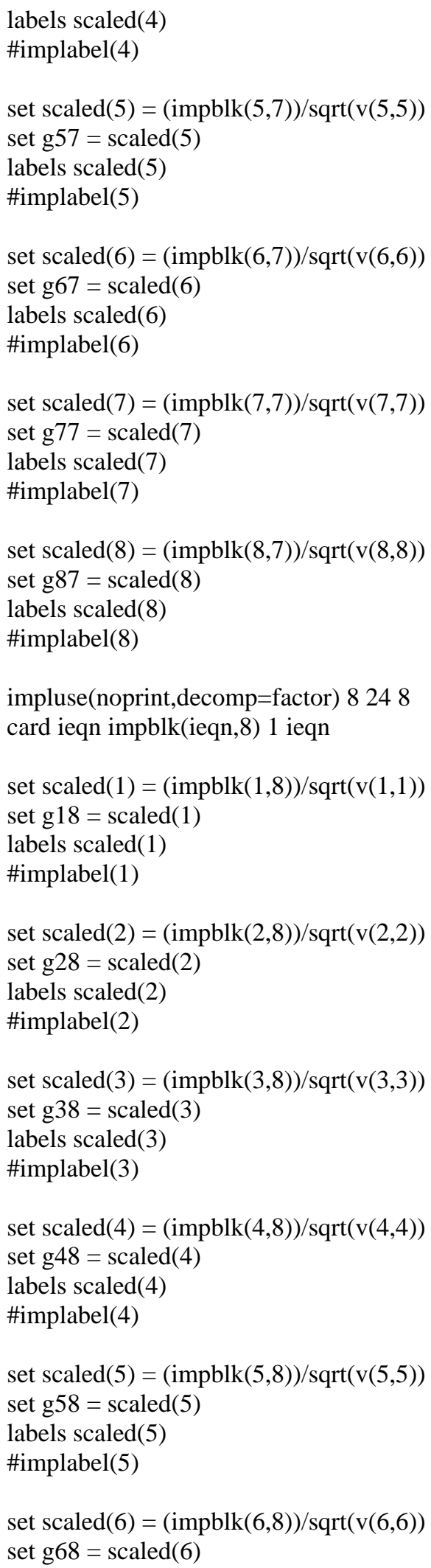




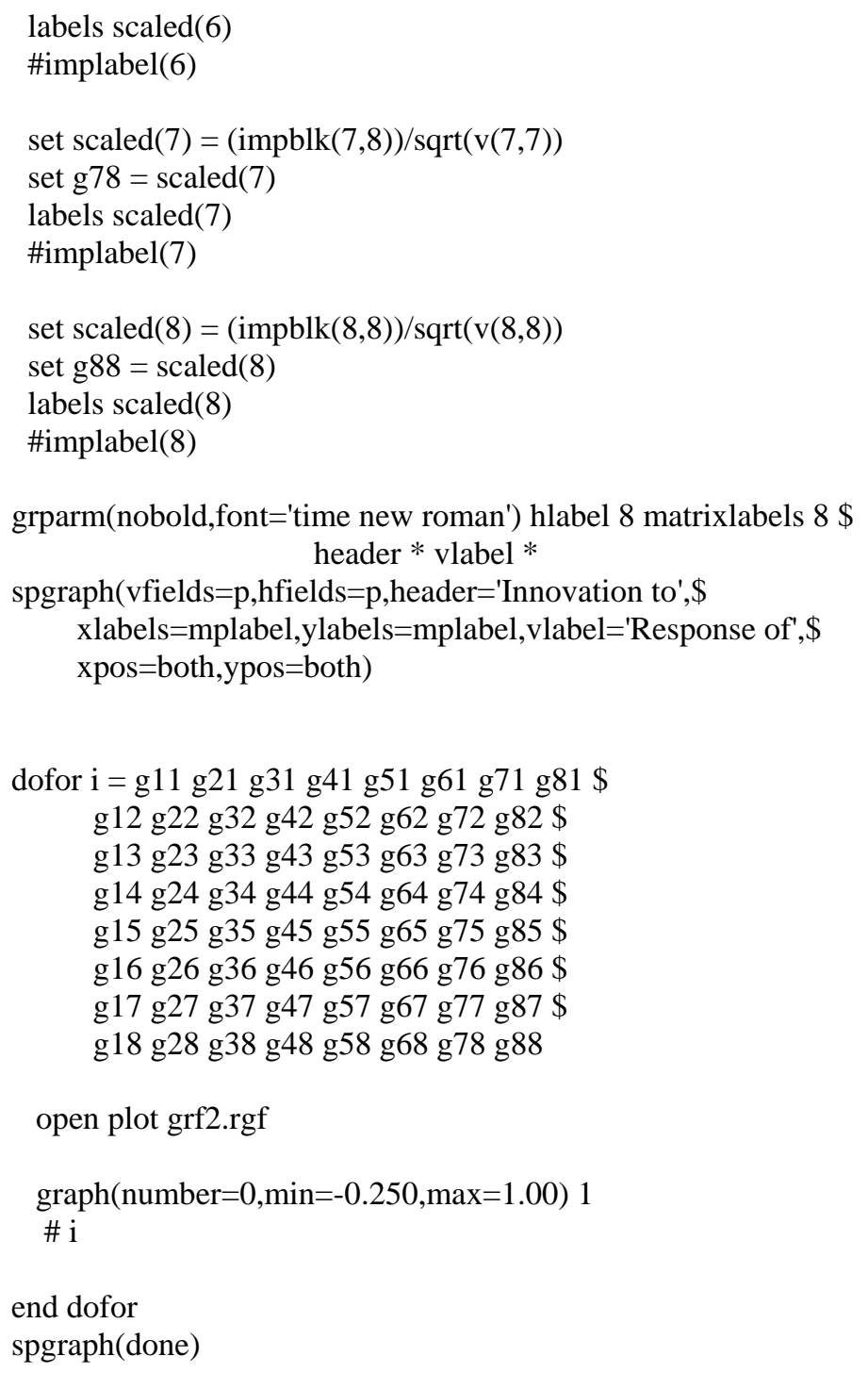

END 


\section{D. Dickey Fuller \& Augmented Dickey Fuller Test}

calendar 1986112

allocate 500 2016:6

eqv 1 to 16

hens eggs eggprice soymealp cornmealp beefprice prkprice inc $\$$

HEN PDXN EPR SMP CMP BPR PPR RDI

$* * * * * * * * * * * * * * * * * * * * * * * * * * * * * * * * * * * * * * * * * * * * * * * * *$

open data altosdata.txt

data(format=free,org=obs) 1986:3 2014:10 1 to 8

*******************************************************

do $\mathrm{i}=1,8$

diff i 1986:4 2014:10 i+8 1986:4

end do $\mathrm{i}$

do $\mathrm{i}=9,16$

linreg i 1986:5 2014:10

\# constant (i-8) $\{1\}$

*******************************************

compute schwarz $=\log (\%$ seesq $)+((\%$ nreg $)) * \log (\%$ nobs $) / \%$ nobs

compute akaike $=\log (\%$ seesq $)+2 *((\%$ nreg $) * 8) / \%$ nobs

compute phi $=\log (\%$ seesq $)+((\%$ nreg $)) * 2.1 * \log (\log (\%$ nobs $)) / \%$ nobs

display @10 \#\#\#\#\%nreg schwarz @+10 \#\#\#\#.\#\#\#\#phi@+10 \#\#\#\#.\#\#\#\# akaike @+10 \#\#\#\#.\#\#\#\#

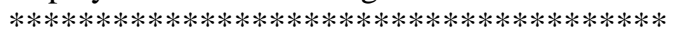

end do $\mathrm{i}$

do $\mathrm{i}=9,16$

do $\mathrm{j}=1,12$

linreg i 1987:5 2014:10

\# constant (i-8) $\{1\} \mathrm{i}\{1$ to $\mathrm{j}\}$

$* * * * * * * * * * * * * * * * * * * * * * * * * * * * * * * * * * * * * * * * * * * * * * * * * * * * * * * * * *$

compute schwarz $=\log (\%$ seesq $)+((\%$ nreg $)) * \log (\%$ nobs $) / \%$ nobs

compute akaike $=\log (\%$ seesq $)+2 *((\%$ nreg $) * 8) / \%$ nobs

compute phi $=\log (\%$ seesq $)+((\%$ nreg $)) * 2.1 * \log (\log (\%$ nobs $)) / \%$ nobs

display @10 \#\#\#\#\#nreg schwarz @+10 \#\#\#\#.\#\#\#\# phi @+10 \#\#\#\#\#\#\#\#\# akaike @+10 \#\#\#\#.\#\#\#

end do $\mathrm{j}$

end do $i$

end 


\title{
5D. Stationarity, Weak Exogeneity, and Exclusion Tests
}

\author{
calendar 1986112 \\ allocate 500 2016:6 \\ eqv 1 to 8 \\ hens eggs eggprice soymealp cornmealp beefprice prkprice inc \\ $* * * * * * * * * * * * * * * * * * * * * * * * * * * * * * * * * * * * * * * * * * * * * * * *$ \\ open data altosdata.txt \\ data(format=free,org=obs) 1986:3 2014:10 1 to 8 \\ ******************************************************** \\ set ser $1=$ hens \\ set ser2 $=$ eggs \\ set ser3 = eggprice \\ set ser4 $=$ soymealp \\ set ser5 $=$ cornmealp \\ set ser6 $=$ beefprice \\ set ser7 $=$ prkprice \\ set ser8 $=$ inc \\ open copy upCIres.tsp.txt \\ source CATSICATSMAIN.SRC \\ @ CATS (proc=tsprop, season=12,lags=1, dettrend=cimean) 1986:3 2014:10 \\ \# hens eggs eggprice soymealp cornmealp beefprice prkprice inc \\ end
}




\section{D. Determining the Presence of Cointegration and Residual Analysis for the Estimated Model}

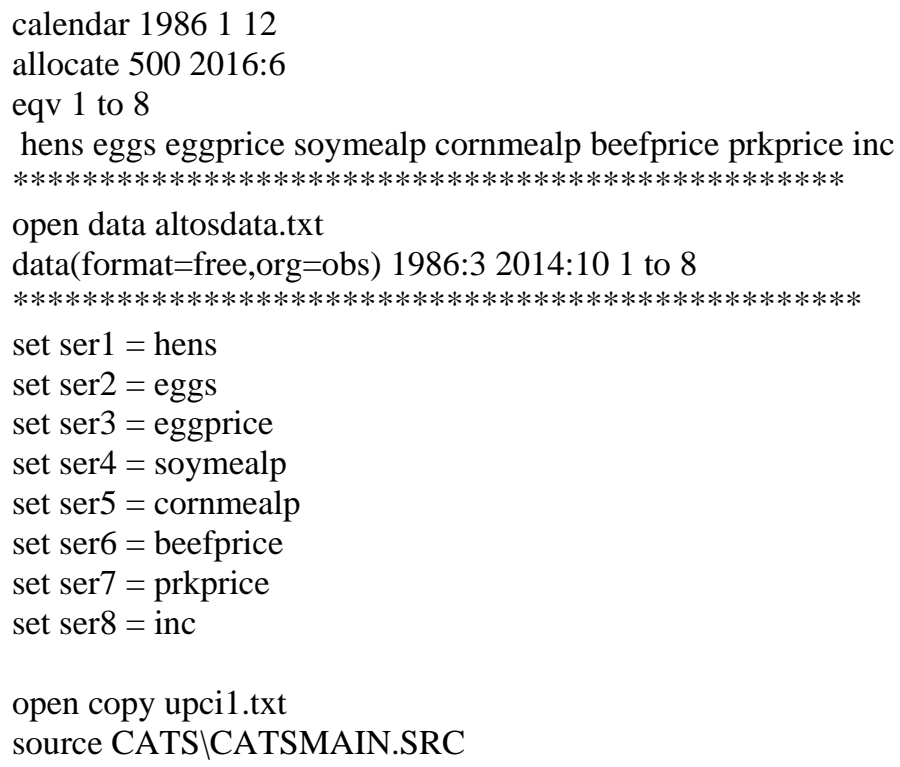

End 


\section{D. Determining the Number of Lags in the VAR Estimated Model}

calendar 1986112

allocate 500 2016:6

eqv 1 to 8

hens eggs eggprice soymealp cornmealp beefprice prkprice inc open data altosdata.txt

data(format=free, org=obs) 1986:3 2014:10 1 to 8

DECLARE RECT PATTERN $(8,8)$

compute $\mathrm{p}=8$

declare rect $\mathrm{A}$

declare rect[series] impblk(p,p)

declare vect[series] scaled(p)

declare vect[labels] implabel(p)

declare vect[strings] mplabel(p)

seasonal seas 1986:1 2016:12 12 1986:12

set trend 1986:1 2016:1 =t

display @10 "levels VAR constant and no lags, no seasonals, no trend "

system 1 to 8

variables 12345678

det constant

end(system)

estimate(noprint,noftests,outsigma=vsigma) 1987:6 2014:10

compute schwarz $=\log (\% \operatorname{det}($ vsigma $))+((\%$ nreg $) * 8) * \log (\%$ nobs $) / \%$ nobs

compute akaike $=\log (\% \operatorname{det}(\mathrm{vsigma}))+2 *((\%$ nreg $) * 8) / \%$ nobs

compute phi $=\log (\% \operatorname{det}($ vsigma $))+((\%$ nreg $) * 8) *(2.01) * \log (\log (\%$ nobs $)) / \%$ nobs

display @10 \#\#\#\#.\#\#\# schwarz @20 \#\#\#.\#\#\# phi @30 \#\#\#\#.\#\#\# akaike

display @10 "levels VAR constant and seasonals, no lags "

system 1 to 8

variables 12345678

det constant seas $\{0$ to 10$\}$

end(system)

estimate(noprint,noftests,outsigma=vsigma) 1987:6 2014:10

compute schwarz $=\log (\% \operatorname{det}($ vsigma $))+((\%$ nreg $) * 8) * \log (\%$ nobs $) / \%$ nobs

compute akaike $=\log (\% \operatorname{det}(\mathrm{vsigma}))+2 *((\%$ nreg $) * 8) / \%$ nobs

compute phi $=\log (\% \operatorname{det}($ vsigma $))+((\%$ nreg $) * 8) *(2.01) * \log (\log (\%$ nobs $)) / \%$ nobs

display @10 \#\#\#\#.\#\#\#\# schwarz @20 \#\#\#\#.\#\#\#\# phi @30 \#\#\#\#.\#\#\# akaike

display @ 10 "levels VAR constant, seasonals and lags "

do $\mathrm{i}=1,6$

system 1 to 8

variables 12345678

lags 1 to i

det constant seas $\{0$ to 10$\}$

end(system)

estimate(noprint,noftests,outsigma=vsigma) 1987:6 2014:10

compute schwarz $=\log (\% \operatorname{det}(\mathrm{vsigma}))+((\%$ nreg $) * 8) * \log (\%$ nobs $) / \%$ nobs 
compute akaike $=\log (\%$ det $($ vsigma $))+2 *((\%$ nreg $) * 8) / \%$ nobs

compute phi $=\log (\% \operatorname{det}($ vsigma $))+((\%$ nreg $) * 8) *(2.01) * \log (\log (\%$ nobs $)) / \%$ nobs display @10 \#\#\#\#.\#\#\# schwarz @20 \#\#\#\#.\#\#\# phi @30 \#\#\#.\#\#\#\# akaike end do $\mathrm{i}$

display@10 "levels VAR constant, seasonals and lags and trend "

do $\mathrm{i}=1,6$

system 1 to 8

variables 12345678

lags 1 to $\mathrm{i}$

det constant seas $\{0$ to 10$\}$ trend

end(system)

estimate(noprint,noftests,outsigma=vsigma) 1987:6 2014:10

compute schwarz $=\log (\% \operatorname{det}($ vsigma $))+((\%$ nreg $) * 8) * \log (\%$ nobs $) / \%$ nobs

compute akaike $=\log (\% \operatorname{det}($ vsigma $))+2 *((\%$ nreg $) * 8) / \%$ nobs

compute phi $=\log (\% \operatorname{det}($ vsigma $))+((\%$ nreg $) * 8) *(2.01) * \log (\log (\%$ nobs $)) / \%$ nobs display @10 \#\#\#\#.\#\#\# schwarz @20 \#\#\#\#.\#\#\# phi @30 \#\#\#.\#\#\# akaike end do i

display @10 "levels VAR constant, no seasonals, no trend and lags "

do $\mathrm{i}=1,6$

system 1 to 8

variables 12345678

lags 1 to $\mathrm{i}$

det constant

end(system)

estimate(noprint,noftests, outsigma=vsigma) 1987:6 2014:10

compute schwarz $=\log (\% \operatorname{det}(\mathrm{vsigma}))+((\%$ nreg $) * 8) * \log (\%$ nobs $) / \%$ nobs

compute akaike $=\log (\% \operatorname{det}($ vsigma $))+2 *((\%$ nreg $) * 8) / \%$ nobs

compute phi $=\log (\% \operatorname{det}($ vsigma $))+((\%$ nreg $) * 8) *(2.01) * \log (\log (\%$ nobs $)) / \%$ nobs

display @ 10 \#\#\#\#.\#\#\#\# schwarz @ 20 \#\#\#\#.\#\#\#\# phi @30 \#\#\#\#.\#\#\# akaike

end do i

display@10 "levels VAR constant, lags and trend "

do $\mathrm{i}=1,6$

system 1 to 8

variables 12345678

lags 1 to $\mathrm{i}$

det constant trend

end(system)

estimate(noprint,noftests,outsigma=vsigma) 1987:6 2014:10

compute schwarz $=\log (\% \operatorname{det}(\mathrm{vsigma}))+((\%$ nreg $) * 8) * \log (\%$ nobs $) / \%$ nobs

compute akaike $=\log (\% \operatorname{det}($ vsigma $))+2 *((\%$ nreg $) * 8) / \%$ nobs

compute phi $=\log (\% \operatorname{det}(\mathrm{vsigma}))+((\%$ nreg $) * 8) *(2.01) * \log (\log (\%$ nobs $)) / \%$ nobs

display @10 \#\#\#\#.\#\#\# schwarz @20 \#\#\#\#.\#\#\#\# phi @30 \#\#\#\#.\#\#\# akaike end do i

end 


\section{D. Forecasting with the Model $^{27}$}

\section{calendar 1986112}

allocate 100 2018:12

eqv 1 to 16

hens eggs eggprice soymealp $\$$

cornmealp beefprice prkprice inc $\$$

dHEN dPDXN dEPR dSMP dCMP dBPR dPPR dRDI

open data beef\&pork.txt

data(format=free,org=obs) 1986:3 2016:5 1 to 8

*print 1986:3 2016:512345678

do $\mathrm{i}=1,8$

diff i 1986:4 2016:5 i+8 1986:4

end do $\mathrm{i}$

*print 1986:3 2016:5 910111213141516

seasonal seas 1986:1 2018:12 12 1986:12

dec sym M00 M11 Mkk S00 Skk iM11 MM

dec rect M01 M0K S0k Sk0

dec rect alfa beta pi tpi

dec rect $\mathrm{ms}$ st VV

dec vect test(i) Lmax(i) trace(i)

dec rect GAMMA tGAMMA

dec vect[vect] iGAMMA(i)

dec vect[vect] ipi(i)

dec rect piXt1 tpiXt1

dec vect[vect] coefXt1(i)

dec vect[vect] $\operatorname{COEF}(\mathrm{i})$

Theil(setup) 1612 2016:5

\#12345678910111213141516

do date $=2013: 10,2014: 10$

make(trans) DZ0 1986:6 date $\mathrm{N}$ p0

\# 910111213141516

make(trans) DDZ1 1986:6 date N p1

\# seas $\{-10$ to 0$\}$

make(trans) Zk 1986:6 date $\mathrm{N}$ pk

\# 1\{1\} $2\{1\} 3\{1\} 4\{1\} 5\{1\} 6\{1\} 7\{1\} 8\{1\}$ constant

compute [integer] $\mathrm{r}=2$

$* * *$ set the rank of cointegrating space $* * *$

compute [integer] $\mathrm{N} 1=\mathrm{N}$

compute [real] invN $=1.0 / \mathrm{N} 1$ 


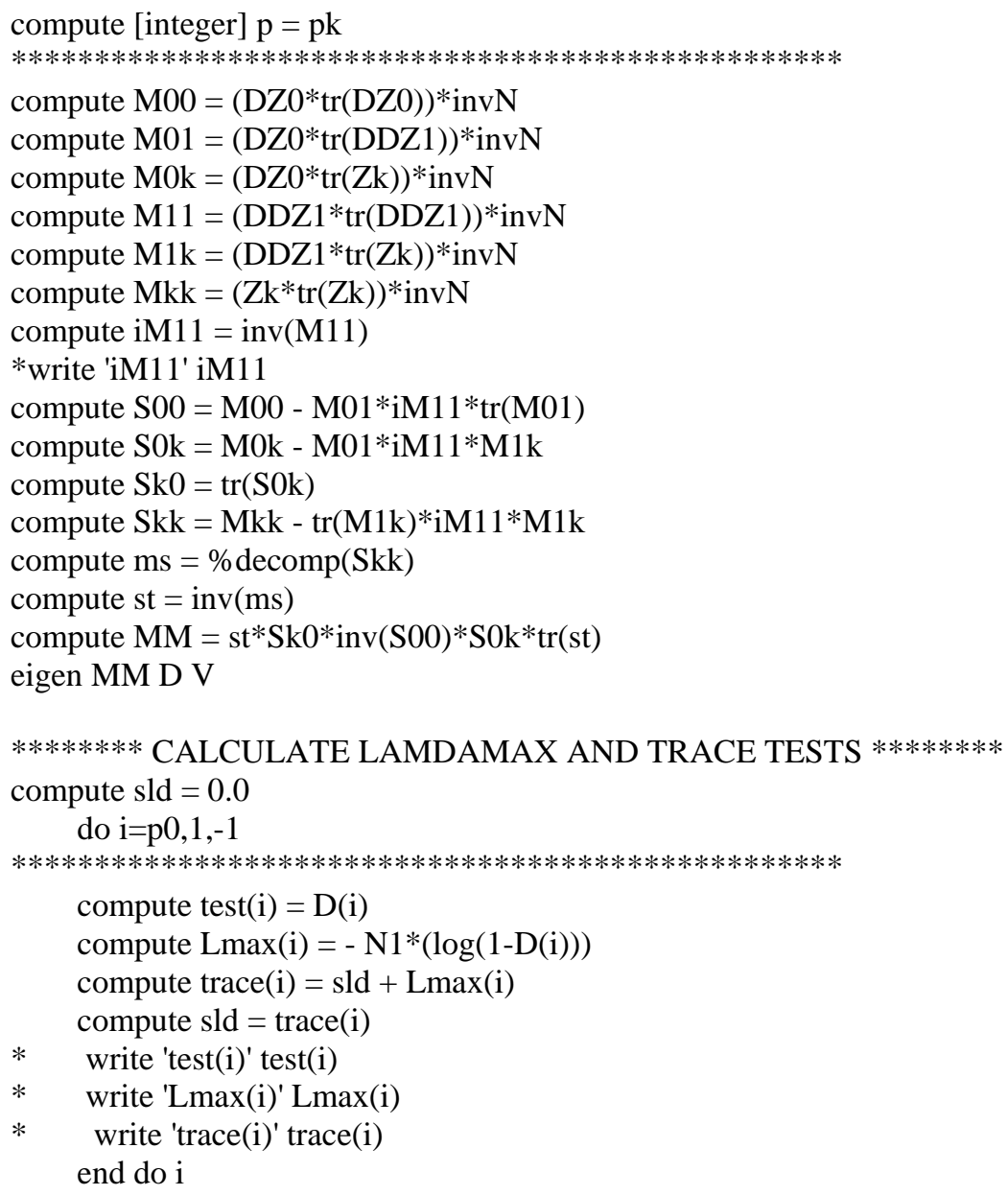




$$
\begin{aligned}
& 0,1,0,0,0,0,0,0,0 \mid \$ \\
& 0,0,1,0,0,0,0,0,0 \mid \$ \\
& 0,0,0,1,0,0,0,0,0 \mid \$ \\
& 0,0,0,0,1,0,0,0,0 \mid \$ \\
& 0,0,0,0,0,1,0,0,0 \mid \$ \\
& 0,0,0,0,0,0,1,0,0 \mid \$ \\
& 0,0,0,0,0,0,0,1,0 \|
\end{aligned}
$$

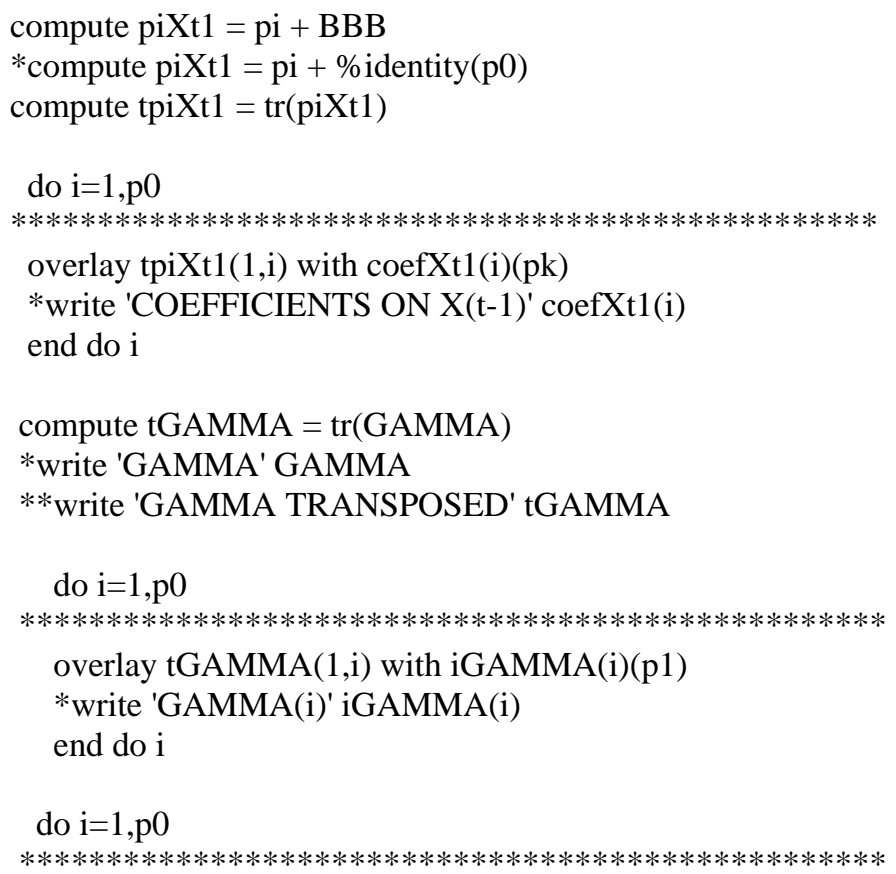




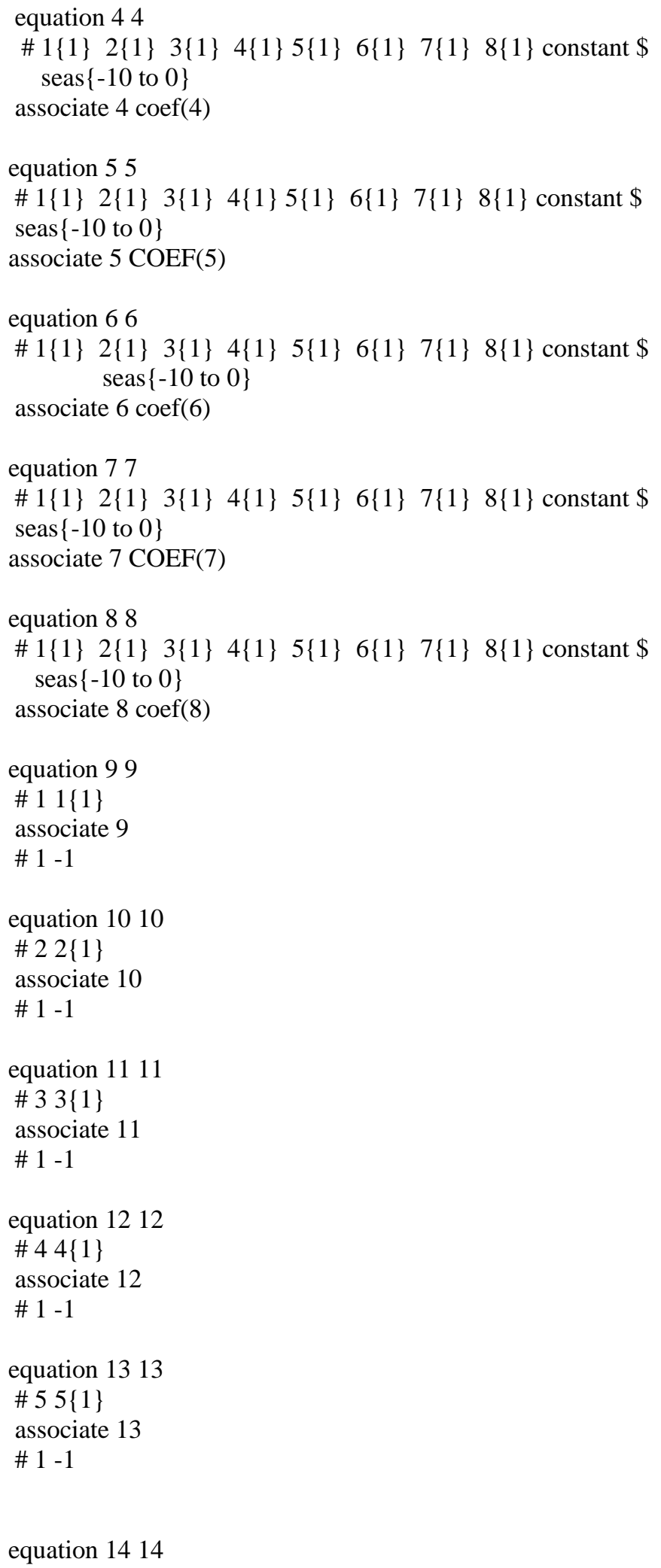




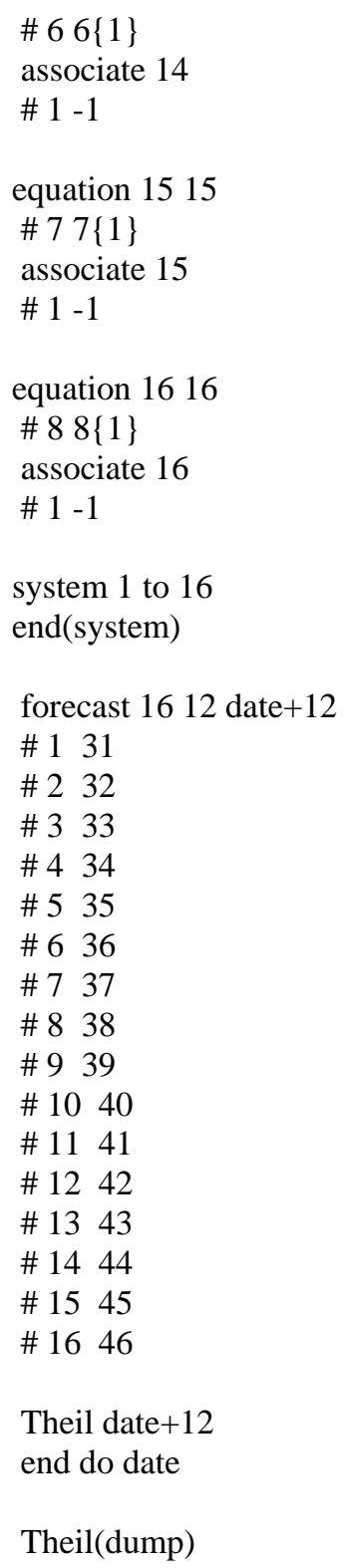

Theil date +12 end do date

Theil(dump)

print 2014:10 2015:10 31323334353637383940414243444546

end

${ }^{27}$ This program was adapted from the original RATS program written by former Texas A\&M graduate student Thanapat Chaisantikul. 